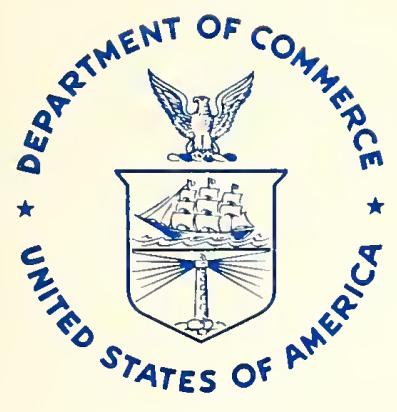

\title{
NOAA Aquaculture Plan
}

\section{Prepared by}

NATIONAL OCEANIC AND ATMOSPHERIC ADMINISTRATION

National Marine Fisheries Service

and

Office of Sea Grant

JOHN B. GLUDE, Editor

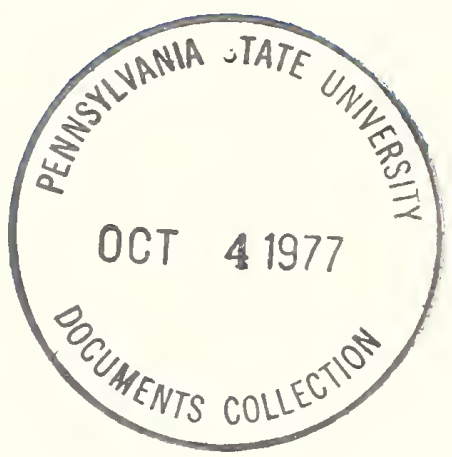

MAY 1977 
For Sale by the Superintendent of Documents, U.S. Government Printing Office

Washington, D.C. 20402 - Stock No. $003-020-00136-0$ 


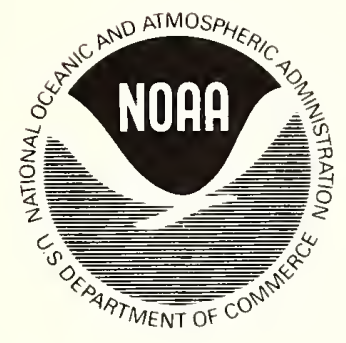

\section{NOAA Aquaculture Plan}

Prepared by

NATIONAL OCEANIC AND ATMOSPHERIC ADMINISTRATION

National Marine Fisheries Service

and

Office of Sea Grant

JOHN B. GLUDE, Editor

Aquaculture Program Coordinator

MAY 1977

U.S. DEPARTMENT OF COMMERCE

Juanita M. Kreps, Secretary

National Oceanic and Atmospheric Administration Robert M. White, Administrator

National Marine Fisheries Service

Robert W. Schoning, Director

Office of Sea Grant

Ned A. Ostenso, Director 


\section{CONTENTS}

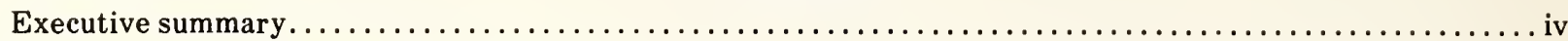

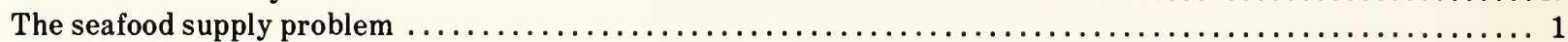

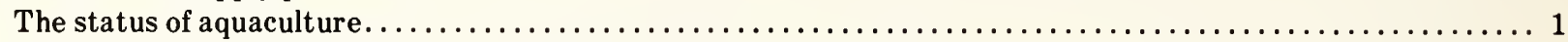

The potential for increasing food production in the United States through aquaculture $\ldots \ldots \ldots \ldots \ldots \ldots \ldots 2$

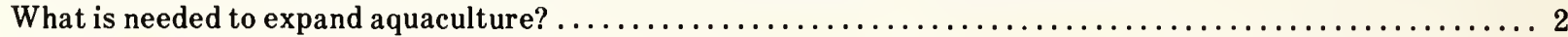

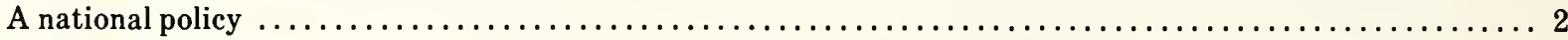

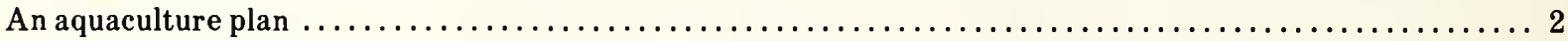

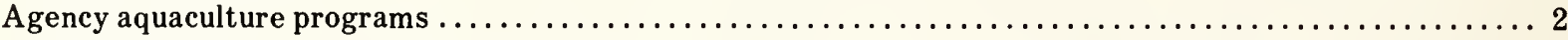

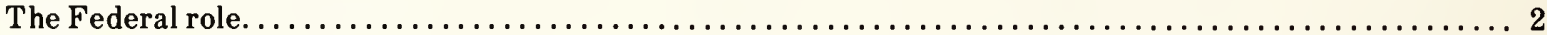

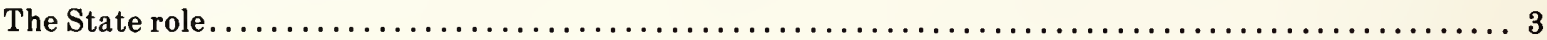

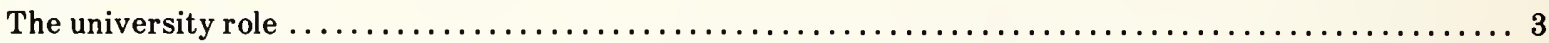

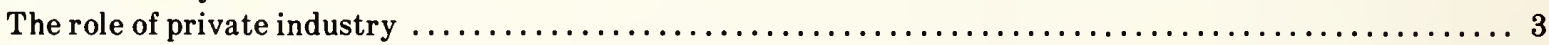

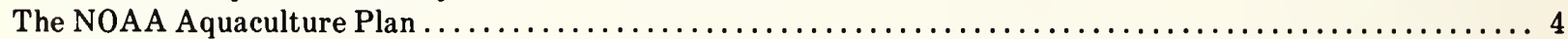

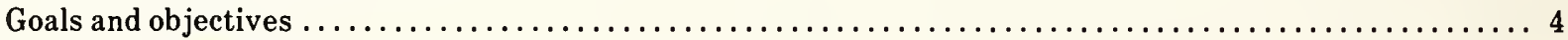

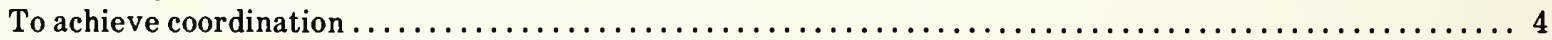

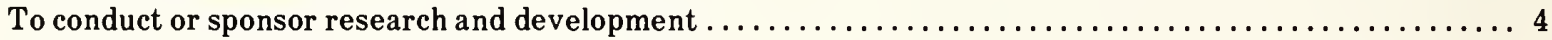

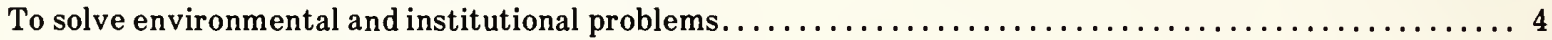

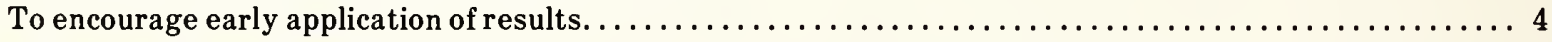

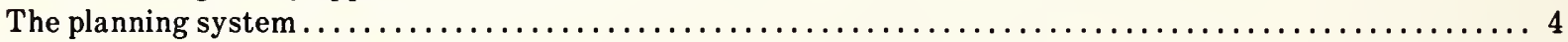

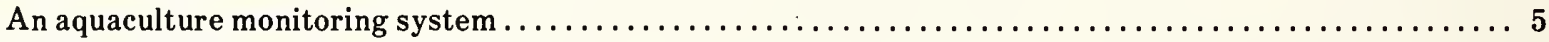

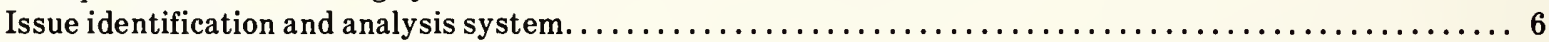

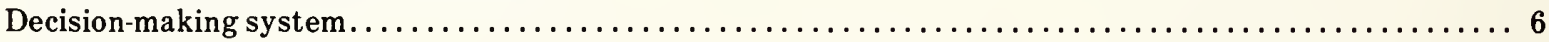

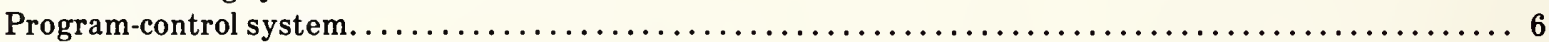

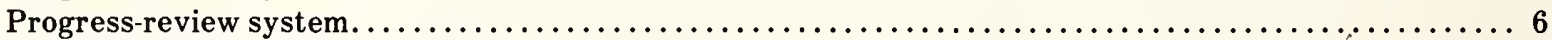

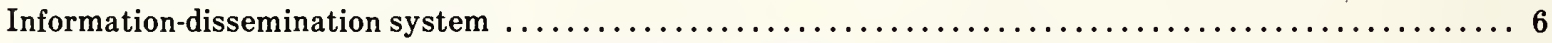

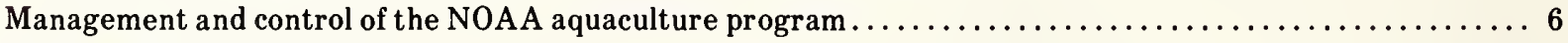

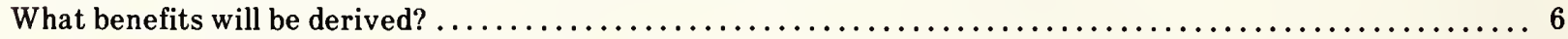

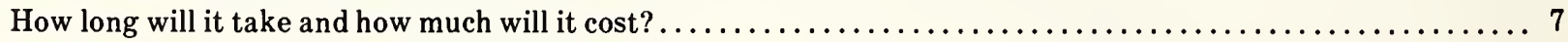

\section{Appendix A}

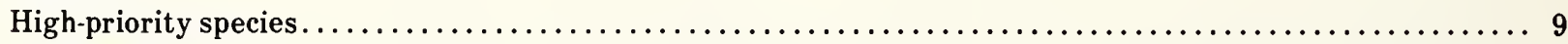

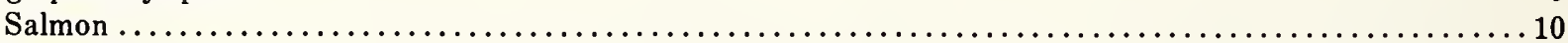

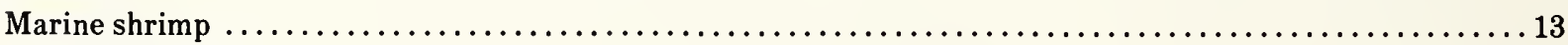

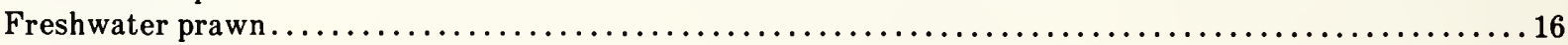

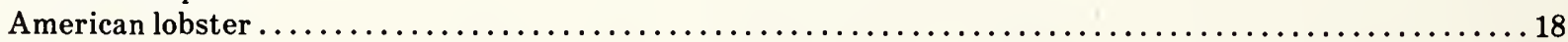

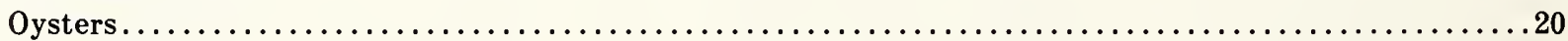

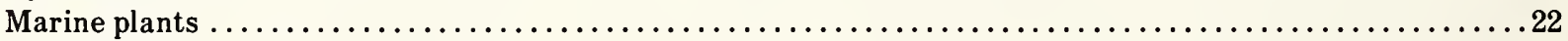

\section{Appendix B}

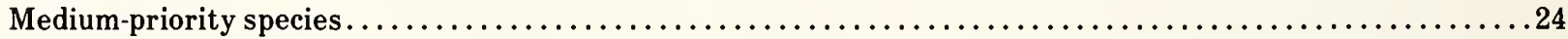

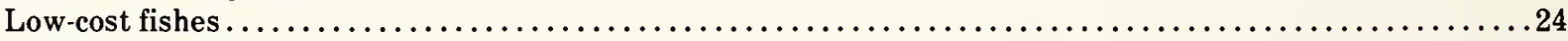

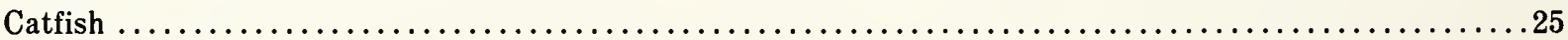

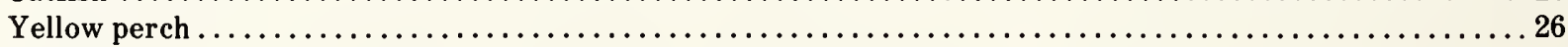

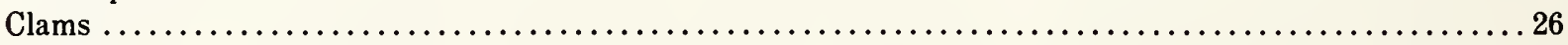

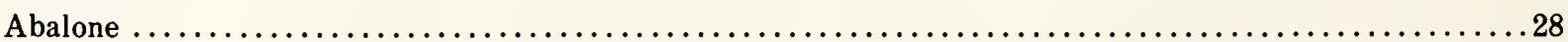

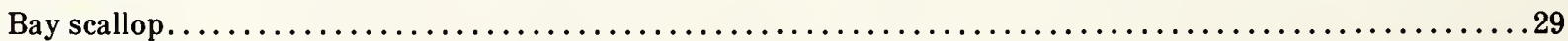

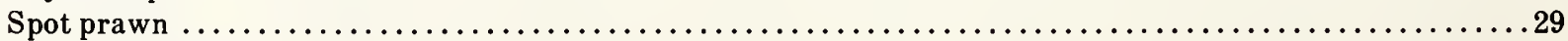

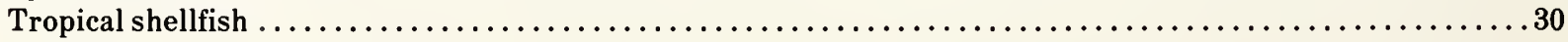

Appendix C

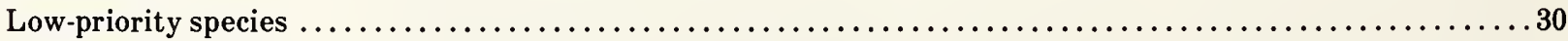

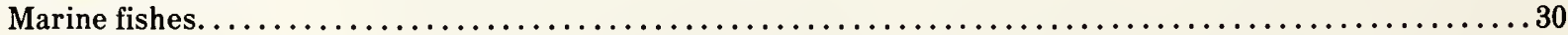

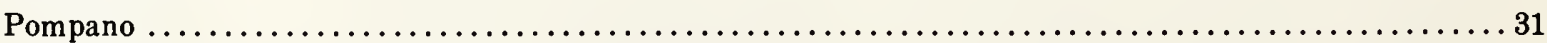

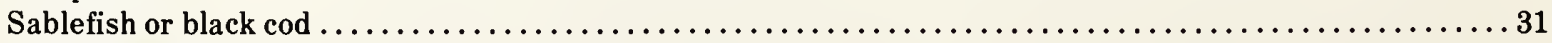

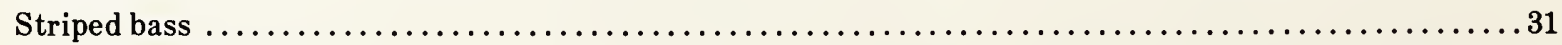

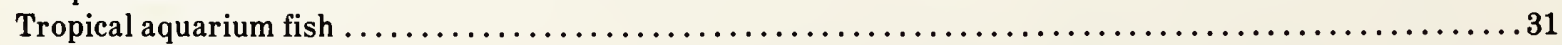

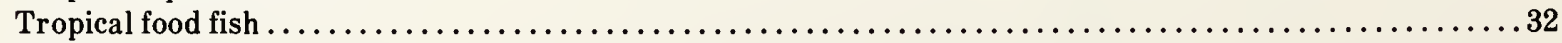

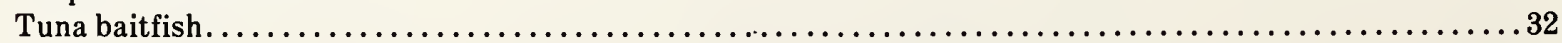

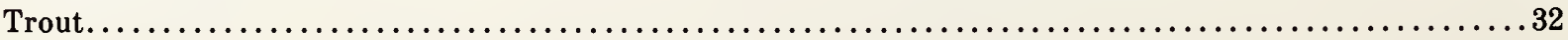




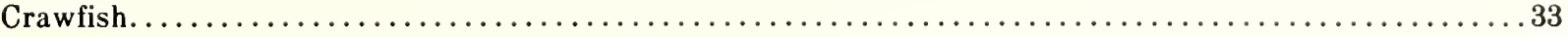

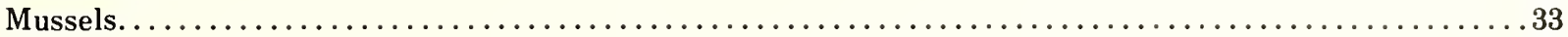

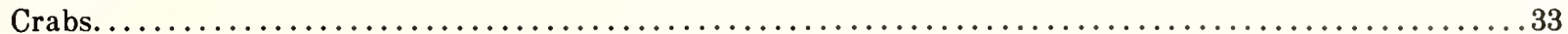

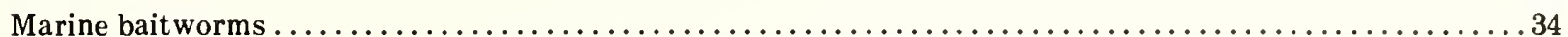

Appendix D

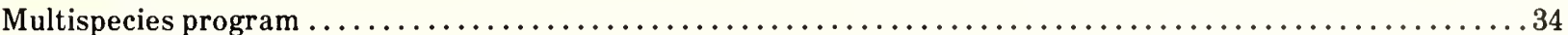

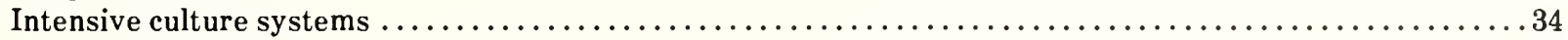

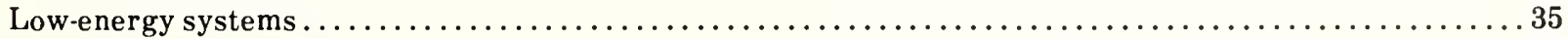

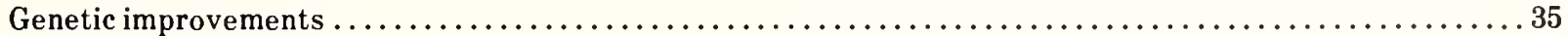

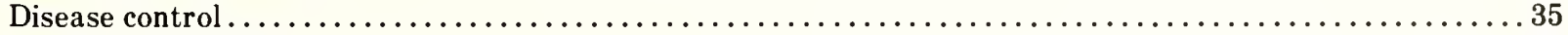

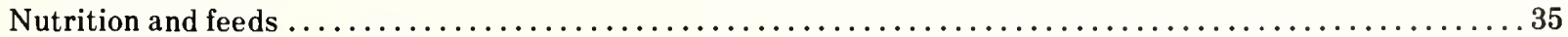

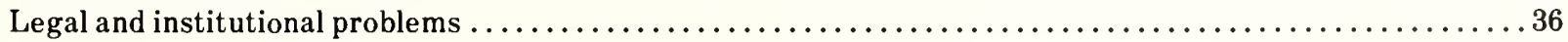

Appendix E

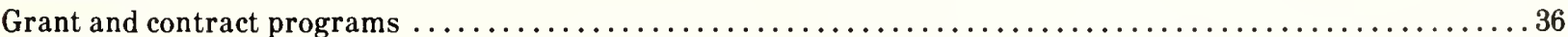

Appendix F

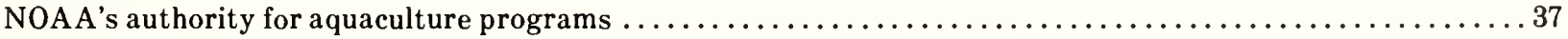

Appendix G

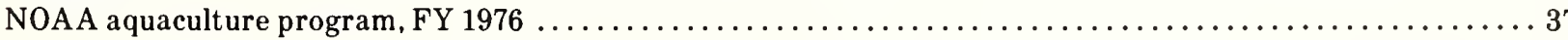

Figures

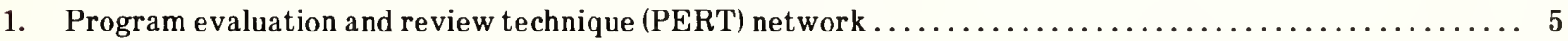

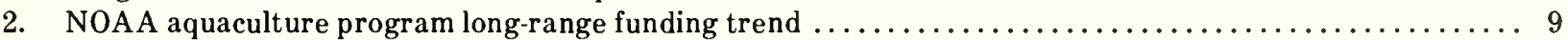

Appendix figures

A1. Projected NOAA funding trend for salmon, Oncorhynchus spp. and Salmo salar ................ 13

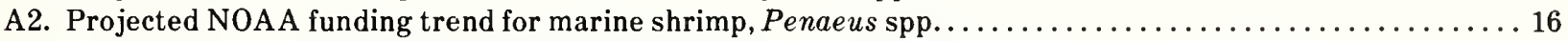

A3. Projected NOAA funding trend for freshwater prawn, Macrobrachium spp. .....................

A4. Projected funding trend for the American lobster, Homarus americanus . . . . . . . . . . . . . . . . . 20

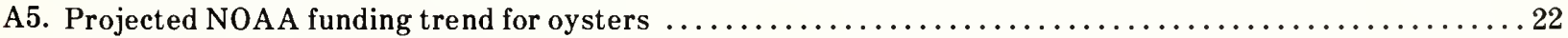

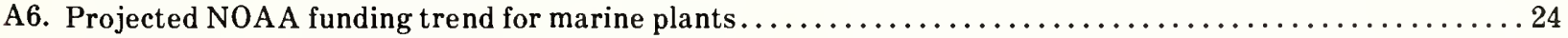

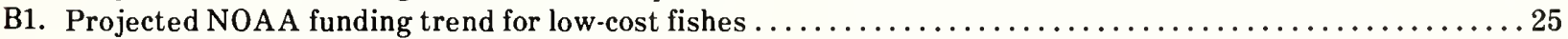

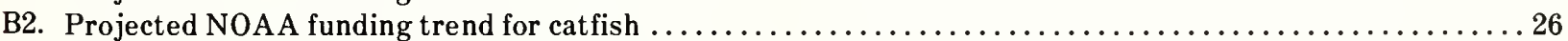

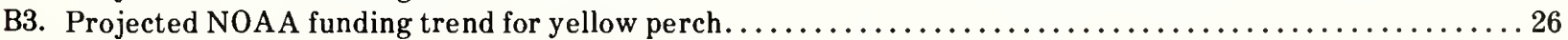

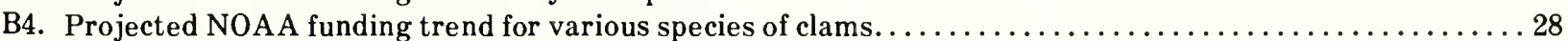

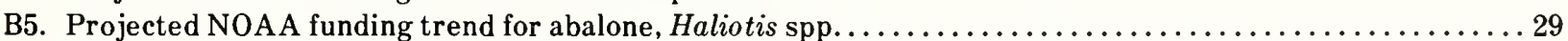

B6. Projected NOAA funding trend for the bay scallop, Aequipecten irradians . . . . . . . . . . . . . . . . 29

B7. Projected NOAA funding trend for the spot prawn, Pandalus platyceros . . . . . . . . . . . . . . . . . 30

B8. Projected NOAA funding trend for aquaculture of tropical shellfish $\ldots \ldots \ldots \ldots \ldots \ldots$

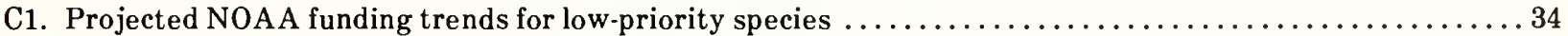

D1. Projected NOAA funding trends for multispecies programs. . . . . . . . . . . . . . . . . 36

\section{Tables}

1. Estimated expenditures by NMFS or its predecessor agencies related to aquaculture of selected species ... 8

2. Estimated expenditures by Office of Sea Grant related to aquaculture of selected species............. 9

Appendix tables

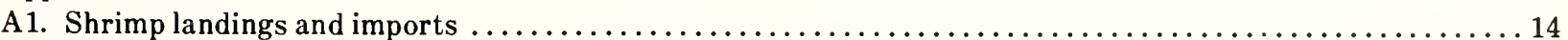

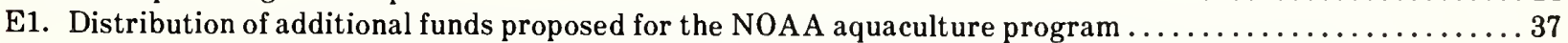

G1. NOAA aquaculture program, FY 1976; activities by species, organization, location, funding level,

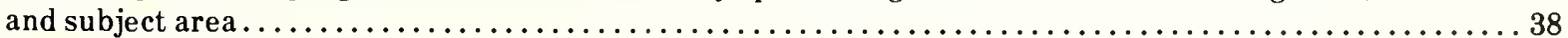

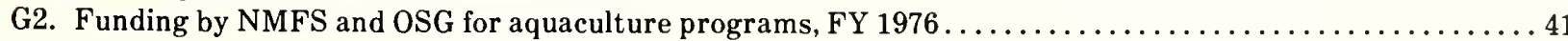

Abbreviations used in this report include:

FAO Food and Agriculture Organization of the United Nations

NOAA National Oceanic and Atmospheric Administration

NMFS National Marine Fisheries Service

OSG Office of Sea Grant

FWS Fish and Wildlife Service of the Department of the Interior 


\title{
NOAA Aquaculture Plan
}

\author{
Executive Summary
}

AQUACULTURE: The culture or husbandry of aquatic animals or plants by private industry for commercial purposes or by public agencies for augmenting natural stocks.

\section{THE SEAFOOD SUPPLY PROBLEM}

Traditional stocks of marine resources, once thought to be unlimited, are now estimated at a maximum level of harvest of 100 to 150 million metric tons (220 to 330 billion pounds) per year. Fish catches currently exceed 64 million metric tons ( 141 billion pounds) annually. On a worldwide basis, a shortage of fisheries products can be expected within 10 years if the population continues to increase.

In the United States, most of our traditional fisheries resources are already being harvested at or near maximum sustainable yield levels. Imports have increased, but world demand is also expanding. This situation is expected to limit the amount of seafood available for export to the United States or to make it excessively expensive. Thus the U.S. demand for traditional seafoods will become critical within the next decade, resulting in physical shortages and increased prices of many products.

\section{THE STATUS OF AQUACULTURE}

Worldwide output from aquaculture has approximately doubled during the last 5 years and now amounts to some 6 million metric tons (13.2 billion pounds), roughly $10 \%$ of world fish production. Some countries already rely upon aquaculture for over $40 \%$ of their total fisheries supply and expect production from aquaculture to increase.

In the United States, public aquaculture of salmon began a century ago and more than one quarter of our salmon $(27,000$ metric tons or 60 million pounds) originates in hatcheries. Private aquaculture produces $40 \%$ of our oysters, half of our catfish and crawfish, nearly all of our trout, and small quantities of several other species for a total of 65,000 metric tons ( 143 million pounds). However, this is only $3 \%$ of U.S. landings or $2 \%$ of U.S. total consumption of fishery products.

\section{THE POTENTIAL FOR INCREASING FOOD PRODUCTION IN THE UNITED STATES THROUGH AQUACULTURE}

There is good potential for increasing fisheries production in the United States by expanding hatcheries and other forms of public aquaculture and by encouraging private farming of fish and shellfish. Procedures for rearing trout, salmon, catfish, and oysters are well known, and with solution of some biological, technological, institutional, or marketing problems, production could be increased significantly. For other species such as shrimp, scallops, clams, crabs, lobsters, and most marine fishes, research and development are required to provide adequate biological and technological knowledge for development of aquaculture.

Although aquaculture in the United States has largely concentrated on species in high demand and limited supply, it is not restricted to high-valued products. Fish, such as buffalo fish, mullet, and various species of carp can be reared in ponds and processed into acceptable low-priced food products.

\section{WHAT IS NEEDED TO EXPAND AQUACULTURE?}

Expansion of aquaculture in the United States will require a national policy, a plan, and implementation of the plan through coordinated efforts of Federal and 
State agencies, universities, and the nation's aquaculture industry.

\section{A National Policy}

A national policy is needed to recognize that development of aquaculture is in the national interest and to call for the protection of coastal and estuarine environments so that aquatic foods can be produced in these areas.

\section{An Aquaculture Plan}

A national plan is needed to identify goals and to describe actions which must be taken by Federal and State governments, universities, and industry to achieve these goals. The agency plan described in this paper primarily identifies actions that should be taken by NOAA. Similar documents will be needed to describe actions that should be taken by other Federal agencies and State agencies.

\section{Agency Aquaculture Programs}

Implementation of the national plan must be through programs of Federal and State agencies in cooperation with universities and the industry. Coordination and joint planning will help to achieve maximum effects of these diverse activities.

\section{The Federal Role}

Many of the concepts and techniques that have made private aquaculture possible in the United States have resulted from research and development conducted in government laboratories or sponsored in universities by the Federal Government. Increased Federal efforts will be needed to provide an adequate information base for development of aquaculture of additional species and solutions to long-range problems of currently farmed fish and shellfish.

\section{The State Role}

States have a significant role in the development of aquaculture since they have primary responsibility for resource management and most have well-developed capabilities for research and development. A major role of the States is to establish laws, policies, and administrative procedures that will encourage aquaculture and to maintain high-quality environments in bays, estuaries, and coastal waters.

\section{The University Role}

Research and development projects at academic institutions largely supported by Federal or State funds have provided much of the basic knowledge needed for aquaculture. These efforts to solve problems that are limiting the development of aquaculture must continue. Advisory services are also needed to be certain that results of research are transferred to industry expeditiously and in the most useful form.

\section{The Role of Private Industry}

The role of industry in aquaculture is to apply results of scientific research and technological development to the production of quality products for U.S. consumers at an acceptable price with an adequate margin of profit.

Private companies often are unwilling or unable to conduct research or development because of the uncertainty of results, the need for specialized facilities and capabilities, and the lack of potential for patentable discoveries. Even so, estimated industry expenditures during the past 5 years for research and development include over $\$ 22$ million for marine shrimp and freshwater prawns, over $\$ 6$ million for oysters and clams, and over $\$ 4$ million for salmon. Further efforts by industry are needed to develop cost-effective production methods, assure high quality and consistent supply of products, and expand markets.

\section{THE NOAA AQUACULTURE PLAN}

\section{Goals and Objectives}

The primary NOAA goal for fisheries is to maintain or increase the national availability of a broad spectrum of aquatic resources and products for the U.S. consumer. As related to aquaculture, the goal is to increase, by public hatcheries or by private industry, production of selected species that are in short supply.

The objective of NOAA programs will be to provide the scientific, technical, legal, and institutional base needed for development of aquaculture and to facilitate early application of research results by information dissemination and extension activities.

\section{To Achieve Coordination}

NOAA will cooperate with other Federal agencies, State agencies, and industry in joint planning and coordination of programs to achieve common objectives.

\section{To Conduct or Sponsor Research and Development}

NOAA will conduct or sponsor research to provide biological and technical information necessary for development of public and private aquaculture of selected species.

\section{To Solve Environmental and Institutional Problems}

NOAA will take action to determine economic, social, institutional, and legal barriers to the advancement of aquaculture and to cooperate with regional, State, and industrial groups to minimize or remove such barriers.

NOAA will foster the development of comprehensive coastal zone management programs to ensure adequate and equitable consideration of aquacultural efforts and to protect aquatic environments from degradation that would prevent their use for aquaculture. 


\section{To Encourage Early Application of Results}

NOAA will provide scientific and technical information to the aquaculture community as a whole, through publications, workshops, and advisory services.

\section{The Planning System}

The first step in developing an aquaculture program is to determine the status of aquaculture of various species and to identify the factors that are inhibiting or limiting its full development. A detailed examination of each limiting factor or barrier is needed to determine the probability that it can be removed, the actions required, the time and costs involved, and the benefits that would accrue from its removal. With this information, it will be possible to select for emphasis those programs related to the removal of barriers that have the greatest importance or urgency in the development of viable aquaculture. After an action is taken to remove the identified barriers, it will be necessary to disseminate information through publications and advisory services to encourage prompt application of findings by industry. An improved planning system with computerized storage and retrieval of information is under development.

\section{BENEFITS}

Expanded aquaculture will benefit the U.S. consumer by increasing the supply of certain fish and shellfish which have reached the upper limit that can be obtained from wild stocks. Higher outputs should result in lower prices for consumers. Public aquaculture to augment natural stocks will benefit recreational and commercial fisheries.

Although fish and shellfish farmers have traditionally concentrated on expensive products, several species of warmwater fish can be reared in low-energy systems and processed into acceptable products for the lowpriced market.

\section{FUNDING NEEDS}

In total, the NOAA aquaculture program should increase from the 1976 level of $\$ 6.4$ million to about $\$ 19$ million by 1979 and continue at that level for another decade. Funding trends for high-, medium-, and lowpriority species and for multispecies programs are included in the appendices. Detailed funding requirements for individual programs will be provided in annual budget requests.

\section{CONCLUSION}

Public or private aquaculture of several major species is largely successful. With the solution to some biological, technological, institutional, or marketing problems, production of these species could be increased to help the United States meet the anticipated demand for seafood. Additional species have potential, but research and development are needed to provide an adequate scientific and technical base for development of aquaculture. The expansion of aquaculture will require the coordinated efforts of Federal and State agencies, universities, and private industry. NOAA proposes to take the lead in these efforts.

Projected funding for the NOAA aquaculture program.

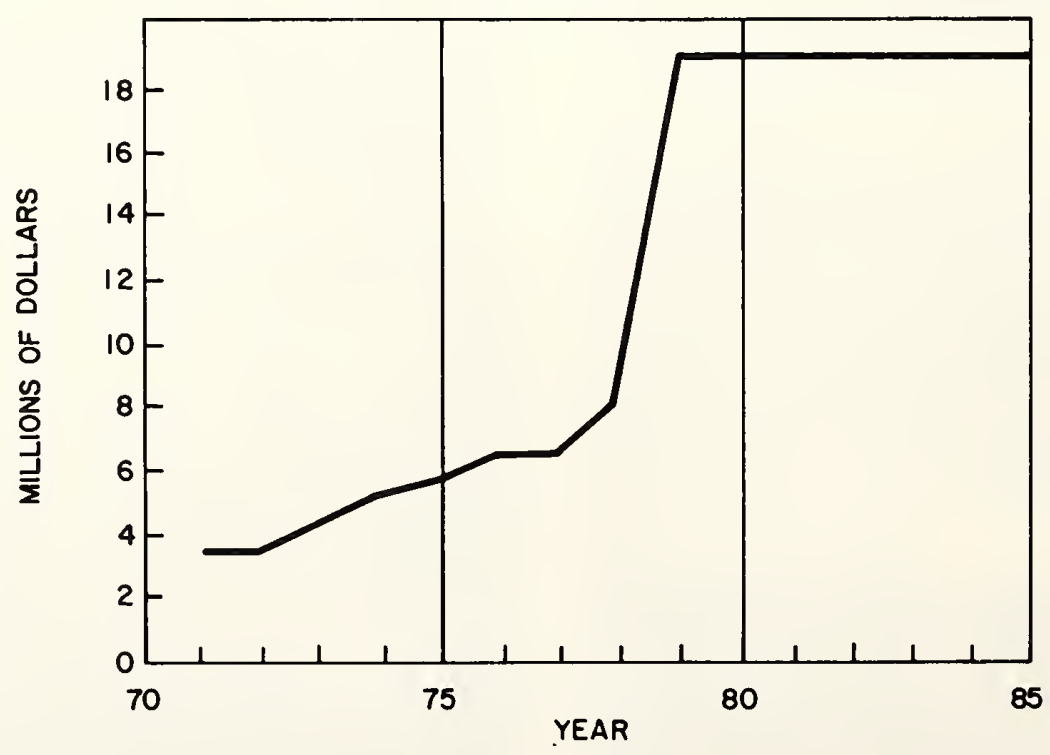




\title{
NOAA Aquaculture Plan
}

\begin{abstract}
AQUACULTURE: The culture or husbandry of aquatic animals or plants by private industry
\end{abstract} for commercial purposes or by public agencies for augmenting natural stocks.

\section{THE SEAFOOD SUPPLY PROBLEM}

Traditional stocks of marine resources, once thought to be unlimited, are now estimated at a maximum level of harvest of 100 to 150 million metric tons (220 to 330 billion pounds) per year. Fish catches currently exceed 64 million metric tons ( 141 billion pounds) annually. On a worldwide basis, a shortage of fisheries products can be expected within 10 years if the population continues to increase. ${ }^{1}$ The Food and Agriculture Organization (FAO) has proposed several courses of action to alleviate the predicted shortage of seafood:

a. Improved management of world fisheries stocks

b. Increased harvest of underutilized species

c. Diversion to the food fish market of those species now used predominately for fish meal

d. Reduction of wastage

e. Increased production by aquaculture.

In the United States most of our traditional fisheries resources are already being harvested at or near maximum sustainable yield levels. Imports have increased, but world demand also is expanding. This situation is expected to limit the amount of seafood available for export to the United States or to make it excessively expensive. Thus the demand for traditional seafoods in the United States will become critical within the next decade, resulting in physical shortages and increased prices for many products unless supplies from sources other than traditional marine fish stocks enter the market in significant amounts. ${ }^{2}$

\section{THE STATUS OF AQUACULTURE}

Worldwide output from aquaculture has approximately doubled during the last 5 years and now amounts to some 6 million metric tons (13.2 billion pounds), roughly $10 \%$ of world fish production. Some countries already

\footnotetext{
${ }^{1}$ FAO Report, Assessment of the world food situation present and future. FAO Report E/Conf. 65/3,125 p.

"National Plan for Marine Fisheries," National Marine Fisheries Service, Washington, D.C. Draft June 1975.

Committee on Commerce, 1974. Economic value of ocean resources to the United States. Prepared at the request of Hon. Warren G. Magnuson, Chairman for the use of the Committee on Commerce pursuant to S. Res. 222, National Ocean Policy Study. U.S. Senate, 93rd Congress, 2nd Sess., committee print, 109 p.
}

rely upon aquaculture for over $40 \%$ of their total fisheries supply and expect production from aquaculture to increase.

In the United States a significant portion of the supply of some species is produced by aquaculture. About $30 \%$ of our total landings of Pacific salmon and over half of the Columbia River salmon caught by commercial and recreational fishermen were reared in hatcheries before being released to grow further in rivers, lakes, and sea. Private aquaculture produces over $40 \%$ of our oysters, half of our catfish and crawfish, nearly all of our rainbow trout, and small quantities of several other species for a total of 65,000 metric tons (143 million pounds). This is about $3 \%$ of U.S. landings or $2 \%$ of U.S. total consumption of fishery products. ${ }^{3}$

While high hopes have been held for rapid development of private aquaculture in the United States, the promise for most species has not been fulfilled. While world aquaculture production has doubled during the last 5 years, U.S. production has remained static. Shrimp farming, successful in Japan, has not become viable in the United States. Pompano culture attracted extensive investment, but has failed to achieve commercial viability. Major biological and technological problems remain to be solved before successful aquaculture can be developed for most other species. In addition, expanded U.S. aquaculture requires space in clean coastal or estuarine water or adequate supplies of high-quality freshwater-but other users also want these limited resources. Institutional problems such as zoning, waste control, and licensing must be solved.

In the Federal Government there is a diffusion of aquaculture efforts. Several agencies, and components within agencies, have conducted aquaculture research and development within the framework of specific missions. Coordination, if any, has been primarily to avoid undesirable overlap rather than to define goals and agree on responsibility for their achievement. Far more serious than overlap are the number of gaps in the research and development effort. Many severe problems that impede commercial success are not being attacked, or the efforts are inadequate.

\footnotetext{
${ }^{3} \mathrm{On}$ the basis of edible fisheries products, percentages are $6.1 \%$ and $3.0 \%$, respectively.
} 
Projects by State and local agencies, regional commissions, and universities generally have been responsive to specific local problems without relation to an overall plan.

\section{THE POTENTIAL, FOR INCREASING FOOD PRODUCTION IN THE UNITED STATES THROUGH AQUACULTURE}

There is good potential for increasing fisheries production in the United States by expanding hatcheries and other forms of public aquaculture and by encourag. ing private farming of fish and shellfish.

Procedures for rearing trout, salmon, catfish, and oysters are well known. With the solution of some biological, technological, institutional, or marketing problems, production of these species could be increased significantly.

Research and development can provide adequate biological and technological knowledge for aquaculture of additional species such as shrimp, scallops, clams, crabs, lobsters, and several marine fishes.

Although aquaculture in the United States has concentrated largely on species in high demand and limited supply, it is not restricted to high-valued products. Fish such as buffalo fish and various species of carp can be reared in ponds and processed into acceptable lowpriced food products.

The extension of U.S. fisheries jurisdiction to 200 miles offshore provides an opportunity for increasing U.S. harvest of natural stocks. However, this is unlikely to provide significantly increased quantities of those species that might be grown by aquaculture.

Production records demonstrate the success of private and public aquaculture of several species and provide a basis for estimating their potential for expansion. Rainbow trout production by private growers has increased from just over 1 million pounds (450 metric tons) in 1954 to over 30 million pounds $(13,600$ metric tons) in 1972. With adequate markets and acceptable feed prices, production could be doubled during the next decade.

Private oyster farms produce 20 million pounds $(9,000$ metric tons) of meats annually. With adequate markets at satisfactory prices and space for oyster culture in the coastal zone, production could be quadrupled during the next decade.

Landings of Pacific salmon could be greatly increased with favorable benefit/cost ratios by expanding public aquaculture. Federal and State salmon culture experts estimate that landings attributable to hatcheries could be increased by half during the next decade if funds were made available for expanding hatchery production.

Private salmon aquaculture, a new industry based on technology developed from public hatcheries, is taking two forms: 1) production of pan-sized or yearling salmon in floating net pens or in seawater ponds; 2) ocean ranching in which juveniles are released to feed in the ocean and are recaptured when they return to spawn. Private salmon aquaculture by the net pen and ocean-ranching systems is just beginning, but already there are ventures in Washington, Oregon, Maine, and several planned in Alaska. Production, which was less than 1 million pounds ( 450 metric tons) in 1975 , could exceed 60 million pounds $(27,000$ metric tons) by 1985 if certain produc tion problems can be solved and markets remain attractive.

Private catfish farming has been a viable industry for several years. About 2,000 farmers and 12 processing firms in 13 southern States produced over 50 million pounds (23,000 metric tons) round weight (1973). The expansion of catfish culture depends on production costs and market prices. With satisfactory profit potential, the industry could at least double its present production by 1985 .

\section{WHAT IS NEEDED TO EXPAND AQUACULTURE?}

The expansion of U.S. aquaculture will require a national policy, a plan, and implementation of the plan through coordinated efforts of Federal and State agencies, universities, and the aquaculture industry.

\section{A National Policy}

Aquaculture has high potential for augmenting the supply of aquatic protein, thereby helping the United States meet its future food needs. Therefore, it is in the national interest to encourage the development of aquaculture and to protect our aquatic environments so that food can be produced in these areas.

\section{An Aquaculture Plan}

A national plan is needed to identify objectives or goals that must be attained and to describe actions that Federal and State governments, universities, and industry must take to achieve these goals. The agency aquaculture plan described in this paper primarily identifies actions that NOAA should take. Similar documents will be needed to describe actions that other Federal and State agencies should take.

\section{Agency Aquaculture Programs}

Implementation of the national plan must be through programs of various Federal and State agencies in cooperation with universities, industry organizations, firms, and individual aquatic farmers. Coordination and joint planning will help achieve the maximum effect of the diverse aquaculture activities now underway or planned for the future.

\section{The Federal Role}

Many of the concepts and techniques that have made private U.S. aquaculture possible have resulted from research and development in government laboratories 
or sponsored in universities or State agencies by the Federal Government. Continuation of Federal efforts will be needed to provide an adequate information base for development of aquaculture of additional species and solutions to long-range problems of currently farmed fish and shellfish.

Federal leadership and guidance are needed to develop a national plan and implement a coordinated national program utilizing the authorities and capabilities of various Federal agencies. This will require the National Marine Fisheries Service (NMFS) and Office of Sea Grant (OSG) of the Department of Commerce to work with the Fish and Wildlife Service (FWS) of the Department of the Interior to develop aquaculture of marine, estuarine, anadromous, and freshwater species.

The Department of Agriculture has vast expertise in animal husbandry that could be applied to solve problems in aquatic farming. Its Extension Service, which has a nationwide system for disseminating information, could serve aquatic as well as terrestrial farmers. Several other Federal agencies have direct or indirect responsibilities related to aquaculture. An Interagency Committee on Aquaculture could provide an effective mechanism for information exchange and joint planning at the Federal level.

\section{The State Role}

States have a significant role in the development of aquaculture since they have primary responsibility for resource management and most have well-developed capabilities for research and development. Several State fisheries agencies have ongoing projects to encourage private aquaculture, or to develop new or improved methods for public aquaculture. Some of the programs are carried out entirely with State funds; others are partially funded by NOAA under the "Commercial Fisheries Research and Development Act of 1964" (P.L. 88-309) or other Federal programs.

Procedures are needed to exchange information among State and regional entities and Federal agencies. Coordination of State and Federal efforts is needed to achieve the national goal of increasing food production through aquaculture, but coordination efforts must respect the objectives of individual States.

\section{The University Role}

Research and development projects at academic institutions largely supported by Federal or State funds have provided much of the basic knowledge needed for aquaculture. At least 30 universities and other research institutions conduct aquaculture-related projects under NOAA's Sea Grant program. These efforts to solve problems that are limiting the development of aquaculture must continue.

For aquaculture to grow and flourish, information dissemination and communications are essential. Advisory services through universities are needed to be certain that results of research are transferred to industry expeditiously and in the most useful form. There is already need for advisory specialists who can visit aquaculture sites, diagnose problems, and help find their solutions. NOAA's National Marine Advisory program is beginning to provide this service through selected universities and through cooperation with the Department of Agriculture Extension Service.

\section{The Role of Private Industry}

The role of industry in aquaculture is to apply results of scientific research and technological development to the production of quality products at an acceptable price with an adequate margin of profit.

Private companies are often unwilling or unable to conduct research or development because of the uncertainty of results, the need for specialized facilities and capabilities, and the lack of potential for patentable discoveries. Since the expected private returns from investment in research and development are low relative to other investments, it is unlikely that adequate and timely research and development would be forthcoming if left to the private sector.

Because of the high risks associated with aquaculture enterprises, significant investment capital will not become available until risks are reduced and the probability of profit from investment is higher. Industry's interest in aquaculture's potential is manifest in the number of companies, large and small, that send representatives to technical meetings and inquire about developments almost daily from NOAA and other agencies. Although industry's present posture is, for the most part, one of watchful waiting, it is ready to move into new fields of aquaculture when an adequate information basis is available to make the risk acceptable.

In short, if U.S. aquaculture is to grow to a level that contributes significantly to the supply of high-quality fishery products in time to meet projected needs, government must assist in developing the base on which a strong aquaculture industry can be structured. Industry cannot do it alone. The situation is roughly analogous to the state of agriculture before the Land Grant system and the Department of Agriculture launched intensive research programs to develop agricultural technology. The analogy has not escaped investors, who regard it as a precedent.

Even so, estimated industry expenditures during the past 5 years for research and development include over $\$ 22$ million for marine shrimp and freshwater prawns, over $\$ 6$ million for oysters and clams, and over $\$ 4$ million for salmon. Some of these expenditures represent contributions to joint programs with government or universities, but most are for direct industry efforts. Further efforts by industry are needed to develop costeffective production methods, assure high quality and consistent supply of products, and to expand markets.

Industry or industry association programs related to furtherance of aquaculture are not subject to coordination in the same sense as government programs. However, voluntary cooperation, exchange of information, 
and participation in joint programs should be encouraged. Effective procedures are needed to obtain advice from aquaculturists in the development of State and Federal programs.

\section{THE NOAA AQUACULTURE PLAN}

The following plan specifies NOAA's goals and objectives, outlines a planning system, and describes problems, solutions, and required actions for several groups of species. Detailed plans regarding specific programs will be presented in annual budget requests.

The plan excludes some activities that fall within the general definition of aquaculture. Operation of public hatcheries to augment natural stocks of fish or shellfish has been excluded because these programs have their own authorizations, budgets, and management systems. However, research and development to provide information needed for public aquaculture have been included because private as well as public aquaculture will benefit from these studies. Culture of freshwater species has been discussed only in general terms, recognizing that primary responsibility for freshwater aquaculture rests with State agencies, or with other Federal agencies such as the Departments of Interior and Agriculture.

\section{Goals and Objectives}

The primary NOAA goal for fisheries is to maintain or increase the national availability of a broad spectrum of aquatic resources and products for the U.S. consumer. As related to aquaculture, the goal is to have public hatcheries or private husbandry increase production of selected species that are in short supply.

The objectives of NOAA programs are to provide the scientific, technical, legal, and institutional base needed for the development of aquaculture in cooperation with other agencies and groups, and to facilitate early application of research results by information dissemination and extension activities.

\section{To Achieve Coordination}

NOAA will cooperate with other Federal agencies in joint planning and coordination of programs to achieve common objectives and will encourage international cooperation in programs to solve mutual problems that limit aquaculture.

NOAA will engage only in those activities that are within its responsibility. It will encourage other Federal agencies, States, local governments, the academic community, and the private sector to cooperate and participate in the development of aquaculture.

\section{To Conduct or Sponsor Research and Development}

NOAA will conduct or sponsor research to provide biological and technological information necessary for development of public and private aquaculture of selected species.
NOAA will carry biological and technological research and development through the pilot or prototype stage. This is defined as the stage of development sufficiently large in production of organisms to permit assessment of its application in public hatcheries or commercial ventures. NOAA will encourage industry participation in research and development efforts and prototypetesting while recognizing that there may be no existing industry for some species proposed for aquaculture.

NOAA will seek a balance between long- and shortrange research and development so that long-range requirements for improvement of aquaculture which are beyond the capability of industry to solve for itself will be met.

NOAA will establish a balance between in-house efforts in research, engineering systems, economics, and marketing with work accomplished under grants or contracts to universities, State agencies, or private firms.

\section{To Solve Environmental and Institutional Problems}

NOAA will take action to determine economic, social, institutional, and legal barriers to the advancement of aquaculture and to cooperate with Federal, State, and local agencies, and industrial groups to minimize or remove such barriers.

NOAA will foster the development of comprehensive programs of coastal zone management to ensure adequate and equitable consideration of aquacultural efforts and to protect aquatic environments from degradation that would prevent their use for aquaculture.

\section{To Encourage Early Application of Results}

NOAA will encourage early application of research results by providing scientific and technical information to the aquaculture community through publications, workshops, and advisory services.

\section{The Planning System}

The first step in developing an aquaculture plan is to determine the status of aquaculture of each species and to identify the factors inhibiting or limiting its full development. A detailed examination of each limiting factor or barrier is needed to determine the probability that it can be removed, the actions required, the time and costs involved, and the benefits that will accrue from its removal. With this information, it will be possible to select for emphasis those programs that have the greatest importance or urgency in the development of viable aquaculture. After an action is taken to remove the identified barriers, it will be necessary to disseminate information through publications and advisory services to encourage prompt application of findings by industry.

It must also be recognized that new research discoveries, new industrial developments, and new marketing situations occur periodically. Some of these will change the evaluation of the potential for aqauculture positively or negatively. The planning system must provide flexi- 
bility to permit new developments and new discoveries to be taken into account and plans modified accordingly.

Development of an improved planning system with computerized storage and retrieval of information was begun in 1975 by the Center for Quantitative Sciences of the University of Washington as a Sea Grant project. This system will provide Program Evaluation and Review Techniques (PERT) network displays for each species to indicate factors inhibiting viable aquaculture and to facilitate the selection of areas needing immediate attention (Fig. 1). The input for this system will include published information and evaluation by Federal and State specialists, university experts, and industry representatives.

The following species groups will be included in the NOAA aquaculture planning system.

Fishes

Anadromous

Pacific and Atlantic salmon, trout, striped bass ${ }^{4}$

Marine

Pompano, mullet, rabbitfish, threadfin, tuna baitfish, etc.

Freshwater

Catfish, trout, carp, perch, buffalo fish, etc. ${ }^{4}$

Crustaceans

Marine shrimp

Freshwater prawn

\footnotetext{
${ }^{4}$ In cooperation with the Department of the Interior.
}

\author{
Lobster \\ Freshwater crawfish ${ }^{4}$ \\ Crabs \\ Mollusks \\ Oysters \\ Clams \\ Scallops \\ Mussels \\ Abalone \\ Marine plants \\ Other \\ Marine baitworms
}

The following provides the framework for planning, implementing, evaluating, modifying, and updating the NOAA aquaculture program.

\section{An Aquaculture Monitoring System}

This will include a computerized listing of the status of biological, technological, legal, institutional, and marketing information and the progress of information for each species with aquaculture potential. The input for this system will be publications, results of state-of-theart workshops, and the best estimates of experts from industry, universities, and State and Federal Government agencies. This information is largely available for a few major species, but needs to be entered into the computerized system for information storage and retrieval now being developed. For other species experts must assemble and evaluate the available information.

Figure 1.-Program evaluation and review technique (PERT) network.

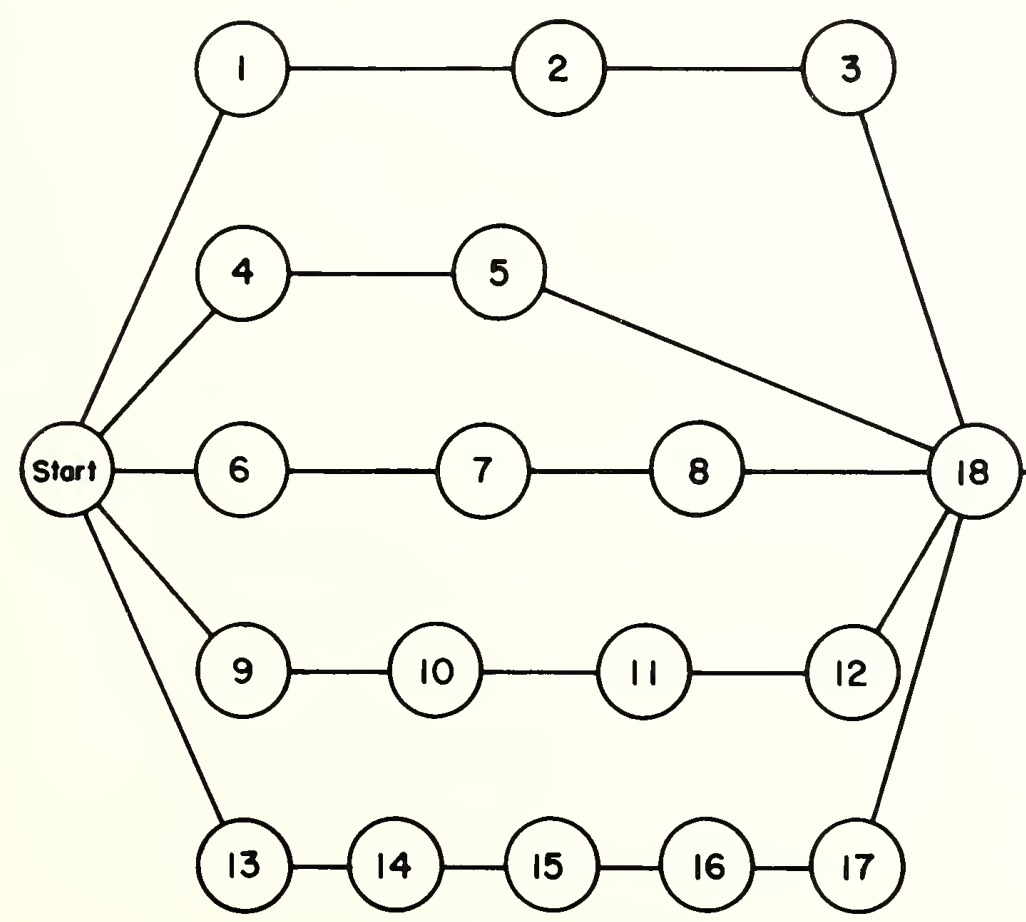

TASKS

1. Demand

3. Price

4. Life history

5. Environmental requirements

6. Culture systems

7. Preservation \& processing systems

8. Marketing systems

9. Seed

10. Feed

11. Mortality control

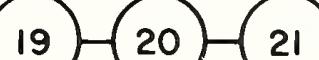

12. Genetic improvements

13. Space availability

14. Permits \& licenses

15. Effluent control methods \& cost

16. Labor supply

17. Investment capital

18. Prototype testing

19. Economic analysis

20. Information dissemination

21. Production

22. Long-term research 
It also will be necessary to update the listings for each species periodically to record progress of research and changed conditions.

\section{Issue Identification and Analysis System}

Panels of experts will be called together in workshops to identify problems and factors that prevent development or limit expansion of commercial aquaculture of each major species. The detailed analysis of problem areas may be aided by application of computer simulation techniques to estimate the probability of solving the identified problems and to estimate costs, benefits, time required, and manpower facilities needed. This also will require periodic updating.

\section{Decision-Making System}

The annual program review during the preparation of budget requests provides an opportunity to analyze progress and to develop logical budget alternatives. Results of these analyses will be presented to decision makers in a form that will identify alternatives and the estimated consequences of various choices.

\section{Program-Control System}

Available funds will be allocated to aquaculture programs within approved subject areas by NMFS and OSG. Results in the form of progress and final reports and publications from government and nongovernment research projects will be used to update the computerized listing of the status of the development of aquaculture for each species.

\section{Progress-Review System}

Periodic program reviews will be made to assure satisfactory progress. Periodic workshops of experts also will be arranged to provide advice for program planning and to assure satisfactory progress towards national objectives. Programs will be modified on the basis of these program reviews and workshops.

\section{Information-Dissemination System}

The NOAA National Aquaculture Information Service will provide current information and access to articles and data of importance to scientists and industry.

NOAA will establish a national advisory program for aquaculture as a specialized function of the National Marine Advisory Service in cooperation with the Extension Service of the Department of Agriculture. This will keep the industry, the public, and State and Federal officials informed of new developments in aquaculture, provide personalized transfer of information to aquaculturists, and provide feedback from users to research and development units.

\section{Management and Control of the NOAA Aquaculture Program}

The coordinated NOAA aquaculture program will focus multidisciplinary and multi-institutional efforts on high-priority areas to expedite the development of aquaculture. The program will cover broad geographic areas and various species with activities ranging from basic biological research to final use of the product. The program will require effective coordination and management by an aquaculture program coordinator with a small but well-qualified staff with the following responsibilities:

1. To prepare and update the NOAA Aquaculture Plan.

2. To implement the NOAA aquaculture planning system including completing and updating the computerized listing of the status of aquaculture of various species and identification of areas for priority attention.

3. To prepare annually a NOAA aquaculture program and budget for that part of the national aquaculture program within NOAA's responsibility. Funding for aquaculture would be included in budgets of individual NOAA components and allocated to approved projects by them, but major reprograming within a fiscal year would require concurrence of the aquaculture program coordinator.

4. To work with each NOAA component through individuals named by the respective directorates as appropriate points of contact.

5. To encourage cooperation of other Federal agencies, State agencies, universities, and industry in coordinated efforts to expedite development of aquaculture. The formation of advisory committees at various levels would assist in this effort.

Implementation of the management and control activities listed above has already begun. A position of Aquaculture Program Coordinator was established in the NMFS Director's office and filled December 1974. Through an agreement with the NOAA Associate Administrator for Marine Resources and the OSG Director, the coordinator was assigned responsibility for preparing the NOAA Aquaculture Plan and developing an annual NOAA aquaculture budget.

The first steps have been taken to coordinate Federal activities related to aquaculture by organizing an Interagency Committee on Aquaculture. The planning system described in this section will be used for preparation of the FY 1979 budget. In the interim, program needs described in appendices $A$ through $D$ will be used for planning purposes and detailed descriptions of programs will be included in annual budget requests.

\section{WHAT BENEFITS WILL BE DERIVED?}

In a larger sense, expanded aquaculture will benefit the U.S. consumer by increasing the supply of certain fish and shellfish which have reached the upper limit that can be obtained from wild stocks. In such cases higher prices cannot stimulate increased production from natural supplies and serve only to restrict fishery products to higher income groups, and thus to fewer people.

Aquaculture also may stabilize or reduce the price of certain fishery products and provide for year-round 
availability of species normally harvested seasonally. Although fish and shellfish farmers have traditionally concentrated on expensive products, private production of species such as oysters has kept price increases well below the average for other species available only from wild stocks. Also several underutilized species of warmwater fish, which can be processed into acceptable products for the low-priced market, could be reared in aquaculture systems when wild stocks become depleted.

Waste or byproducts from aquacultural operations can be used for terrestrial animal feeds or in the culture of additional aquatic species in polyculture systems. There also is the possibility of using aquaculture systems to reclaim nutrients from sewage, which traditionally has been discharged into lakes, rivers, and bays.

An important advantage of aquaculture is that production can be increased in U.S. waters, thus avoiding the difficult problem of competing for limited resources in multinational high-seas fisheries. Although open-sea aquaculture has potential, it is unlikely that it will develop beyond the new 200 -mile economic zone.

Public aquaculture provides a method for augmenting natural stocks of some species for the benefit of the recreational and commercial fisheries. It also can be an important management technique for State or Federal agencies that have responsibility for conservation and management of fishery resources.

Evaluation of benefits and associated costs will be a continuing objective of the NOAA aquaculture program, because this information will be a major factor in program planning and budgeting. The benefits from NOAA expenditures for aquaculture are difficult to measure quickly because of the time required for private industry to apply the results of government-sponsored research. It may well take a decade or more from the start of a research program until private aquaculture reaches commercial viability. Tables 1 and 2 show NMFS and OSG expenditures related to aquaculture of selected species, and give some indication of the time and funding required to provide an adequate informational base for development of aquaculture.

It also is difficult to relate NOAA expenditures to achievement of viable aquaculture because States, universities, and several other Federal agencies also sponsor or conduct research that contributes to the fund of knowledge of various species. In some cases, NOAA research has been primarily for management purposes or for public aquaculture, and the development of facts and methods needed for private aquaculture has been a spinoff benefit.

Aquaculture of some species may never reach viability, even though significant research efforts are expended. Aquaculture may prove uneconomical because of increasing production costs or because adequate supplies from wild stocks or from imports are obtainable at a lower cost. Basic biological factors may prevent economic culture of some species. Aquaculture may also be prevented by legal, political, or zoning problems.
Review of past programs, however, provides solid evidence of payoff from government expenditures. For example, expenditures by NMFS and its predecessor agencies for development of improved methods for public aquaculture of Pacific salmon have been less than $\$ 7$ million since 1960. During that time, salmon production of the Columbia River increased from 10 to 30 million pounds $(4,500$ to 13,600 metric tons) per year, largely from the hatchery program, with benefit/cost ratios of $7 / 1$ for coho and 3.5/1 for fall chinook.

Government expenditures to develop methods for rearing pan-sized salmon since 1969 , when the program began, to 1976 have been less than $\$ 4$ million, but already there are several companies producing and marketing this product. These companies have supplemented NOAA efforts by spending an estimated $\$ 4$ million for research and development during the past 5 years.

\section{HOW LONG WILL IT TAKE AND HOW MUCII WILL IT COST?}

NOAA or its predecessor agencies have conducted or funded various programs concerning species with potential for aquaculture. Past approaches, however, were highly skewed toward biological research, often for purposes of management, not aquaculture. Most efforts were sporadic and poorly funded. Few, if any, engineering, economic, or market-related information needs have been met, and a systems approach has never been applied to aquaculture. Although historic records indicate that more than a decade has elapsed from the time government research began until viable aquaculture developed, it is reasonable to expect that adequately funded, well-coordinated programs would lead to more rapid development of private aquaculture.

Implementation of the Sea Grant program authorized in 1966 has expanded aquaculture efforts at universities and has led to a significant increase in the number of scientific papers in this field. Sea Grant-sponsored research has provided a scientific basis for aquaculture of several species and has solved limiting problems of others.

NMFS programs related to aquaculture of salmon and marine shrimp have expanded since 1970 , but efforts concerning oysters and clams have decreased. Small projects concerning catfish and freshwater prawn have continued with little or no increase. Without increased funds for the past 3 years, it has been necessary to curtail most NMFS aquaculture projects.

Expansion of aquaculture will require continuation of some ongoing projects funded by Sea Grant or NMFS. Other projects will be phased out when funds are needed for projects with higher priority.

It is already obvious from analysis of the current status of aquaculture and the government efforts now being applied that the pace of some ongoing projects should be quickened to achieve timely solutions to limiting problems. Since commercial application of research results may take as long as a decade, research should 
Table 1.-Estimated expenditures by NMFS or its predecessor agencies related to aquaculture of selected species.

\begin{tabular}{|c|c|c|c|c|c|c|c|c|}
\hline \multirow[b]{2}{*}{ Year } & \multirow[b]{2}{*}{ Oysters } & \multirow[b]{2}{*}{ Clams } & \multicolumn{2}{|c|}{ Pacifc salmon } & \multirow[b]{2}{*}{ Catfish } & \multirow[b]{2}{*}{$\begin{array}{l}\text { Fresh- } \\
\text { water } \\
\text { prawn }\end{array}$} & \multirow[b]{2}{*}{ Lobster } & \multirow[b]{2}{*}{$\begin{array}{l}\text { Marine } \\
\text { shrimp }\end{array}$} \\
\hline & & & $\begin{array}{c}\text { Public } \\
\text { (hatch- } \\
\text { eries) }\end{array}$ & $\begin{array}{c}\text { Private } \\
\text { (pen- } \\
\text { rearing) }\end{array}$ & & & & \\
\hline 1938 & 7 & & & hiousc & Ula - & & & \\
\hline 1939 & 40 & & & & & & & \\
\hline 1940 & 43 & & & & & & & \\
\hline 1941 & 47 & & & & & & & \\
\hline 1942 & 62 & & & & & & & \\
\hline 1943 & 70 & & & & & & & \\
\hline 1944 & 73 & & & & & & & \\
\hline 1945 & 104 & & & & & & & \\
\hline 1946 & 105 & & & & & & & \\
\hline 1947 & 108 & & & & & & & \\
\hline 1948 & 102 & & & & & & & \\
\hline 1949 & 138 & 33 & & & & & & \\
\hline 1950 & ${ }^{1} 130$ & ${ }^{2} 89$ & & & & & & \\
\hline 1951 & 113 & 92 & & & & & & \\
\hline 1952 & 102 & 90 & & & & & & \\
\hline 1953 & 114 & 89 & & & & & & \\
\hline 1954 & 108 & 77 & & & & & & \\
\hline 1955 & 249 & 88 & & & & & & \\
\hline 1956 & 179 & 88 & & & & & & \\
\hline 1957 & 268 & 63 & & & & & & \\
\hline 1958 & 288 & 65 & & & & & & \\
\hline 1959 & 387 & 71 & & & & & & \\
\hline 1960 & 468 & 86 & ${ }^{3} 253$ & & & & & \\
\hline 1961 & 457 & 83 & 554 & & & & & \\
\hline 1962 & 524 & 86 & 562 & & & & & \\
\hline 1963 & 605 & 83 & 555 & & & & & \\
\hline 1964 & 730 & 35 & 418 & & & & & \\
\hline 1965 & 607 & 35 & 392 & & & & & \\
\hline 1966 & 800 & 3 & 326 & & & & & ${ }^{7} 60$ \\
\hline 1967 & 794 & 3 & 346 & & & & & 68 \\
\hline 1968 & 800 & 3 & 381 & & $5_{10}$ & & & 240 \\
\hline 1969 & 813 & 8 & 407 & & 243 & $6_{20}$ & 25 & 395 \\
\hline 1970 & 827 & 18 & 476 & ${ }^{4} 134$ & 270 & 22 & 30 & 210 \\
\hline 1971 & 28 & 24 & 545 & 146 & 255 & 20 & 19 & 411 \\
\hline 1972 & 30 & 20 & 421 & 213 & 246 & 36 & & 391 \\
\hline 1973 & 15 & 28 & 516 & 196 & 234 & 51 & & 359 \\
\hline 1974 & 12 & 25 & 543 & 381 & 230 & 124 & & 329 \\
\hline 1975 & 143 & 24 & 1,284 & 425 & 182 & 65 & & 353 \\
\hline 1976 & 274 & 20 & 1,269 & 410 & 194 & 119 & & 447 \\
\hline Total & 10,764 & 1,429 & 9,248 & 1,905 & 1,864 & 457 & 74 & 3,263 \\
\hline
\end{tabular}

1'Research on artificial propagation of oysters began about 1950; industry hatcheries became viable about 1970 .

${ }^{2}$ Research on artificial propagation of hardshell clams began about 1950; industry hatcheries became viable about 1970.

${ }^{3}$ Artificial propagation of salmon began a century ago-but expanded research on nutrition, disease control, and improved hatchery methods began about 1960 and led to highly efficient hatcheries with favorable benefit/cost ratios by 1970 .

${ }^{4}$ Research on pen rearing of salmon in seawater began at low level in 1969. As of 1976, private ventures were approaching viability. The concept of ocean ranching, based largely on research and development related to public hatcheries, was legalized in Oregon in 1971, but may not reach commercial viability before 1980.

${ }^{5}$ Research on catfish culture began many years ago, but was expanded during the late 1960's. Commercially viable industry developed by about 1970 .

${ }^{6}$ U.S. development of freshwater prawn culture began in 1969 and as of 1976 , several private ventures were approaching viability.

${ }^{7}$ Research on shrimp aquaculture in the United States began at a low level about 1966. Private culture may not become viable before 1980. 
Table 2.-Estimated expenditures by Office of Sea Grant related to aquaculture of selected species.

\begin{tabular}{ccc}
\hline $\begin{array}{c}\text { Oysters } \\
\text { and } \\
\text { clams }\end{array}$ Salmon Catfish & $\begin{array}{l}\text { Fresh- } \\
\text { water } \\
\text { prawn Lobster }\end{array}$ & $\begin{array}{c}\text { Marine } \\
\text { shrimp }\end{array}$
\end{tabular}

\begin{tabular}{rrrrrrr}
\hline & \multicolumn{7}{c}{ Thousand dollars } & & \\
& & & & & \\
1971 & 385 & 180 & 3 & 80 & 128 & 168 \\
1972 & 367 & 173 & 3 & 76 & 123 & 161 \\
1973 & 587 & 275 & 6 & 122 & 196 & 256 \\
1974 & 721 & 338 & 8 & 196 & 240 & 316 \\
1975 & 850 & 461 & 0 & 262 & 338 & 197 \\
1976 & 760 & 533 & 0 & 181 & 318 & 163 \\
Total & 3,670 & 1,960 & 20 & 917 & 1,343 & 1,261 \\
\hline
\end{tabular}

begin now if it is to provide the scientific basis for expansion of aquaculture to meet the increased food needs projected for the future. NOAA's portion of the Federal effort needed to expand public and private aquaculture is described in appendices A through $\mathrm{D}$.

In total, the NOAA aquaculture program should increase from the 1976 level of $\$ 6.4$ million to about $\$ 19$ million by 1979 . This funding trend would provide the research facilities and expanded effort needed to improve the state of knowledge of various species and to develop farming methods for those that prove amenable to aquaculture. It would provide funds for joint programs with industry, universities, and States; about two thirds of the work would be accomplished by grants or contracts. Finally, it would provide the continuing efforts needed for long-term programs such as genetics and disease control.

Figure 2.-NOAA aquaculture program long-range funding trend.

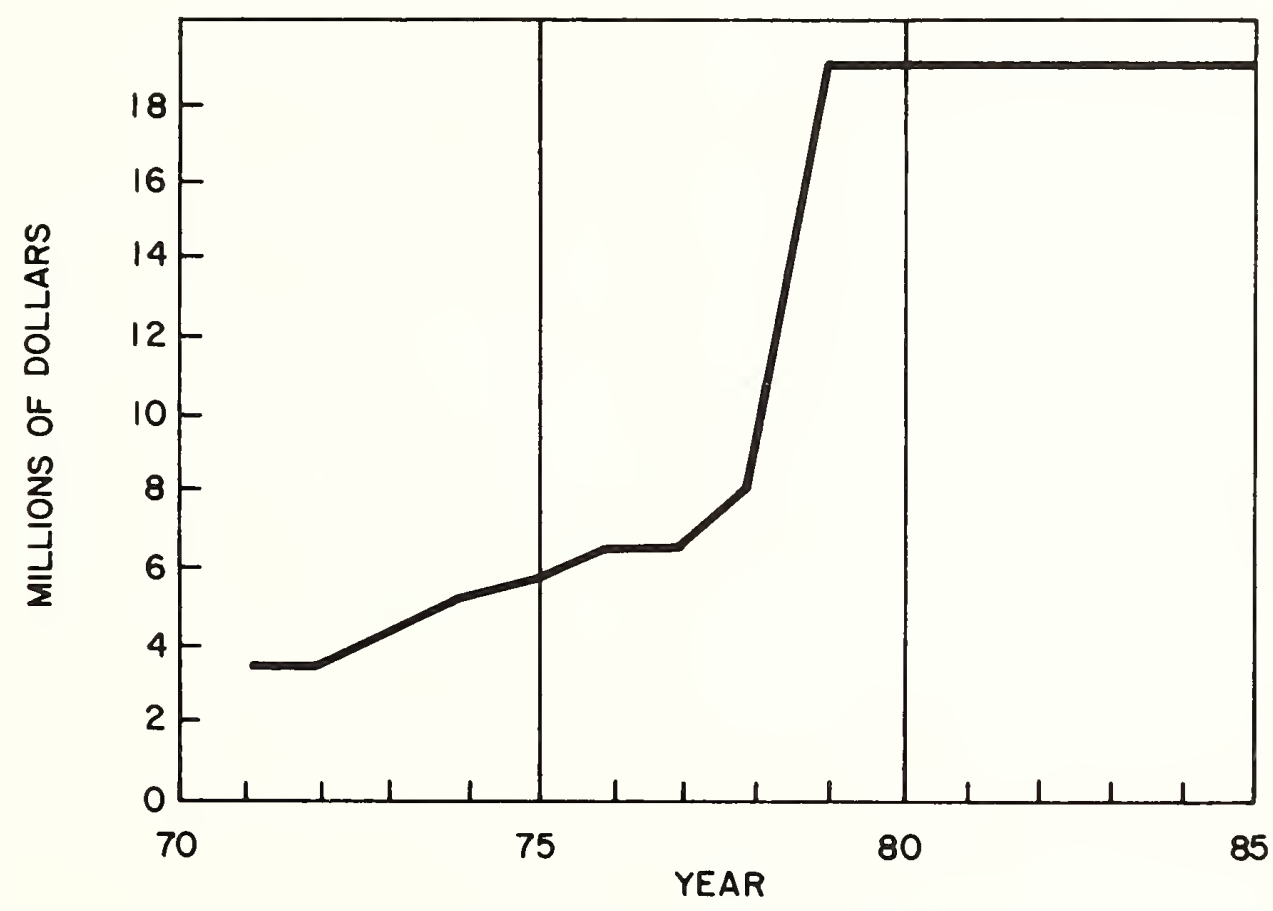

\section{APPENDIX A}

\section{High-Priority Species}

Guidance for the development of the current NOAA aquaculture program and determination of high-priority needs for the near future has been provided by several studies, conferences, and reports as follows:
NOAA Aquaculture Survey, 1972

Commonly known as the "Mardela Report," this survey was made by the University of Hawaii and the Mardela Corporation of Burlingame, Calif. The views of 255 
persons were obtained through mail questionnaires and 12 regional workshops in which all aspects of marine and estuarine aquaculture were discussed.

\section{Pacific Islands Aquaculture Workshop}

This Sea Grant workshop, held at the Hawaii Institute of Marine Biology, served both as a check on the general conclusions of the NOAA Aquaculture Survey as applied to a specific regional case, and also identified elements of aquaculture unique to tropical and subtropical island groups and established priority importance for these elements. Attendees represented industry, university and research organizations, State and territorial marine resource agencies, and four Federal agencies.

\section{Workshops on Lobster Mariculture, 1973 and 1974}

Sponsored jointly by NMFS and Sea Grant, these workshops were attended by all principal investigators involved in lobster research and provided an in-depth examination of problems affecting culture of a single high-value species. A planned program to attack identified problems resulted from these workshops.

\section{The Special Emphasis Document, "Aquaculture in the National Oceanic and Atmospheric Administration"}

This document, prepared by a NOAA team in September 1973, summarized the status of U.S. aquaculture and recommended an expanded NOAA program directed first toward salmon, shrimp, freshwater prawn, lobster, and mollusks.

\section{The National Fisheries Plan, Discussion Draft, August 1974}

This report, used as a background paper for regional meetings, summarized the status of aquaculture and listed problems and possible solutions for aquaculture of salmon, oysters, shrimp, lobsters, other mollusks, other marine species, and freshwater species.

\section{Workshops on Freshwater Prawn Culture,} November 1974 and June 1976

Sponsored jointly by Sea Grant and NMFS, these workshops were attended by all principal investigators, many administrators, and industry representatives.

\section{Workshop on Marine Shrimp Culture, October 1975}

Sponsored jointly by Sea Grant and NMFS, this workshop was attended by all principal investigators and industry representatives.

There also are numerous program documents describing Sea Grant research and development projects related to aquaculture in various universities and NMFS projects in government centers.

It is obvious from analysis of information from these sources that programs concerning several major species groups are of high priority at this time and must con- tinue to a logical conclusion. The following section provides a summary of the current status of aquaculture, major limiting problems, and suggested actions for salmon, marine shrimp, freshwater prawn, lobster, oysters, and marine plants.

\section{SALMON}

\section{Status of Aquaculture}

Over $7 \%$ of the seafood consumed in the United States is Pacific salmon of the genus Oncorhynchus; large quantities also are exported. The ultimate extent of the domestic and foreign market is not known, but, historically, U.S. fishermen landed up to 270,000 metric tons ( 600 million pounds), about three times the current landings.

The world demand for salmon continues to increase and exceeds the maximum sustainable yield from wild stocks. Recent pressures on the domestic supply from the international market can be expected to continue, and imports will decrease.

The Atlantic salmon, Salmo salar, once abundant in New England, has been depleted by changes in the freshwater environment that have blocked migrations and destroyed spawning beds. Supplies are too limited to support a commercial fishery, but a small recreational fishery continues.

There is some potential for increasing Atlantic salmon supplies in New England by public hatcheries and by private culture in floating net pens. However, recent experiments indicate that the coho is more adaptable to farming methods than the Atlantic salmon.

Public salmon hatcheries began in 1872 in northern California. Now nearly 100 hatcheries on the Pacific coast employ over 600 workers and cost State and Federal governments more than $\$ 9$ million per year.

Techniques for hatching and rearing salmon have improved greatly through the years. A recent analysis of hatchery operations in the Columbia River drainage and the resulting runs of salmon indicated benefit/cost ratios of 3.5/1 for fall chinook salmon and 7/1 for coho.

In total, hatchery-reared Pacific salmon contributed an estimated 27,000 metric tons (60 million pounds) to the total catch of 89,000 metric tons ( 197 million pounds) in 1974. By expanding public aquaculture, landings could be increased by an estimated 14,000 metric tons ( 30 million pounds) by 1985 .

\section{Pen Rearing}

NMFS experiments which began in 1969 showed that it was possible to rear coho, Oncorhynchus kitsutch, and chinook salmon, $O$. tschawytscha, to marketable size of 12 ounces in less than a year in floating net enclosures in Puget Sound. During 1971-72, a cooperative pilot experiment by NOAA and private industry raised more than 132,000 pounds (60 metric tons) of pan-sized Pacific salmon in one-quarter acre of pens at Manchester, 
Wash. In another experiment, the University of Washington, in cooperation with a private company, made joint studies in Puget Sound to determine the environmental impact of pen rearing of salmon.

Subsequently, all five species of Pacific salmon were reared in seawater pens, but the coho appeared to be best suited because of its good growth, acceptable feed conversion rate on dry foods, and high resistance to disease.

Another concept, being developed in Rhode Island, is the production of pan-sized or yearling salmon in commercially available farm silos supplied with recirculated and reconditioned seawater. If pilot-scale tests confirm present indications, salmon may be grown to market size in facilities remote from the sea.

\section{Problem Areas of Pen Rearing}

The major problems that limit pen rearing of salmon are:

Egg supplies. - Pen rearing of salmon has depended on eggs surplus to State hatchery needs. Most growers place importance on developing ocean-ranching operations or rearing brood stock to maturity to ensure availability of eggs.

Genetic improvement.-Most growers believe that considerable benefits can be derived in the future through genetic selection of pen-reared salmon, but do not feel that this is a limiting factor at the present time.

Diseases.-Most growers feel that disease is the most serious threat to successful commercial salmon farming and that government programs are needed to develop vaccines, treatments, and therapeutic culture methods. Growers also need assistance to obtain Food and Drug Administration clearance of drugs and medicines that are efficacious in controlling diseases.

A vailability of saltwater farm sites. - Because of the small area required for pen rearing of salmon, most growers do not consider the availability of sites as a serious deterrent to future expansion. On the other hand, permission for commercial developments close to the shoreline is subject to increasing scrutiny by public agencies and upland landowners. A combination of restrictive coastal zoning regulations and specific environmental requirements for the location of floating farms will limit acceptable sites. Environmental modifications, such as wave control by floating breakwaters, could greatly increase the area suitable for pen rearing of salmon.

A vailability and cost of feeds. - Salmon growers feel that the availability of feeds at acceptable prices could become a limiting factor. Growers estimate that commercial production of pen-reared salmon could increase to over 40 million pounds (10,000 metric tons). Since about 2 pounds of feed is required to produce 1 pound of salmon, more than 80 million pounds $(36,000$ metric tons) of feed would be needed. This would require more marine fish wastes than the total available from U.S. Pacific coast landings in 1974. Therefore, it may be necessary to develop alternative sources of protein such as microorganisms (single-cell protein), food-processing wastes, leaf proteins, and fisheries resources unsuitable for direct use as human food.

Economics. - Although salmon farming is technically feasible at this time and several companies are in production, its economic viability will not be clear for perhaps 3 to 5 years. Market demand, prices, and production costs are particularly difficult to forecast.

Effluent control-National and State regulations will require abatement of pollution at all aquacultural sites to prevent environmental degradation. This could increase production costs, but in some cases waste or byproducts may be used in the culture of additional species (polyculture).

Habitat protection. - High-quality water is required for successful salmon culture. It is also important to prevent introduction of exotic species or undesirable salmon stocks that might adversely affect salmon culture by increasing competition, predation, or disease.

Legal and institutional barriers. - Although private culture of salmon in captivity is legal in all four West Coast States, administration by State agencies is not uniformly conducive to the development of private ventures. In addition, environmental policy and coastal zoning acts require environmental impact statements, clearances, and permits. The growing awareness of environmental quality and a realization that sea farming will have a visual impact on landowners will place increasing burdens on prospective growers who wish to secure approval for new farm sites.

Even though several major problems must be solved, there is high probability of establishing a sound industry based on production of pan-sized or yearling salmon in floating net pens, shoreside ponds, or inland silos. If markets remain attractive and if feeds can be obtained at acceptable prices, production could increase from the 1975 level of nearly 1 million pounds (450 metric tons) to a level exceeding 20 million pounds (9,000 metric tons) by 1985 .

\section{Ocean Ranching}

Ocean ranching as a system for private salmon culture was developed by a NOAA-sponsored project at Oregon State University, supplemented by University of Washington research supported by Sea Grant and private industry funds. Subsequently, this concept was applied to Alaska salmon by joint projects of NMFS and the Alaska Department of Fish and Game.

Oregon and Alaska amended their laws to permit ocean ranching in 1971 and 1974. The ocean-ranching law in Alaska permits only nonprofit hatcheries, which presumably would be operated by cooperatives or fishermen's associations, processors, or native corporations. Ocean ranching of salmon can be conducted in California under permit from the Department of Fish and Game, but local opposition has prevented development of commercial ventures. The Washington legislature failed to pass bills introduced in 1975 and 1976 to 
permit ocean ranching, but two previously approved experimental permits remained in effect.

Pink salmon, $O$. gorbusha, and chum salmon, O. keta, are especially attractive for ocean ranching since they migrate to saltwater soon after hatching. They require little, if any, feeding while in freshwater and only minimal hatchery facilities. However, pink and chum salmon are less valuable than coho, chinook, or sockeye salmon and a smaller percentage of chum and pink salmon will survive at sea and return to the parent stream.

Returns of $0.5 \%$ of released chum and $1.0 \%$ of pink salmon fry to a private hatchery are needed to ensure a favorable benefit-to-cost relationship at 1976 market value. Even under conditions where up to $70 \%$ of the hatchery fish are captured in a common-property fishery, returns of this magnitude could be expected. Nonprofit hatcheries in Alaska are attractive because of the potential for increasing harvest in the public fishery by fishermen participating in the aquaculture venture. In Oregon, where there is no longer effective public fishery on chum or pink salmon, the prospects for successful ocean ranching are especially favorable.

Ocean ranching of coho, chinook, and sockeye salmon requires rearing juveniles to smolt size before release. This means that the cost of construction and operation of facilities such as hatcheries, rearing pens, or floating net pens for these species will be much higher than for rearing pink or chum salmon. Furthermore, coho and chinook salmon are highly prized by recreational fishermen and even sockeye salmon are now taken at certain locations, so interception of returning adults is likely to be greater than for pink and chum salmon. However, the higher prices for coho, chinook, and sockeye and their higher marine survival should compensate for greater costs of production and for interceptions by public fisheries.

The first private chum salmon hatchery began operation in 1971 in Oregon, and this concept has now expanded to nine ventures in Oregon and two in Washington. One Washington venture released 300,000 pink salmon fry, and one private hatchery in Oregon released more than 1 million chum salmon fry in 1974. Several nonprofit private hatcheries capable of producing 10 to 20 million juveniles annually are planned in Alaska.

All the private U.S. pink and chum salmon hatcheries use the new low-cost gravel or Astroturf incubator hatchery techniques, which are largely the product of NOAA-sponsored research and development.

\section{Problem Areas of Ocean Ranching}

The major problems expected in development of ocean ranching of salmon are:

Economics. - Although public salmon hatcheries in the Columbia River system can show favorable benefit/ cost ratios, the economics of private ocean ranching have not been tested by commercial application or even by pilot scale tests.

Legal and institutional barriers.-Ocean ranching has been legalized in California, Oregon, and Alaska, but procedures for obtaining required permits are slow and costly, and the results are uncertain.

Egg supplies. - Wild stocks of chum salmon remain at low abundance levels in Washington and Oregon, and only limited quantities of eggs are available for private aquaculture. It appears likely that eggs will remain in short supply until successful ocean-ranching ventures increase the number of returning adults. Pink salmon eggs are also in short supply, especially during oddnumbered years when runs traditionally are poor. Adequate supplies of coho and chinook eggs are expected to be available from surplus adults returning to public hatcheries, but State regulations may limit amounts sold to private salmon growers.

Maintaining genetic variability of stocks. - It will be necessary to establish procedures for proper selection of parents to maintain the genetic integrity of wild stocks and to avoid genetic modifications that might reduce the ability of smolts to survive at sea.

Diseases.-Disease control at hatcheries will be as important for ocean ranching as it is for pen rearing. Additionally, the possibility of losses from disease such as Vibrio when smolts enter the estuaries must be considered.

Site selection. - Only certain locations are likely to be fully acceptable for ocean-ranching ventures because of the specialized requirements such as adequate water supply, available private land, minimum interception of returning adults by commercial or recreational fishermen who are not participating in the venture, etc. As a result, ocean ranching may be limited to a few ventures in each State.

Production strategy. - Selection of species and races of salmon, production systems, age, size, timing of release, and environmentally induced behavior changes will greatly influence the degree of success of oceanranching ventures.

Biological and social restrictions. - Procedures may be required by the States to minimize adverse effects of ocean ranching on wild stocks. These may include marking of juveniles before release, stocking of natural areas, specialized hatchery procedures to preserve genetic variability or to control diseases, and release of juveniles to improve recreational fisheries. Such restrictions and requirements may reduce the economic incentive for private investment in ocean ranching ventures.

In the long run, prospects are good for expansion of Pacific salmon production by ocean ranching. If permits can be obtained, private ventures could add 40 million pounds $(18,000$ metric tons) to the salmon supply by 1985.

\section{Actions Required}

Problems of developing private salmon aquaculture, possible solutions, and actions required are summarized in the following listing. 
Problem

Legal and institutional barriers

Egg supplies

Genetic improvement for pen culture

Maintaining genetic variability of ocean-ranching stocks

Disease control

Availability of sites in suitable environment

Availability of cost effective feeds

Improved production efficiency

Verification of technology and economics of ocean ranching

Market development for yearling salmon

\begin{tabular}{|c|c|}
\hline Control quality & Industry \\
\hline $\begin{array}{l}\text { Improve distribution } \\
\text { and marketing system }\end{array}$ & Industry \\
\hline Promote markets & \\
\hline
\end{tabular}

\section{Summary}

Federal actions should include continuation of research in government facilities or through universities

Select for breeding Industry

Determine procedures Government, for selecting brood university

stock

\section{Implement procedures Industry}

Research to identify causes and develop controls

Prevent and treat diseases

Develop disease-resis tant strains

Revise policies to encourage private aquaculture

Simplify permit systems

Protect habitat; control pollution

Provide adequate effluent control

Be a good neighbor

Industry

Government, industry

Find alternative protein sources

Government, university, industry

Industry

tion facilities

Reduce labor costs; Industry improve business management

Test at pilot scale

Government, industry

Develop product Industry

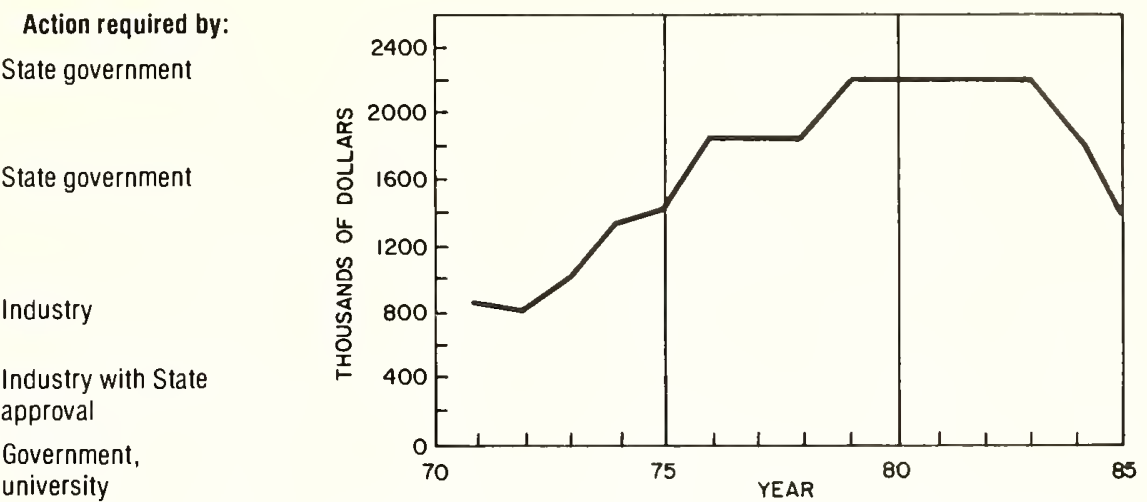


Appendix Table A1.-Shrimp landings and imports.

\begin{tabular}{cccc}
\hline Year & $\begin{array}{c}\text { Total landings } \\
\text { (heads-on) }\end{array}$ & $\begin{array}{c}\text { Total imports } \\
\text { (heads-on) }\end{array}$ & $\begin{array}{c}\text { Dockside price } \\
(15-20 \text { count, } \\
\text { heads-on) }\end{array}$ \\
\hline & & & \\
1970 & 367.5 & 395.6 & Dollars/lb \\
1971 & 387.9 & 308.0 & 0.74 \\
1972 & 385.0 & 407.5 & 1.03 \\
1973 & 372.2 & 326.2 & 1.15 \\
1974 & 369.6 & 368.5 & 1.37 \\
& & & \\
\hline
\end{tabular}

Under these conditions aquaculture will become increasingly attractive as a means of augmenting supplies of shrimp.

Shrimp aquaculture became technically possible more than a decade ago when Japanese scientists developed methods for rearing the larvae in captivity and growing the postlarvae to market size in seawater ponds. In Japan, commercial shrimp farming is profitable because of the availability of egg-bearing females at acceptable cost, low-cost labor, and a luxury market for the product.

Interest in shrimp aquaculture developed in the United States in the 1970's, and several companies attempted to adapt methods developed in Japan for Penaeus japonicus to the culture of the three major United States species: $P$. aztecus, the brown shrimp; $P$. duorarum, the pink shrimp; and $P$. setiferus, the white shrimp. Most of these early ventures met with limited success. Companies found they had to invest larger sums than anticipated in research and development, and some exhausted their funding before getting into production. A further complicating factor was the lack of methods for getting adults to mature in captivity. As a result, it was necessary to capture egg-bearing females at sea and bring them ashore where they were kept until they spawned. The high cost of postlarvae produced under this system made the economics of shrimp culture questionable at U.S. market prices.

Even though some of the companies that attempted shrimp culture have terminated their efforts, others continue to improve culture methods and are nearing commercial success. Most commercial activity is directed toward the culture of $P$. setiferus and $P$. aztecus from the northern Gulf of Mexico and $P$. vanname $i$ and $P$. stylirostris from the Pacific coast of Central America. Considering the large number of penaeid shrimp species available worldwide, it is likely that other species will be used as technology progresses. Recent success with $P$. vannamei and $P$. stylirostris in Texas suggests that these species may have better production characteristics than species indigenous to the Gulf of Mexico. Some companies have begun shrimp farming in Latin America where low-cost land, year-round warm water, and low-cost labor are available, and where effluent controls are less restrictive than in the United States.
Shrimp farming in the United States, using currently available systems, will develop along the Gulf coast where shrimp can be reared to market size in about 140 days. Low-cost land with access to saltwater is available there, and the warm climate permits a long growing season.

Greater quantities of shrimp could be produced in the southern States by improved methods of aquaculture. By starting postlarval shrimp in heated raceways before transferring them to saltwater ponds, up to seven crops per year could be produced with up to 4,000 pounds per acre $(4,480 \mathrm{~kg} / \mathrm{ha})$ per crop. As the technology for intensive culture improves, heated raceways or tanks with recirculated water may be used throughout the production cycle. This system would allow shrimp culture on a year-round basis even in areas remote from the sea. The choice of production system will depend on production costs in relation to market price.

\section{Problem Areas}

The major problems expected in the development of of marine shrimp farming are:

Obtaining egg-bearing females.-Present culture methods depend on obtaining egg-bearing females at sea and letting them spawn at coastal hatcheries. The resulting larvae are grown to the postlarvae stage in hatcheries and then put in grow-out ponds. The economic feasibility of this process has been demonstrated in the United States and Central America by largescale commercial ventures located where egg-bearing females can be obtained from fishing grounds close to a hatchery. It is questionable whether this process is economically feasible for small-scale operations, or in cases where fishing grounds are remote from the shrimp farms, or where the desired species are not readily available.

Year-round farming of desirable species will not be realized until maturation and mating technology has been perfected. Considerable progress toward this goal has been made through joint government-universityindustry research. Some shrimp have matured and spawned successfully both under laboratory conditions and in ponds. Our understanding of the reproductive processes and factors influencing them is improving rapidly, and scientists are optimistic that maturation and spawning will be accomplished routinely by shrimp farmers in the near future.

Diseases. - With the development of confined rearing, disease problems can be expected. Studies of the effects of various diseases and methods for prevention and treatment have begun. Where applicable, methods used for treatment of fish diseases are being used; however, special techniques will be needed for treating most shrimp diseases.

Production costs. - The cost of land and construction of ponds, tanks, and hatcheries make shrimp farming a capital-intensive venture. With improvements in technology, production systems will tend toward intensive culture with recirculated water systems and effluent 
control to meet EPA requirements. Even with efficient plant design and mechanized operations, U.S. labor costs will be high.

Production consistency.--Although production at commercial levels has been demonstrated in short-term projects, considerable research will be required to develop procedures for maintaining production at acceptable levels on a long-term basis. The major factors affecting production are: 1) species selection for a given locality, 2) stocking density, 3) quantity and quality of feeds, 4) proper management to ensure good water quality, 5) diagnosis and treatment of disease, 6) efficiency of harvesting, and 7) handling and storage to ensure a quality product. A coordinated research effort of government, universities, and industry to improve production consistency is under way.

Economics. - Shrimp culture is categorized as a "highrisk" venture, because it is in an early stage of development. Economic analyses are needed as a guide for industry investment decisions.

Genetic improvement. - Successful husbandry of terrestrial animals has depended on selective breeding of strains that adapt to specified growing conditions, grow rapidly on economical diets, resist diseases, and have desirable market characteristics. Rapid genetic improvement should be possible with shrimp as soon as maturation and breeding technology is perfected because of their comparatively short generation time (less than 6 months) and the large number of offspring produced from a single mating $(100,000$ or more).

Feeds. - The problem of suitable feeds for shrimp is important. In addition to being cost-effective and nutritious, the physical structure should minimize wastage and fit the requirements for mass feeding systems. Greater knowledge of the nutritional requirements of shrimp is needed as a basis for improving feeds.

\section{Actions Required}

The problems anticipated in developing commercial shrimp aquaculture, possible solutions, and actions required are summarized in the following listing.

Problem

Obtaining eggbearing temales

Disease control

\section{Possible solution}

Perform research to find ways of getting adults to mature and mate in captivity Improve procedures for collecting gravid females at sea and rearing larvae

Perform research, including genetic modification for disease resistance, when maturation problem is solved

Modify culture methods University, industry to prevent or reduce mortality

Apply control measures Industry

Government,
Problem

Production costs

Production consistency

Genetic improvement

Availability and cost of feeds

Economics
Action required by:

Government, university, industry

University, industry university

\section{Possible solution}

Action required by:

Design production

facilities to minimize

construction cost

Perform research to delineate effluent problems and devise water purification techniques

Develop intensive culture systems that require less space and less water

Simplify Federal and State permit system to encourage commercialization Implement techniques for effluent control and intensive culture

Perform research to improve knowledge of factors causing variation in production Implement manage-

Evaluate economics of current culture systems and of new systems during pilot-scale testing

Provide investmentanalysis assistance

Conduct long-term genetics research to

Perform research on nutrition, feed formulation, and testing

Develop and test alter native protein sources ment practices improve stocks
Industry

Government, university

Government, university

Federal and State agencies

Industry

Government, university

Industry

Government, university, industry

Government, university

Government, university, industry

Government, university, industry

Government, university, industry

\section{Summary}

The commercial development of penaeid shrimp culture can be accelerated by expanding the technology base through a coordinated program involving government, universities, and industry.

Government and university action is required to complete the life cycle in captivity, improve culture systems, develop disease controls, provide assistance in investment analysis, and make genetic improvements.

Industry action is needed to improve production facilities and procedures, control diseases, and improve business management.

The long-range potential for commercial aquaculture of shrimp is good. Estimated U.S. production for 1976 is more than 1 million pounds ( 450 metric tons) and will probably remain near this level for the next few years. By 1980 , the technology should permit a rapid expansion. How long this expansion will continue depends on market prices set by consumer demand and by competition from non-U.S. aquaculture groups. Some U.S. 
firms in Latin America will probably shift back to the United States as improved culture systems with competitive costs are developed. Intensive or high-density culture that requires sophisticated equipment, instrumentation, and an advanced degree of mechanization may give U.S. producers a competitive advantage. By 1985, shrimp production from private aquaculture in the United States could exceed 15 million pounds $(6,800$ metric tons).

Appendix Figure A2.-Projected NOAA funding trend for marine shrimp, Penaeus spp.

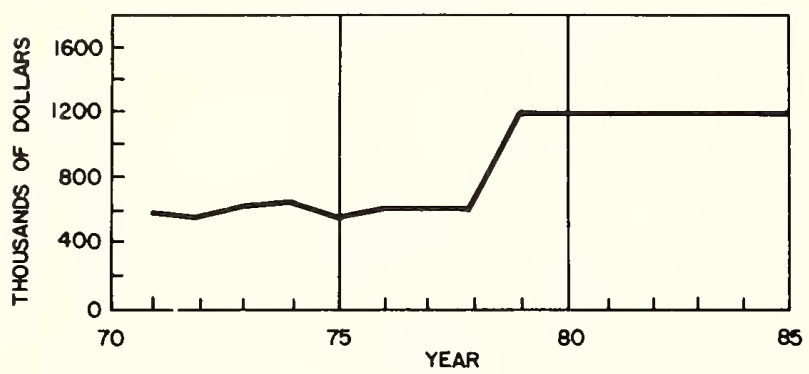

The 1976 NMFS program related to aquaculture of marine shrimp was based at Galveston, Tex., and Sea Grant projects were located in Texas and Louisiana. Funding should double and continue at that level for about 8 years (appendix figure A2). This would provide the increased research efforts needed to solve the problem of getting adults to mature and spawn in captivity and to develop and test intensive culture systems. Thereafter, funding could decrease to the level needed for genetics, disease control, extension activities, and other long-term programs.

\section{FRESHWATER PRAWN}

\section{Status of Aquaculture}

There are more than a dozen species of the genus Macrobrachium with nearly worldwide temperate and tropical distribution. The species range in size from the U.S. native $M$. ohione, comparable to northern pink shrimp, to the very large $M$. rosenbergii, a native of the western Pacific and Southeast Asia. One U.S. species, native to southern Florida, $M$. carcinus, is almost as large as $M$. rosenbergii.

Freshwater prawns have been an item of commercial importance for many years outside the United States. Imports into this country from Southeast Asia are estimated at about a million pounds ( 450 metric tons) per year. Precision is not possible because import figures do not distinguish between the freshwater prawns and marine shrimp. It is known, however, that larger prawns are imported for specialty outlets, principally highpriced restaurants on the U.S. west coast.

Research and development supported by NMFS and
OSG funds have shown the high potential for aquaculture of freshwater prawns. The Anuenue Fisheries Research Center of the Hawaii Department of Land and Natural Resources has become the world center for research into the culture of the Malaysian prawn, $M$. rosenbergii.

Procedures for rearing larval freshwater prawns have been developed in Hawaii, and juveniles have been grown to marketable size in 7 months. Under a cycling system, annual production of 3,000 pounds (1.4 metric tons) of marketable prawns per acre has been achieved. Even higher yields appear possible through improved water quality and flow, habitat design, and better feeds.

The emergence of freshwater prawns as an aquaculture species is so recent that few marketing studies have been made on the U.S. mainland. The best data available are from Hawaii, where the market potential for that State alone is estimated to be about $\$ 8$ million annually. Large freshwater prawns compete with lobsters, crabs, and large marine shrimp in the restaurant trade. Consequently, freshwater prawn culture is tied to and affected by supply and demand for luxury crustacean items as a whole.

Commercial farming of $M$. rosenbergii has been achieved in the Hawaiian Islands, southern Florida, and Puerto Rico. About 30 acres of ponds were in production in Hawaii by 1975, and "Island Prawns" were on the menu of many local restaurants. Industry plans included expansion of production, especially in Hawaii and Puerto Rico.

Outside the United States, development is underway in Caribbean and Central American nations, in Mauritius, and in the Pacific where the French, through CNEXO (Centre National pour l'Exploitation des Oceans), are attempting culture of $M$. rosenbergii. All such activities have drawn heavily on the expertise and experience of the Anuenue Fisheries Research Center.

Freshwater prawn culture in Latin America is attractive because of the following factors, even though such operations depend on stability of governments and administrative systems:

High water temperatures throughout the year

Availability of inexpensive land

Inexpensive labor

Availability of adequate supplies of clean water

Less restrictive effluent controls than in the United States.

Experts predict substantial growth of freshwater prawn culture in the United States during the next 3 years. If the present relation between prices and production costs can be maintained, the industry could produce 10 million pounds (4,500 metric tons) annually by 1985 .

\section{Problem Areas}

The major problems which limit aquaculture of freshwater prawns are: 
Cost effective foods.-For the freshwater prawn, a priority problem - as in all crustacean culture - is a suitable, cost-effective feed. The initial Hawaiian success was achieved with chicken "broiler starter" ration, which was not optimum either in nutritional value or in cost-effectiveness, but which did permit initiation of profitable commercial culture activity. The Hawaii Institute of Marine Biology tested several experimental diets and began preliminary studies on the physiology of nutrition. There is still insufficient knowledge about nutritional requirements of freshwater prawns to permit formulation of cost-effective foods.

Temperature requirements. - The Malaysian prawn, $M$. rosenbergii, requires temperatures from $20^{\circ}$ to about $34^{\circ} \mathrm{C}$. This limits U.S. production in natural waters to the southern part of the U.S. mainland, Puerto Rico, Hawaii, American Samoa, Guam, and Micronesia. Experimental culture as far north as South Carolina indicates potential for rearing a crop each summer from hatchery-produced juveniles. Other possibilities for expanding areas in the United States suitable for production of freshwater prawns are to use other species with lower temperature requirements such as $M$. ohione or to crossbreed species to achieve a hybrid with desired characteristics. Some preliminary attempts at crossbreeding have begun as Sea Grant projects, but results to date have not been encouraging. The use of thermal effluents or geothermal waters to provide suitable temperatures in northern latitudes presents another possibility.

Culture systems. - Freshwater prawns tend to be territorial and aggressive although much less so than crabs or lobsters. Experiments in South Carolina indicate improved survival by installing several horizontal substrate units in grow-out tanks to provide each prawn with adequate space. Another problem is the harvesting and sorting for market, which is a time-consuming, labor-intensive operation. Further biological and engineering studies are needed to maximize the efficiency of culture systems.

Disease control. - Disease has not yet proven to be a major problem, but the danger is always present in animal husbandry and is even more likely in aquatic culture systems. Some research has begun at the University of Hawaii as a Sea Grant project.

Genetic improvement.-All U.S. stocks of $M$. rosenbergii are descendants of two berried females which were among the 36 adults shipped to Hawaii from Penang, Malaysia, in 1965. This situation presents an interesting genetics problem and an opportunity to improve stocks by selective mating with adults from other lines. Since $M$. rosenbergii can be reared throughout its life cycle in captivity, improvement by genetic manipulation holds high potential. Desired character istics for acquaculture include improved growth rates, efficient food conversion, shortened larval development, docility, increased fecundity, low-temperature tolerance, high meat yield, disease resistance, etc. Selective breeding trials have begun in Hawaii.

Processing and marketing.-Processing, distribution, and marketing procedures are needed to control quality of the product and permit market development.

Economics. - A realistic appraisal of the possibility of economically successful culture of freshwater prawns is needed as a guide for potential investors. This appraisal should take into account culture technology at its present level of development, the possible effects of major technological improvements, demonstrated and potential markets for freshwater prawns and competing products, and similar factors.

\section{Actions Required}

The problems of developing aquaculture of freshwater prawns, possible solutions, and actions required are summarized in the following listing.

Problem

Cost-effective feeds

Temperature requirements

Culture systems

Disease control

enetic improvement

Processing and marketing

Economics

$$
\text { Economics }
$$

ics

(2)

\section{Possible solutions}

Determine nutritional requirements, formulate feeds

Locate in warmwater areas

Develop culture system using thermal effluent or geothermal water

Perform biological
research to establis research to
parameters

Use systems engineering to increase plant efficiency

Provide quality control

Perform research to identify causes and develop controls

Prevent and treat disease

Perform long-term genetics research Breed selectively at hatcheries

Perform technological
research
Provide quality control
Develop markets
Analyze economics of
production systems
and pilot-scale tests
Disseminate results to
assist industry in
investment decisions

Action required by:

University, government, industry

Government, industry

University,
government
Industry, government
Industry

University, government

Industry

Government, university Industry

Government, university Industry Industry

University, government

University, government

\section{Summary}

Freshwater prawn culture is approaching commercial viability and has a high probability of success in selected locations. The following actions are required:

Government and university action is required to develop disease controls, make genetic improvements, 
determine basic nutritional requirements, improve culture systems, improve processing procedures, and evaluate economics.

Industry action is needed to select proper sites, produce satisfactory feeds, control production, control quality, develop markets, and apply selective breeding at hatcheries.

Sea Grant projects related to aquaculture of freshwater prawns were based at Hawaii and South Carolina in FY 1976. NMFS projects concerning freshwater prawns included those supported by PL 88-309 funds at Florida, Hawaii, and Puerto Rico, and a government laboratory project in Maryland to begin studies of basic nutritional requirements.

Culture systems being developed in NOAA-supported projects will be ready for testing within 2 years. This effort will require about double the present level of funding for a 3-year period (appendix figure A3). Thereafter, funding could decrease gradually to about the 1976 level during the following 4 years. Increased funding will also permit research to determine the basic nutritional requirements of freshwater prawns.

Appendix Figure A3.-Projected NOAA funding trend for freshwater prawn, Macrobrachium spp.

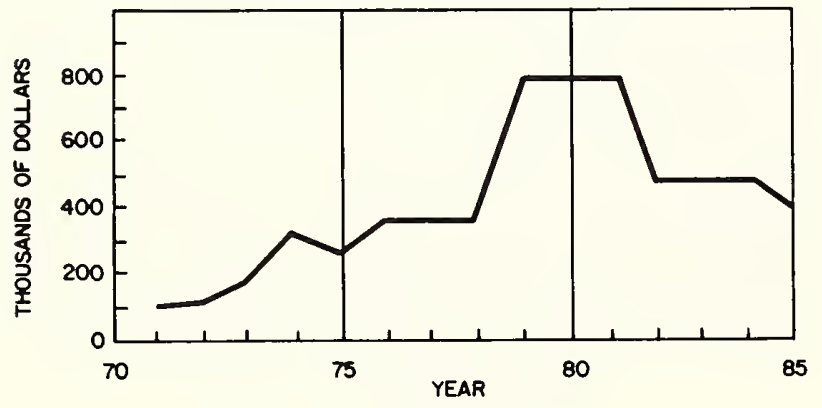

AMERICAN LOBSTER

Status of Aquaculture

The American or northern lobster, Homarus americanus, traditionally is a highly prized seafood. The U.S. market is limited at present by supply.

U.S. landings of 28 million pounds ( 12,700 metric tons) were supplemented by imports of 18 million pounds $(8,200$ metric tons) in 1974 . The National Plan for Marine Fisheries ${ }^{6}$ projects the demand in the United States for an additional 40 million pounds (18,000 metric tons) by 1985 ; prospects are poor for increasing imports to provide this quantity. Offshore stocks have declined from their virgin condition, but the extent of the decline has not been clearly documented. The development of

\footnotetext{
${ }^{6}$ National Marine Fisheries Service. 1976. The national plan for marine fisheries, $81 \mathrm{p}$.
}

technically and economically feasible aquaculture systems would help to alleviate the projected shortage.

Since 1950, the Massachusetts State Lobster Hatchery has reared larval lobsters each year for release in various areas of the Commonwealth. Annual production has averaged 250,000 fourth-stage lobsters. Unfortunately, it has not been possible to release large quantities of these lobsters in any one particular area, and evidence is lacking that the release of larvae in the natural environment significantly improves local lobster fisheries.

The greatest contribution of the Massachusetts hatchery has been an evaluation of culture techniques and numerous improvements which led to a good biological and technological base for development of private aquaculture. The American lobster has been cultured through all stages of its life cycle at this station, and it has been found that larval development and growth rate of juveniles can be expedited by increasing the water temperature. An $8^{\circ} \mathrm{C}$ elevation in temperature may reduce the larval period by a factor of nearly four. Growth to market size, which requires 5 to 8 years in nature, can be reduced to 2 years if water temperatures are increased to about $21^{\circ} \mathrm{C}$.

The potential for private aquaculture of lobsters led to expansion of lobster research in other areas as part of a national program. The Sea Grant program in 1974 included projects to develop lobster feeds (Louisiana State University and University of California); to determine nutrition, physiological, and environmental requirements for mass culture (University of California-Davis); to determine the potential of culture in thermal effluent from powerplants (San Diego State University); to determine the efficacy of alternate methods for mass hatching and culture of larvae (University of Rhode Island and State University of New York); and to identify and isolate natural chemical substances which determine lobster behavior (Woods Hole Oceanographic Institute).

By 1976, the NOAA lobster aquaculture program had been concentrated at Bodega Bay (University of California-Davis), San Diego (San Diego State University), the University of Rhode Island, and the University of Maine. State lobster research continued at the State lobster hatchery at Martha's Vineyard, Mass.

\section{Problem Areas}

Major problems in the development of commercially viable aquaculture of lobsters include:

Feeds. - The problem of suitable feeds for lobsters is critical. In addition to being cost-effective and nutritious, the physical structure of the feeds should minimize wastage and fit the engineering requirements for mass feeding systems.

Culture systems. - Hatchery methods have developed, but engineering for grow-out facilities is required. Lobters are both aggressive and territorial, and although their space, water quality, and temperature needs are 
known, growing lobsters to market size is capital- and labor-intensive.

Economics.-Development of an economic data base depends principally on calculation of production costs in various kinds of systems to evaluate each engineering improvement and to analyze the economics of each element of the total system. It should lead to concentration of efforts on high-cost areas to achieve reduction of production costs. Finally, it should provide potential investors with an objective evaluation of the profit potential for lobster aquaculture.

Disease.-Disease is an ever-present threat, particularly as intensive culture is developed in warm waters. Known diseases of lobsters that have caused mortalities in intensive culture systems can be managed at present, e.g., Pediococcus (Gaffkemia) and Leucothrix. Primary problems are fungal infections which can be prevented by engineering design and prophylactic procedures to maintain clean systems.

Genetic improvement. - Characteristics to be sought for a "domesticated" lobster include a more docile temperament, increased growth rate, and a higher percentage of meat. The limited heterogeneity of the American lobster, $H$. americanus, compared to the European lobster, $H$. vulgaris, reduces the probability of genetic improvement, but crossbreeding offers promise.

Water quality control - High-quality water is necessary for lobster culture. In recirculated systems, ammonia levels must be carefully controlled to avoid toxic effects. Recent experiments indicate that lobster culture in artificial seawater is technically possible. If these initial experiments are confirmed in pilot-scale tests, lobsters might be raised onshore in areas remote from the sea.

Pilot-scale tests of production systems.-Research and development should have progressed in less than 2 years to the point that pilot-scale tests of intensive and extensive systems could be made.

The best estimate of experts involved in research and development is that the problems limiting commercial lobster culture can be solved by 1980 and that private production could reach 5 million pounds $(2,300$ metric tons) by 1985 . For the present, private investment in commercial lobster culture should be discouraged.

\section{Actions Required}

The problems of developing aquaculture of the American lobster, possible solutions, and actions required are summarized in the following listing.
Problem

Cost-effective feeds

\section{Possible solution}

Determine basic nutritional requirements Formulate and test food
Problem systems

Genetic improvement

Space for aquaculture in suitable environments

Economics of lobster culture
Economical culture
Possible solution

Study behavior

Study engineering

design

Make pilot-scale test

Perform research to

find causes and

controls

Apply preventive and treatment methods

Conduct long-range genetics program

Maintain areas with high water quality and encourage private lobster culture by appropriate laws, policies, and coastal zoning plans

Select sites for suitable temperature and water quality

Use artificial seawater for intensive culture onshore

Be a good neighbor

Analyze the economics of production systems and pilot-scale tests

Disseminate results to assist industry in investment decisions
Action required by:

University, government

University, University, government

University, government

Industry

Government, university

State government, industry, public

Industry

University, industry

Industry

University, government

University, government government

\section{Summary}

There is no commercial aquaculture of lobsters at present, and private investment should be discouraged until several biological, technological, and economic problems are solved. Experts believe this can be accomplished within 4 years if funding continues. The following actions are required:

Federal action through universities and government laboratories is needed to develop economic culture systems, cost-effective foods, disease control, and to make pilot-scale tests with analysis of economics to assure commercial applicability of laboratory results.

State action is required to maintain areas of high water quality and to encourage private lobster culture.

Industry action, at the appropriate time, is needed to select suitable sites, apply available biological and technological information, and develop efficient production procedures.

NOAA funding should triple within 2 years to begin pilot-scale evaluation of intensive culture systems developed in Sea Grant projects and continue at this level for about 3 years. Thereafter, funding could be gradually reduced to about the 1976 level to continue long-range projects such as genetics and disease control (appendix figure A4). 


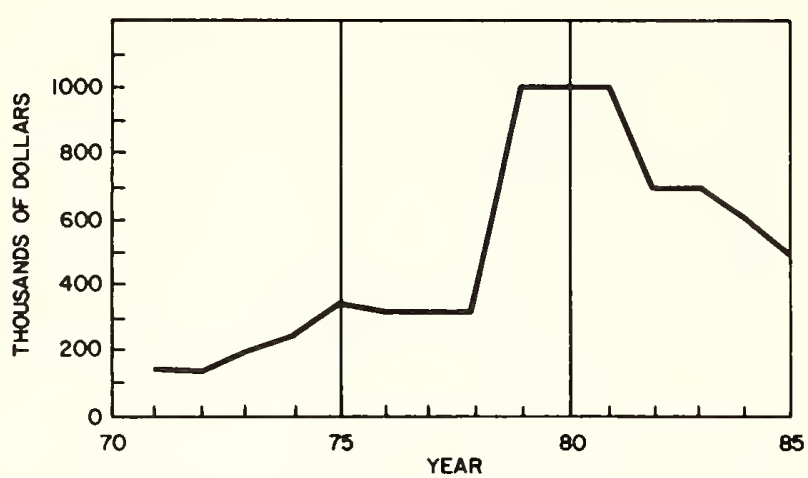

Appendix Figure A4.-Projected funding trend for the American lobster, Homarus americanus.

\section{OYSTERS}

Status of Aquaculture

Most of the earliest and best culture efforts in the United States were devoted to oysters, and culture technology is well understood and widely applied. At the present time, about $40 \%$ of the U.S. oyster production comes from private aquaculture. Although private aquaculture of oysters is discouraged in some east coast and Gulf States where public fisheries are well established, other States have encouraged private oyster culture and have found that production per unit of area under private management far exceeds that in a public fishery. The entire oyster production of the Pacific coast comes from private farms that raise the Pacific oyster, Crassostrea gigas, which was imported from Japan, and the native oyster, Ostrea lurida.

The United States is the largest oyster-producing and oyster-consuming country in the world. According to Food and Agriculture Organization statistics, U.S. consumption in 1973 was 69 million pounds $(31,000$ metric tons), $56 \%$ of the world total of 123 million pounds $(55,800$ metric tons). The U.S. supply included 49 million pounds (22,000 metric tons) from domestic production and 20 million pounds $\left(9,000\right.$ metric tons) from imports. ${ }^{7}$

U.S. oyster production has been decreasing for many years, and the 1973 level of about 49 million pounds $(22,000$ metric tons) of meats per year is less than onethird of the historical peak production of 152 million pounds $(69,000$ metric tons) in 1908 , and well below the 75-million-pound (34,000 metric tons) level of the late 1940 's. Many areas that formerly produced oysters are no longer suitable because of domestic or industrial pollution. Mass mortalities have decreased production in Chesapeake Bay, Delaware, and the Gulf of Mexico. Seed supplies from natural reproduction have also

\footnotetext{
${ }^{7}$ Food and Agriculture Organization of the United Nations, 1973 Yearbook of Fishery Statistics.
}

decreased in many places, because water quality has become unsuitable for larvae or juveniles.

Concurrently, imports of oysters, largely from Japan and more recently from Korea, have increased from 111,000 pounds (50 metric tons) of meats in 1947 to 19 million pounds $(8,600$ metric tons) in 1973 . Total U.S. consumption of oysters has remained at about 70 million pounds (32,000 metric tons) of meats for the past 30 years; increases in imports were offset by decreases in U.S. production.

Bell et al. (see footnote 5) predicted an increase in aggregate consumption of oysters in the United States from 70 million pounds ( 32,000 metric tons) in 1970 to 125 million pounds ( 57,000 metric tons) by 2000 . World consumption was predicted to increase from 165 to 416 million pounds $(75,000$ to 189,000 metric tons) of meats during that period. With increased world demand, it appears unlikely that the predicted increase in U.S. demand could be provided by imports; greater U.S. oyster production will be needed. ${ }^{8}$

Despite the problems of the U.S. oyster industry pollution, competition from low-priced imports, losses from diseases and predators, and increased production costs - there are opportunities for greatly increased production. Although it is unlikely that significant increases can be achieved by expanding the fishery on wild stocks, the technology of private oyster farming is well known and methods used in other parts of the world could be applied in the United States to vastly increase production. Even though suitable space for aquaculture of oysters has decreased, there remain adequate areas for increasing oyster production by a factor of 2 to 10 . With adequate markets and acceptable costs, U.S. production from private aquaculture could be increased from the 1973 level of 20 million pounds $(9,000$ metric tons) to 80 million pounds $(36,000$ metric tons) by 1985 .

\section{Problem Areas}

The major problems that limit aquaculture of oysters are:

Space in suitable environments.-Oyster culture requires control of space in bays and estuaries that often is desired for other uses. The importance of allocating space in such areas for food production should be recognized in coastal zoning plans. Oyster culture also requires high-quality water, so it is important to protect the aquatic environment of bays and estuaries from degradation.

One alternative is to develop intensive methods such as raft culture to reduce space requirements. Another alternative is to develop intensive culture systems in which oysters could be reared onshore through their entire life cycle under controlled conditions. This concept is technically possible, but economic feasibility

\footnotetext{
${ }^{8}$ Economics Research Division, 1974. Basic economic indicators, oysters 1947-1973, U.S. Dep. Commer., NMFS, Curr. Fish. Stat. 6273, 43 p.
} 
has not been determined. Scientific skills of university and government specialists are needed to answer the difficult questions concerning oyster genetics, nutritional biochemistry, pathology, engineering, and design of intensive culture systems. A project to develop and evaluate procedures for intensive culture of oysters and clams began at the University of Delaware in 1972 and should be ready for pilot-scale testing by 1978 .

Seed supply. - Natural reproduction is sporadic, and seed production from natural sources is uncertain. Hatchery methods developed in government and university laboratories have been applied by industry, but production problems attributed to water quality, diseases, and food supplies continue.

Disease and predator control-Unexplained mass mortalities of oysters occur nearly everywhere oysters are raised. Some causes have been identified and procedures to alleviate losses have been developed, but other losses are unexplained. Predators such as starfish, oyster drills, and crabs cause extensive losses in certain areas. Early control measures included selective poisons, but such procedures have become environmentally unacceptable. New noncontaminating control methods are needed.

Limited demand.-Total oyster consumption in the United States remained at a static level for the past 30 years whereas population has increased. Industry efforts are needed to provide high-quality products with new market forms through improved distribution and marketing systems.

Inconsistent supply. - Public fisheries on wild stocks harvest low-cost oysters, but supplies fluctuate widely from year to year resulting in uncertain market prices and varying demand for privately produced crops. Also, fresh oysters from the public fishery are available only during the open season. Expansion of private farming and reduction of public fisheries would help stabilize supplies and prices.

High production costs. - Increasing costs and relatively low price levels have created a difficult economic situation for oyster farmers. Improved efficiency of operations, including mechanization of oyster shucking, is needed. Another alternative is to concentrate on the smaller volume market for specialty products.

Low-priced imported oysters. - With an increase in imports from near zero in 1940 to over $25 \%$ of the market by 1973 , U.S. oyster farmers are in a difficult economic position.

Genetic improvement. - Since oysters can be reared throughout their entire life cycle in captivity, genetic improvement of stocks is technically possible. Recent development of disease-resistant strains in Virginia confirm the validity of this approach. Government research and development are needed for long-range projects such as genetic improvement, but industry hatchery operators could apply selective breeding procedures.

\section{Actions Required}

The problems of developing or expanding oyster culture, possible solutions, and actions required are summarized in the following listing.

\section{Problem}

Space for private oyster culture in suitable environments

.

Seed supply

Disease and predator control

Limited demand

Inconsistent supply

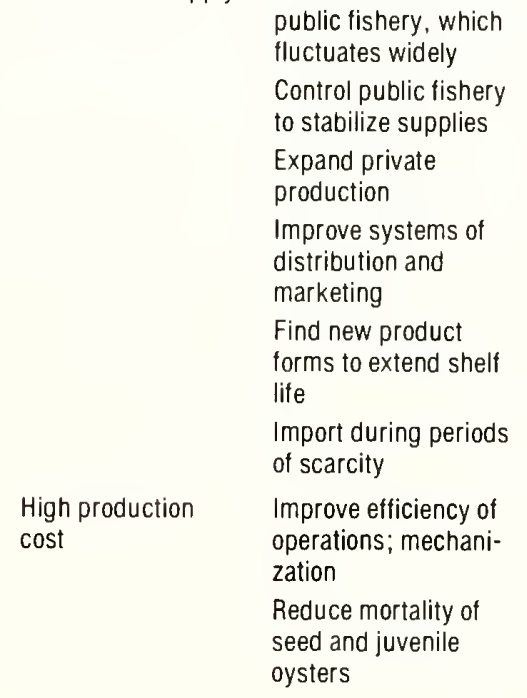

\section{Possible solution}

Revise State laws and policies and coastal zoning plans to encourage private aquaculture Protect habitat and control pollution

Develop intensive culture systems that require less space Be a good neighbor

Make better use of natural seed Improve hatchery methods

Develop new sources of natural seed

Expand hatchery production by applying results of genetics research

Research including genetic modification for disease resistance Modify operations to reduce adverse effects Apply control measures

Promote and develop markets

Consistent supply

Control quality Improve system of distribution and marketing

Find new uses and product forms

Reduce or eliminate public fishery, which ates widely public fishery

Expand private

Improve systems o forms to extend shelt Import during periods of scarcity

\section{Action required by:}

Industry, public, states

Government, industry

Government, university, industry

Industry

Industry

Government university

Industry, government

Industry

Government, university

Industry

Industry

Industry

Industry

Industry

Industry

Industry, univer-

sity, government

Political action to

change State laws or policies

Management by State government

Industry

Industry

Industry, university, government

Industry

Industry

Industry, university, government 
Low-priced imported oysters

Genetic improvement
Apply new culture methods

Produce specialty products for highpriced market

Promote domestic oysters

Improve production efficiency

Develop specialty products

Perform long-term research on genetics Apply selective breeding at hatcheries
Industry

Industry

Industry

Industry

Industry

Government, university industry table G1 were in Georgia (genetics); Massachusetts (aquaculture engineering); New York (hatchery disease); Oregon (hatchery improvement); South Carolina (culture in impoundments); Virginia (hatchery foods and disease control by genetic selection); and Washington (pathology and genetics). The largest Sea Grant project, located at the University of Delaware, included a multidiscipline effort to develop systems for intensive culture of oysters and clams in closed-cycle systems.

Funding for oyster projects should increase as shown in appendix figure A5 to permit pilot-scale evaluation of intensive culture systems and initiation of adequate programs to achieve genetic improvement of stocks and identification of causes of mortalities. After 4 years, funding should decrease gradually to the level required for long-term programs of genetics and disease control.

\section{Summary}

Private oyster culture is already viable, but several actions are required for expansion:

Action by industry is needed to develop markets, improve distribution systems, improve production efficiency, and increase seed supplies by hatcheries or by better use of natural seed.

States should act to encourage private oyster culture, maintain or restore high water quality, and to assist industry to collect natural seed and increase its survival.

Federal action at government laboratories or through universities is needed to determine cause of diseases and develop control methods, improve hatchery methods, conduct long-term genetics research, develop intensive culture systems for the future, and develop new products through technological research.

NMFS programs related to oyster culture in 1976 listed in appendix table G1 include genetics and hatchery disease studies at Milford, Conn., and a PL 88-309 project concerning culture of the mangrove oyster at Puerto Rico.

Sea Grant oyster projects in 1976 listed in appendix

Appendix Figure A5.-Projected NOAA funding trend for oysters.

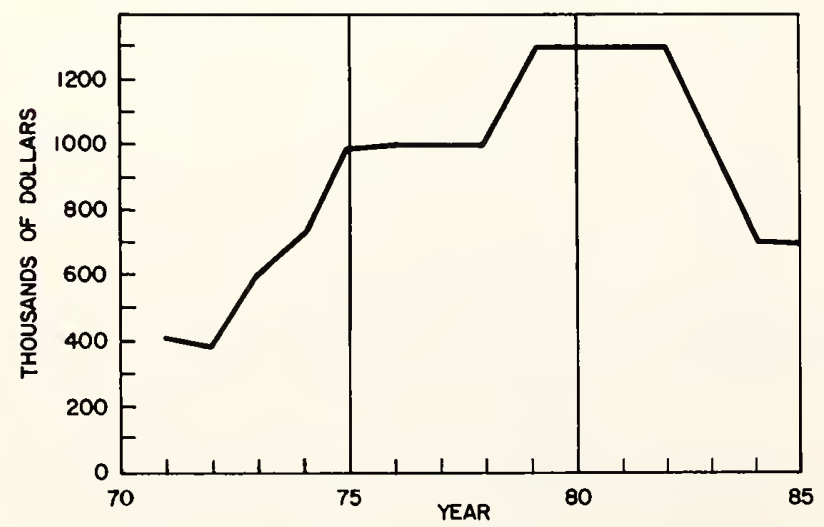

\section{MARINE PLANTS}

\section{Status of Aquaculture}

Aquaculture of marine plants or seaweeds is of great importance in some foreign countries (Japan and Korea, for example) where marine plants such as Porphyra, foods. Over 822 million pounds (373,000 metric tons) of seaweeds are produced annually through aquaculture in Japan and Korea. In tropical waters such as Singapore and the Philippines, species such as Eucheuma are grown extensively.

In the United States there is some harvesting of natural stocks of marine plants, principally for extraction of alginates which can be used as stabilizers in food products. The Irish moss, Chondrus crispus, occurs in New England, but the supply is inadequate to fill industrial needs. In the Pacific Northwest the native seaweeds of the genera Iridaea and Gigartina are harvested in moderate quantities for industrial purposes and a seaweed of the genus Porphyra, preferred as human food in Japan, is abundant in some areas. tive converter of solar energy into biological materials that are useful for a variety of industrial products. The State of California leases subtidal kelp beds, and the industry takes certain steps to restore the population primarily by controlling the herbivorous sea urchin by physical or chemical means. Mass culture techniques have been developed and juvenile plants are being transplanted into depleted areas to promote new bed development.

The culture of red algae such as Chondrus and Eucheuma for industrial uses is in the embryonic stage of development in the United States, but Eucheuma is farmed in the Philippines following methods developed in a Sea Grant-supported project at the University of Hawaii. The marine colloid industry is participating in efforts to develop methods for increasing the supply of raw materials through aquaculture. Undaria, and Gracilaria are used directly as human

The giant kelp of the genus Macrocystis is an effec- 
An attractive aspect of the culture of marine plants is the fact that they can directly utilize nutrients from the water. Marine plant aquaculture affords the potential for recovery of nutrients from domestic sewage and agricultural waste.

\section{Problem Areas}

The major problems which limit aquaculture of marine plants are:

Space in suitable environments. - Attached seaweeds require a firm substrate in coastal areas with adequate circulation of nutrient-rich water. However, the coastal zone is also desired for various other uses, some of which are incompatible with seaweed culture.

High production costs. - Culture, harvesting, and processing of marine plants tend to be labor-intensive which may make culture in the United States less economical than in foreign countries.

Market development. - The worldwide demand for phycocolloids such as agar, alginates, and carrageenan for use in a wide variety of foods, pharmaceutical and cosmetic products is increasing, but no significant U.S. market has developed for direct use of marine plants for human food. Interest has developed recently in the use of seaweeds as a source of fertilizer since they contain useful quantities of many trace elements needed to stimulate growth of agricultural crops.

Improved culture systems. - Research with Eucheuma in Florida indicates culture in tanks can produce 60 times the yield per unit of area of open-water culture. The development of intensive culture systems could improve the profitability of marine plant culture in the United States. ${ }^{9}$

Genetic improvement. - Marine plants used in aquaculture have not been improved by selective breeding as have land plants used in agriculture, but similar improvements in yield, growth rate, and disease resistance can be anticipated.

Nutrient requirements. - Nutrient requirements as related to growth, disease resistance, and reproduction are unknown. Some Sea Grant-supported research in California, Florida, New Hampshire, and Washington concerns nutrition of various species.

\section{Actions Required}

The problems of developing aquaculture of marine plants, possible solutions, and actions required are summarized in the following listing.

\section{Problem}

Space in suitable environments

\section{Possible solution}

Revise State laws, policies, and coastal zoning plans to encourage private aquaculture
Action required by:

State government, industry, public
Market
development

Improved culture systems

Genetic

improvement

Nutrient requirements
Possible solution

Modify substrate for seaweed culture

Develop intensive culture in tanks

High production costs

ing to increase
efficiency
Provide quality control

Perform long-term research on genetics Breed selectively

Perform biological research

Select sites in proper environment

Provide proper nutrient levels in intensive culture systems
Action required by:

Industry

Industry

Government, university, industry

University, industry

Industry

Industry

University, government, industry

University, government

Industry, government

Industry

Government, university

Industry

University, government Industry

Industry
University, industry

\section{Summary}

Aquaculture of marine plants holds considerable potential but its development will require the following actions:

Federal action, principally through support of university research, is needed to establish biological parameters for development of improved culture systems and for genetic improvement.

Appendix Figure A6.-Projected NOAA funding trend for marine plants.

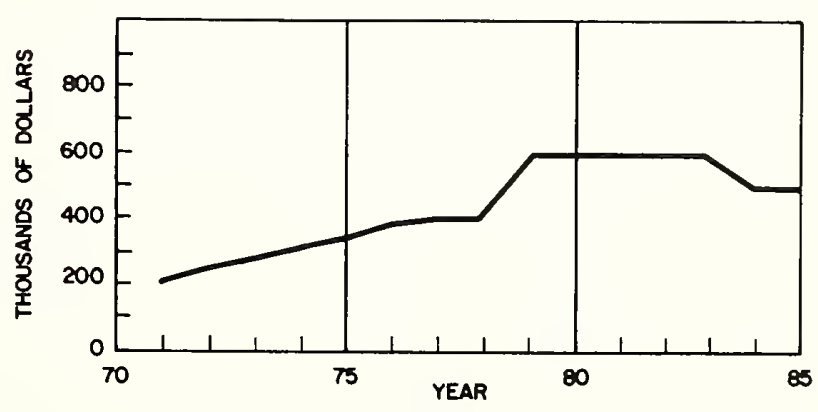


State action is needed to assure availability of space for culture of marine plants in suitable environments.

Industry action is needed to reduce production costs, develop new products and markets, and to control quality.

NOAA programs in 1976 related to aquaculture of marine plants consist of Sea Grant projects at universities in California, Delaware, Hawaii, New Hampshire, Rhode Island, and Washington.
Funding for marine plant projects should increase by about $50 \%$, maintain that level for 5 years and then decrease gradually to approximately the 1976 level as indicated in appendix figure A6. This type of funding program will permit the development and prototype testing of culture systems for temperate-water species followed by a long-term program of genetics and disease control.

\title{
APPENDIX B
}

\author{
Medium-Priority Species
}

Several species or species groups have distinct poten tial for aquaculture, but have not reached commercial production for a variety of reasons. In some cases natural supplies have been sufficient to supply the market and there has been little economic incentive for private aquaculture. As maximum sustainable yield levels of natural stocks are reached, it may become attractive to produce some of these species by farming. In other cases, the level of biological and technological information has been insufficient to indicate to potential investors an opportunity for private aquaculture with acceptable risk.

Finally, certain species appear in the medium-priority list because of their relevance to NOAA responsibilities and policies. For example, freshwater species such as trout, catfish, crawfish, and several species of baitfish are reared commercially but primary responsibility at the Federal level for these species is lodged within other agencies. The authorization for the Sea Grant program specifies the seas and the Great Lakes, which generally excludes programs related specifically to inland fish farming. The authority of NMFS relates primarily to marine and anadromous species except for statistics, marketing and similar programs concerned with commercial fisheries in freshwater and administration of the Commercial Fisheries Research and Development Act of 1964 (PL 88-309). As a result, NOAA activities related to private aquaculture in freshwater consist mainly of cooperation with other agencies to achieve national goals of increasing the supply of aquatic products to meet projected U.S. needs for the future.

\section{LOW-COST FISHES}

Over half of the 13 billion pounds $(6$ million metric tons) of fishery products produced by aquaculture in the world consists of finfish produced in 10 nations in
Southeast Asia. Most of this production is based on various species of carp reared by low-technology aquaculture in freshwater ponds or species such as mullet and milkfish reared in saltwater ponds along the coast.

In the United States, the concept of culturing lowcost species is a departure from previously held views that only high-valued species are suitable subjects for aquaculture. There is no U.S. industry at the present time based on the concept of producing low-cost fishes, but extensive experimental culture of freshwater species has been done by Auburn University, and experimental mullet culture has been developed by the Oceanic Institute in Hawaii.

The development of warmwater fish culture utilizing species that will produce maximum protein returns at the least cost has much appeal. Fishes selected for maximum productivity and desirable growth characteristics under warmwater conditions might include carp, buffalo fish, tilapia, mullet, milkfish, and catfish. Selective breeding of adaptable species for maximum growth would be an essential part of the development just as it has been for poultry and livestock. Scientists at Auburn University have corroborated the Chinese experience that indicated that species combinations are highly useful and productive in pond fish culture. Fish that utilize plants, plankton, and detritus would be reared with appropriate omnivorous or carnivorous fishes in a polyculture system.

Pond culture of carp and buffalo fish will yield more than 2,000 pounds per acre $(2,240 \mathrm{~kg} / \mathrm{ha})$ per year and up to 20,000 pounds per acre $(22,400 \mathrm{~kg} / \mathrm{ha}$ ) per year has been reported in Israel. The herbivorous white amur or grass carp may be started in a pond as fry and will produce more than 4,000 pounds per acre $(4,480 \mathrm{~kg} / \mathrm{ha})$ per year. If culture facilities permit introduction of 3-inch $(7.6-\mathrm{cm})$ fingerlings, 2-pound $(0.9-\mathrm{kg})$ white amur may be harvested in 3 months. Three crops a year could yield a total of $8,000-12,000$ pounds per acre $(9,000-14,600$ 
$\mathrm{kg} / \mathrm{ha}$ ) assuming fertility of the water could be maintained.

Although no extensive market has developed for species such as carp, new processing methods make it practical to use a wide variety of species not previously accepted as prime food fish. Methods are now available for production of high-quality processed products in which convenience, food value, standardized quality, and price are more important than the name of the species. Yields can be increased and labor cost reduced by mechanically separating edible flesh from the skin and bones. This method lends itself to flavor control and improved stabilization of the product during frozen storage. It also is possible to combine filleted fish of various species with the minced flesh to achieve a more desirable texture in the final product.

Fish blocks made from comminuted flesh of buffalo fish and carp by NMFS technologists at Seattle were found to be highly acceptable and considerable enthusiasm has been shown by processors in inland areas where wild buffalo fish, carp, and other warmwater species are relatively abundant. However, it is likely that a commercial operation of major proportions would quickly reduce wild stocks to uneconomic levels. Large-scale aquaculture would then be needed to provide a reliable supply of low-cost raw materials.

Space for pond culture of freshwater fishes can be found in the low-cost delta land along the Gulf of Mexico. $A$ recent government study ${ }^{10}$ indicated that over 2 million acres $(810,000$ hectares) of delta land in the Gulf States are apparently available and suitable for aquaculture development. Development of pond fish culture on only one-fourth of this delta land, with a production of 4,000 pounds of fish per acre $(4,480 \mathrm{~kg} / \mathrm{ha})$ would yield 2 billion pounds $(910,000$ metric tons) of landed fish per year.

Similar areas along the Gulf and southeast coasts could be used for construction of ponds for saltwater species. In addition, use of geothermal water in the western United States could increase production of warmwater fishes. Production from farming of low-cost fishes could supply much of the additional fish that will be needed by our expanding population.

Obviously, extensive research, development, and economic analysis will be needed to determine the feasibility of this concept and to demonstrate its commercial applicability. A NOAA program in cooperation with other Federal and State agencies and with industry should follow this sequence:

1. Utilize natural stocks of carp, buffalo fish, tilapia, mullet, and other species which can be obtained at a low cost for development of a processing industry and a market for minced flesh products, recognizing the fact that natural supplies of some of these species are quite limited.

\footnotetext{
${ }^{10}$ Greenwood, M. R. 1971. Untapped inland fisheries. In Sidney Shapiro (editor), Our changing fisheries, 534 p. U.S. Dep. Commer., NOAA, NMFS.
}

2. From a survey of available knowledge determine which species of fish suitable for aquaculture could be expected to produce protein at the lowest cost.

3. Develop techniques for polyculture of selected fresh and saltwater species in the southern States, where there is a long growing season and available low-cost land and water. These studies would be directed toward improving efficiency of traditional pond culture methods to minimize production costs.

4. Develop techniques for high-density culture and determine economic feasibility. Intensive culture systems have potential in areas where the constraints of available low-cost land, water, waste control, and zoning prevent extensive pond culture systems.

5. Develop methods for utilizing waste heat and geothermal waters for aquaculture of low-cost fishes and determine economic feasibility.

NOAA programs related to low-cost fishes have been primarily exploratory studies to determine if acceptable products could be made from carp, mullet, and similar species. Biological research to determine the status of knowledge concerning various species should begin soon. Research to develop intensive culture systems should begin in FY 1979 and continue for about a decade. NOAA funding should increase gradually to about $\$ 800,000$ and continue at that level for about 5 years as shown in Appendix B1. Additional funding by State and other Federal agencies will be needed to provide an adequate level of effort to assure development of aquaculture of low-cost fishes.

Appendix Figure B1.-Projected NOAA funding trend for lowcost fishes.

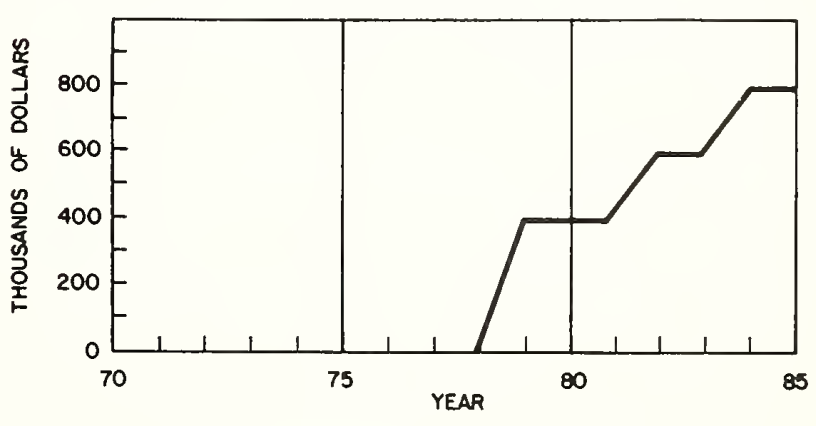

\section{CATFISH}

Private catfish farming has been a viable industry for more than 5 years and approximately 2,000 farmers and 12 processing firms are concentrated in 13 southern States; about $80 \%$ of them in Mississippi, Arkansas, and Louisiana.

Total production from farming is estimated at over 50 million pounds (23,000 metric tons) round weight, of which 20 million pounds $(9,000$ metric tons $)$ are pro- 
cessed for the market by large firms and the other 30 million pounds ( 14,000 metric tons) are processed locally on a small scale or are sold through fee-fishing lakes. Private production, considerably larger than harvest from wild stocks, has stabilized at the present level.

Three major problems limiting the expansion of catfish farming are the high cost of prepared feeds, consumer resistance to high retail prices, and competition from low-priced catfish from South America. In addition, water supplies are dwindling and more stringent effluent control procedures are being required that probably will make it necessary to install water reuse and treatment facilities. This also will cause some farmers to go from the open ponds to raceways, which lend themselves to water reuse.

Although disease control and prevention methods are used on a regular basis throughout the industry, losses from disease are still significant. The potential for expanding catfish culture depends on production costs and market prices. With satisfactory profit potential, the industry output could double during the next decade.

NOAA catfish programs in 1976 included the transfer of funds to the Fish and Wildlife Service (FWS) of the Department of the Interior for biological research, nutrition studies, and gear development. It is proposed that funding for this program be transferred to the FWS budget in the near future. A PL 88-309 project in Puerto Rico concerned polyculture of channel catfish and tilapia. In addition, NMFS marketing and statistics programs include catfish. Other Federal agencies with responsibility for development of aquaculture of catfish and other freshwater species include the Departments of Interior and Agriculture.

NOAA activities related to catfish will include service programs such as marketing and statistics in cooperation with other Federal agencies and funding State programs under the Commercial Fisheries Research and Development Act of 1964 (PL 88-309). NOAA also is concerned with the possibility of polyculture of catfish and several low-cost species to produce acceptable products for the mass feeding market in anticipation of the projected increase in demand for aquatic products in the United States.

NOAA catfish programs will require moderate increases in funding for marketing and statistics pro-

Appendix Figure B2.-Projected NOAA funding trend for catfish.

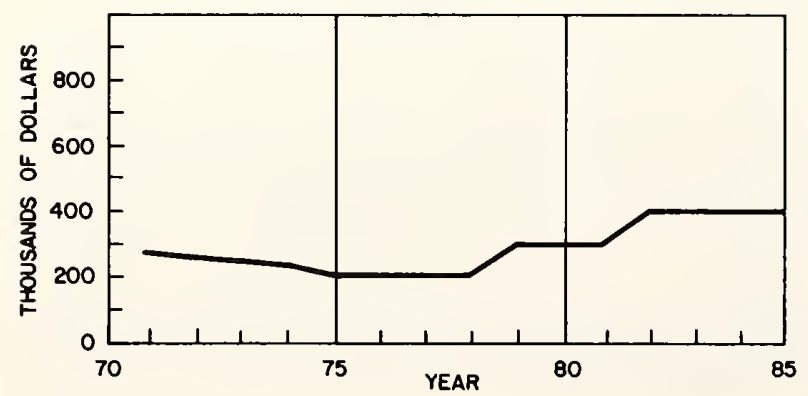

grams, State projects, and for cooperation with other Federal agencies in joint programs (appendix figure B2).

\section{YELLOW PERCH}

Several species in addition to trout, catfish, and carp have potential for aquaculture. Most of the research and development concerning freshwater fishes has been conducted by the FWS, State fisheries agencies, or universities.

Under the Sea Grant authorization, which includes the Great Lakes, NOAA has funded a project at the University of Wisconsin to develop culture systems for the yellow perch, Perca flavescens. In this project, perch were reared in small tanks supplied by heated well water that was reconditioned by a filtering system after use and recirculated through the system.

The intense interest in yellow perch culture was indicated by attendance of 500 individuals at a workshop sponsored by the University of Wisconsin in April 1975. By 1976, several commercial perch culture enterprises were being developed with firm orders for the product at attractive prices.

With the 15-million-pound (6,800-metric-ton) commercial fishery in Lake Erie (1974) threatened by contaminants including PCB's (polychlorinated biphenyls), aquaculture may be needed to supply the market for yellow perch and perhaps other species.

Funding for NOAA projects related to Great Lakes species such as yellow perch should increase to about $\$ 200,000$ for at least 7 years. This would provide for some acceleration of research in cooperation with State and other Federal agencies.

Appendix Figure B3.-Projected NOAA funding trend for yellow perch.

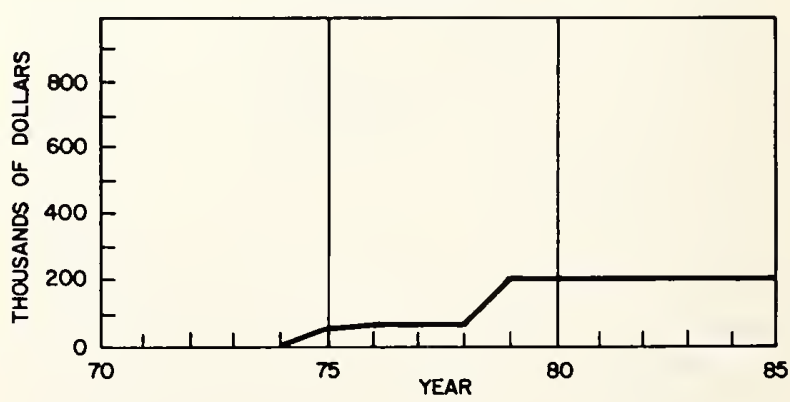

\section{CLAMS}

Many species of clams live in the intertidal or subtidal areas along our coasts and in bays and estuaries. Seven of these hold some potential for aquaculture: the eastern hard-shell clam, soft-shell or steamer clam, butter clam, littleneck clam, Manila clam, geoduck, and surf clam. 
The eastern hard-shell clam, Mercenaria mercenaria, known as littlenecks or cherrystones when small and quahogs when large, occurs from Maine to the Gulf of Mexico. Wild stocks are harvested on public lands. Private aquaculture ventures are located on Long Island, New York; at Wilmington, North Carolina; and several other locations.

In the New York venture, hard-shell clams are raised along with oysters in a private hatchery and held in trays in the warm effluent from a power plant to accelerate growth. When the clams reach the proper size they are planted on privately controlled beds. This venture was begun recently and it is too soon to determine its financial success. This company also selectively harvests natural sets of clams on beds under its control and occasionally transplants seed clams to areas where growth and survival are better. Procedures for this form of aquaculture are well established and operations are profitable.

The North Carolina venture includes a hatchery capable of producing more than 4 million seed clams per year for sale or for planting on leased beds. Again, it is too early to evaluate the financial success of this venture.

The Virginia Institute of Marine Science successfully produces seed clams in its hatchery at Wachapreague, Va. Good survival has been achieved in Virginia by placing coarse material such as gravel on the beds prior to planting seed clams, but this procedure has been less successful in Florida.

Intensive culture using artificially produced algal foods is being tested by the University of Delaware. In this Sea Grant-supported project, hard-shell clams have been grown to marketable size in one-third the time required for wild stocks in Delaware Bay.

The soft-shell or steamer clam, Mya arenaria, is harvested by hand in the intertidal zone in New England and by hydraulic escalator harvester in the subtidal beds of Chesapeake Bay. Fairly extensive beds of soft-shell clams occur at the mouth of several rivers in the Pacific Northwest. Several firms have begun harvesting these clams with hydraulic escalator harvesters on privately owned or leased beds in the intertidal zone.

Larvae of the soft-shell clam have been reared experimentally in hatcheries and it appears that commercial aquaculture could succeed if seed supplies were available; if intertidal beds could be leased; and if predators, such as the green crab, Carcinus maenas, in New England, could be controlled.

In the Pacific Northwest, a simple aquaculture system could be based on transplanting seed clams from contaminated areas at the mouths of rivers to clean areas for cleansing and growth. Later, when hatcheryproduced seed becomes available, these operations could be expanded into full-scale aquaculture.

The butter clams, Saxidomus nuttalli and S. giganteus, occur on the Pacific coast from Alaska to California. These species are extensively utilized except in areas where harvesting is prevented because of paralytic shellfish poisoning that occurs when the clams feed upon the dinoflagellate Gonyaulax sp. This condition is prevalent in Alaska where extensive beds of butter clams remain unutilized.

Commercial farming of butter clams, principally in the State of Washington, is largely based on selective harvesting of natural stocks on privately owned or leased beds in the intertidal zone or on subtidal beds leased from the State. In some cases, intertidal beaches that have become unproductive because of a change from gravel to sand have been restored to full productivity by depositing a layer of gravel over the beach. The coarse gravel provides the small clams with protection against wave action and predators.

The native littleneck clam of the Pacific coast, Protothaca staminea, like the butter clam, has been harvested for many years. At present, the entire U.S. commercial production of this clam comes from private clam farms, and prices have increased in response to the limited supply. As with butter clams, the productivity of sandy beaches has been restored by depositing a layer of gravel over them. The present simple form of aquaculture of both butter and littleneck clams may develop into full-scale aquaculture when hatchery-produced seed becomes available.

The Manila clam, Tapes semidecussata (Venerupis japonica), was accidentally introduced from Japan with seed oysters many years ago and is now the most valuable commercial clam in the Pacific Northwest. Occurring high in the intertidal zone, the Manila clam fits in a separate niche from the native littleneck clam and the butter clam. Production of the Manila clam is principally from licensed clam farms in the State of Washington. Supplies are fully utilized and prices have increased.

Larvae of the Manila clam can be cultured readily in hatcheries and quantities of seed for prospective clam farmers can be purchased from several private hatcheries. However, techniques for rearing hatcheryproduced seed clams to a size at which they can be planted successfully on growing beds have not been developed fully, and this has discouraged commercial clam farming. When this problem is solved, aquaculture of the Manila clam should expand rapidly.

The geoduck, Panope generosa, the largest temperatewater clam, is extremely abundant in Puget Sound, Wash., below the low-tide level, where commercial harvest occurs on beds leased from the State. Methods for rearing the larvae of the geoduck clam have not been developed and an extended period of resesarch and development will be required before aquaculture of this clam can become a reality.

The surf clam, Spisula solidissima, supports the largest U.S. mollusk fishery. This clam lives on the continental shelf from Canada to South Carolina and extends from the surf zone seaward to a depth of over 100 feet.

The surf clam is harvested commercially by large hydraulic dredges, with landings of up to 96 million pounds (44,000 metric tons) of meats (1974). Wild stocks appear to be fully exploited and production dropped $47 \%$ during the first quarter of 1976 compared to 1975 . 
There is a possibility that aquaculture techniques could be developed to augment the natural supply of surf clams. The larvae have been reared in the NMFS laboratory at Milford, Conn., and juveniles grow rapidly. With control of the 200-mile economic zone, the United States could restock offshore beds with seed clams and control harvesting when the clams reach commercial size. A system of licensing and catch taxes could recover most or all of the costs of this public aquaculture program. Although the proposed surf clam aquaculture program may not develop for some years, research and development should begin now to establish and test culture systems.

In summary, the increasing demand for clams, the limited supply, their sedentary nature, and the fact that they obtain their own food without additional cost make it attractive to consider aquaculture as a means of increasing production. Although the life history of most clams is well known and larval culture in hatcheries is possible, there remains a problem of rearing juveniles until they reach the size at which they can be planted on intertidal or subtidal beds. In some places, tidelands may not be available for private clam culture because of legal restrictions or local customs. Aquaculture in such places would require the development of intensive culture methods for use on shore or culture in deeper waters beyond the intertidal zone.

Although NMFS conducted research on hard-shell and soft-shell clams of the Atlantic coast during the 1950's and 1960 's, these investigations have been completed. As of 1976, NOAA programs related to clams included occasional pathological studies at the NMFS laboratory at Oxford, Md., and studies of processing techniques at the Northeast Utilization Research Center at Gloucester, Mass. Sea Grant-supported research included projects at the University of Delaware on intensive culture methods and at the University of Washington on survival of seed planted on intertidal beds.

Future NOAA programs should include an expansion of pathology and genetics studies and research to obtain adequate biological and technological information for development of aquaculture of various species of clams. Funding for NOAA programs should increase to about $\$ 800,00$ annually during the next 7 years as shown in appendix figure $\mathrm{B} 4$.

Appendix Figure B4.-Projected NOAA funding trend for various species of clams.

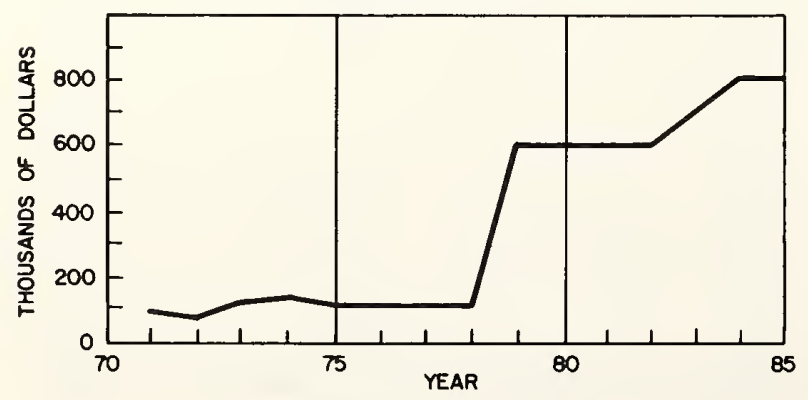

\section{ABALONE}

Several species of abalone occur from Mexico to Alaska but the largest and most important from a commercial and recreational standpoint is the red abalone, Haliotis rufescens, which is found principally in California. Commercial landings of abalone are less than a million pounds per year but the demand is great and prices are high and increasing.

Many years ago, Japanese workers developed procedures for rearing larvae of abalone through their pelagic stage and for feeding and culture of juveniles until they were large enough to plant in the sea. A number of Japanese Government hatcheries rear abalones to about 1 centimeter in diameter at which time they are sold to fishermen's cooperatives at a moderate price for planting in areas where macroalgae are available for food. Growth rate of abalones is rather slow and about 3 years after planting is required for them to reach harvestable size.

Private abalone culture was first tried in California in 1965 and although the firm developed satisfactory mass cultivation techniques for red abalone, it could not lease a coastal area in which to grow them to market size.

Another firm, located on the central California coast near Cayucos, began operations in 1968. This venture is directed toward mass cultivation of red abalone from the egg to harvestable size in shoreside ponds.

A third firm, established in 1972, plans to purchase seed abalone and grow them in specially designed habitats placed on bottom in a 50 -acre, open coastal tract near Point Sur, Calif., that it has leased from the State.

Most private abalone culturists feel that they are "breaking trail" and that too much of their time and money is required for research and development. Government-sponsored prototype tests of culture systems would make it possible for abalone culturists to move directly into production and would make it easier to attract investment capital.

The principal problems of abalone culture include the slow growth rate, high postlarval mortality, design of tank culture systems and open-coastal habitats, costeffective feeds and feeding systems, and adequate space for production facilities.

A PL $88-309$ project by the California Department of Fish and Game includes research on abalone culture. Several completed studies by the University of California were funded by OSG.

NOAA activities related to abalone culture should be limited for the present to funding university and State projects to provide adequate biological and technological knowledge for development of private aquaculture and to verify the applicability of laboratory research by pilotscale testing. At some time in the future, genetics research and selective breeding to improve growth rate will be needed. This will require a gradual increase in funding during the next 7 years as shown in appendix figure B5. 


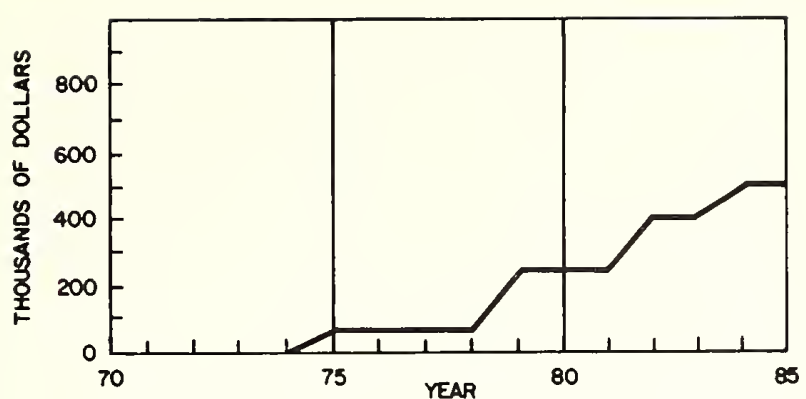

Appendix Figure B5.-Projected NOAA funding trend for abalone, Haliotis spp.

\section{BAY SCALLOP}

The bay scallop, Aequipecten irradians, has traditionally enjoyed high consumer acceptance in the United States and the scallop industry would be much larger than it is if the natural supply of this bivalve were greater and its annual abundance more predictable. The newly developed fishery for the calico scallop, $A$. gibbus, of the Southeast Atlantic States provides a product of similar size, and may reduce the price of bay scallops during periods when calico scallops are abundant. Supplies of bay scallops are variable, probably because of their short life cycle and environmental changes in shallow bays where they live.

There is high potential for private aquaculture of bay scallops because they live in the nearshore environment where control of production areas is possible. As compared to the American oyster and the hard-shell clam, relatively little scientific work has been done on the culture of bay scallops. However, the species has been induced to spawn and larvae have been reared successfully through metamorphosis by various investigators. The species also has been reared from postlarval stage to marketable size in less than a year by scientists of the Virginia Institute of Marine Science.

There is adequate biological and technological information for aquaculture of bay scallops at the present time but pilot-scale testing would be desirable to make sure that the methods developed at Wachapreague, Va., can be applied successfully at commercial levels. Factors which may limit aquaculture include the availability of juveniles, water quality, the cost of waterfront land, and a legal framework which will allow individuals to lease areas for scallop culture. However, a number of individuals and firms are interested in beginning aquaculture of bay scallops, and it appears likely that a viable industry will develop within the next 5 years.

The following areas of research are relevant to scallop culture, as they are to culture of other mollusks: genetics, disease, nutrition, culture systems, engineering, and economic analysis. Hatchery design may be only a minor problem if the techniques and systems developed for oyster hatcheries are applicable to scallop culture.

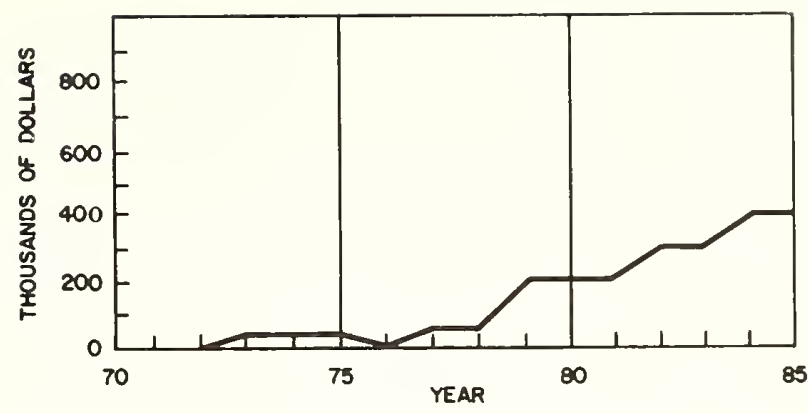

Appendix Figure B6.-Projected NOAA funding trend for the bay scallop, Aequipecten irradians.

The expertise of NMFS scientists in larval oyster culture should be applied to the solution of problems inherent in scallop culture.

The Sea Grant project related to bay scallop culture at the Virginia Institute of Marine Science was completed in 1975. Expansion of efforts to permit testing of laboratory findings in field trials would require about 5 years. Genetics and disease research also will be needed if a commercial bay scallop aquaculture industry develops. Proposed NOAA funding trends are shown in appendix figure B6.

\section{SPOT PRAWN}

The spot prawn, Pandalus platyceros, occurs along the west coast of North America from Unalaska to San Diego, and in Asian waters including Siberia, Korea, and Japan. The spot prawn lives in bays and inlets as well as on the continental shelf and slope at a depth of 4 to 487 meters (13 to 1,600 feet). It reaches a weight of 110 grams ( $1 / 4$ pound) and a length of 25 centimeters ( 10 inches). This species is the fastest growing pandalid shrimp although its growth rate is slower than that of many penaeids.

The spot prawn has characteristics that indicate it may be a suitable species for aquaculture. It lives at salinities of 25 to $30 \%$ and temperatures from $2^{\circ}$ to $20^{\circ} \mathrm{C}$ and adapts well to shallow-water environments. It is gregarious and no significant cannibalism occurs even if held under crowded conditions. Adult breeding stock can be captured at depths of 30 to 120 meters (about 100 to 400 feet) and transported with low mortalities. No serious disease problems have occured to date in captivity.

A research teal a at the NMFS Aquaculture Experiment Station, Manchester, Wash., recently succeeded in attempts to get adults to mature in captivity. About 70 females which had been held at Manchester after spawning the previous year produced eggs which hatched successfully. At this point a major obstacle to aquaculture - maturation and reproduction in captivity - has been 


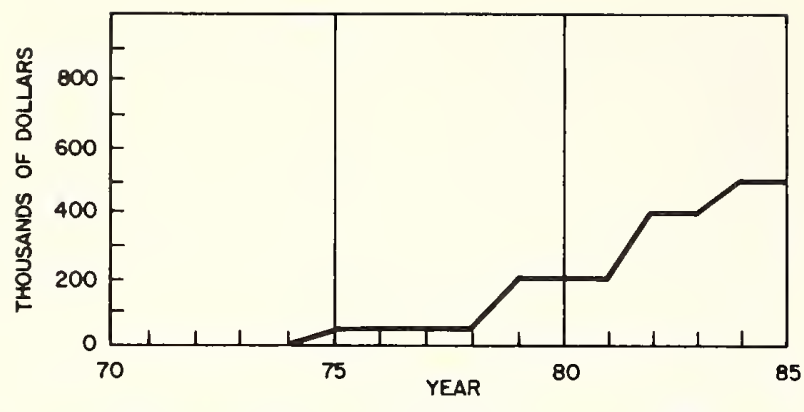

Appendix Figure B7.-Projected NOAA funding trend for the spot prawn, Pandalus platyceros.

removed for the spot prawn but not for penaeid shrimp of the Gulf of Mexico. This suggests that additional efforts be applied to develop procedures for aquacuiture of the spot prawn in temperate waters.

Other advantages of the spot prawn are that the larvae are large at the time of hatching (6 to 7 millimeters) and feed directly on zooplankton during the first stages of development. During later development the larvae and postlarvae adapt to artificial diets. Survival to metamorphosis has routinely been 68 to $78 \%$ at $14^{\circ} \mathrm{C}$.

Potential problems in the culture of pandalid shrimp are about the same as those for penaeid shrimp. However, the environmental requirements differ as the spot prawn is basically a temperate-water species. First experiments indicate accelerated growth and satisfactory survival when juvenile spot prawn are held at $14^{\circ}$ to $18^{\circ} \mathrm{C}$ instead of their natural environmental temperature of $10^{\circ} \mathrm{C}$ or less.

Finally, there appears to be some potential for rearing the spot prawn as a companion crop with salmon since both species require about the same environmental conditions. The prawns will consume the dead salmon which drop to the bottom of the net pens, thereby reducing feeding costs. Experiments at Manchester, Wash., have shown that large prawns and small salmon can be kept in the same pen without predation losses.

At the present time there is inadequate technological and economic information regarding $P$. platyceros cul- ture to encourage the development of commercial aquaculture. Research to determine the feasibility of culture has been conducted by the California Department of Fish and Game, University of California-Davis, the University of Washington, and NMFS. At the present level of research effort and funding, viable aquaculture cannot be expected in less than a decade.

NOAA funding should gradually increase during the next 6 years to permit development of culture systems and prototype testing. Subsequently, funding could be decreased to the level required for long-range genetics and pathology programs.

\section{TROPICAL SHELLFISH}

A Sea Grant-sponsored artificial upwelling project located at St. Croix, Virgin Islands, is testing the concept of using nutrient-rich deep waters for aquaculture. Oysters, Crassostrea gigas, and clams, Tapes semidecussata (Venerupis japonica), grew rapidly in tanks of upwelled water with excellent conversion of plant protein (phytoplankton) to animal protein. Results of this project indicate a good potential for increasing food production in tropical areas by the system of aquaculture.

NOAA-sponsored projects concerning tropical shellfish aquaculture should continue at the 1976 level of funding for about 4 years as shown in appendix figure B8.

Appendix Figure B8.-Projected NOAA funding trend for aquaculture of tropical shellfish.

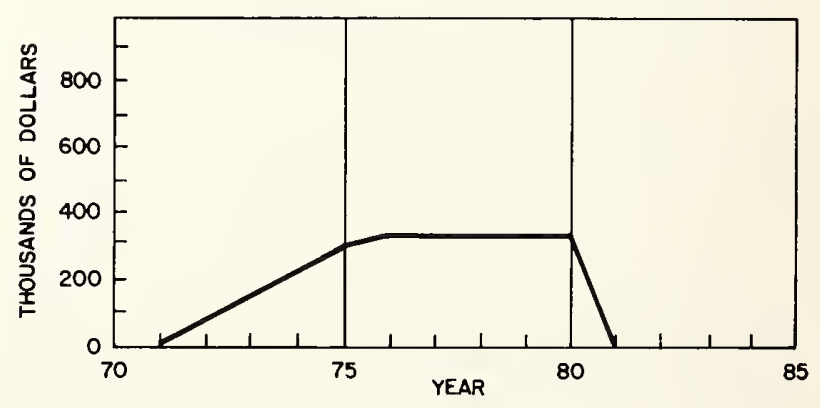

\section{APPENDIX C}

\section{Low-Priority Species}

A number of species appear to have potential for aquaculture but adequate biological and technological information is needed to evaluate their potential and then to provide a sound basis for development of an aquaculture industry. With funding limitations, work on these species has a lower priority than projects concerning species with known potential for aquaculture.

Some species may appear on the low-priority list because they are peripheral to NOAA's area of responsibility even though commercial aquaculture of these species may already exist.

\section{MARINE FISHES}

Several species of fish are farmed in the marine environment and contribute significantly to the supply 
of protein and the development of commerce, especially in Asia. Annual production of milkfish, Chanos chanos, is estimated at 167,000 metric tons ( 368 million pounds). Mullets are also produced by aquaculture, especially in Southeast Asia.

In Japan, more than a dozen marine or anadromous fishes are being cultivated in seawater on an experimental basis. More than 30,000 metric tons (66 million pounds) of the yellowtail, Seriola quinqueradiata, were produced by private aquaculture in 1968 , exceeding the catch from wild stocks. ${ }^{11}$

In Great Britain, methods have been developed for rearing the plaice, Pleuronectes platessa, and a pilotscale project has been conducted to develop commercial aquaculture methods.

In the United States, there are relatively few species of marine fish that are readily adaptable to aquaculture at present. Adequate supplies of many species are available by harvesting wild stocks, and prices are too low to attract investment in aquaculture. Some flatfish are in good demand and in short supply but methods for aquaculture have not been developed, although it appears likely that the British experiments with plaice will provide a good starting point for development of procedures applicable to U.S. species. Preliminary work in Sea Grant projects in North Carolina and Hawaii have indicated fast growth of the dolphin fish, Coryphaena sp., in captivity. Known in Hawaii as mahi mahi, this fish is in high demand and may have some potential for aquaculture. Japanese research and development on the culture of the yellowtail, $S$. quinqueradiata, had led to an extensive aquaculture industry but it is not known whether these methods would be adaptable to Seriola dorsalis, the American species prized by California anglers.

The maturation, spawning, and larval culture of a number of marine fish can now be accomplished routinely at the NMFS Southwest Fisheries Center at La Jolla, Calif. Marine fishes which have been successfully matured and spawned include the northern anchovy, Engraulis mordax; the Pacific sardine, Sardinops caeruleus; the croaker, Bairdiella icistia; and the Pacific mackerel, Scomber japonicus.

\section{Pompano}

The pompano, Trachinotus carolinus, is a highly prized fish caught in small quantities in the southern part of the United States. Initial research by NMFS and the Florida Department of Natural Resources indicated potential for private aquaculture of pompano and a number of small-scale commercial efforts began along the Florida coast. Most of these commerical ventures have failed because they were begun before an adequate technological base for culture of pompano was available.

The first attempts at pompano culture were based on the collection of wild fingerlings from the surf zone

\footnotetext{
${ }^{11}$ Pillay, T. V. R., editor. 1972. Coastal aquaculture in the IndoPacific region. Fishing News (Books) Limited, London, $497 \mathrm{p.}$
}

since methods for achieving spawning in captivity and larval culture had not been developed. Nutritional requirements were not known and the available foods were apparently deficient. Environmental requirements and factors which caused extensive mortalities were poorly understood. Methods were later developed for spawning pompano and rearing the larvae and were applied by a commercial aquaculture firm in the Dominican Republic.

Although there is a high probability that the problems listed above could be solved by a well-funded research program conducted by a competent staff, there is little or no effort going into this project at the present time. NOAA funding for efforts to develop commercially applicable procedures for maturation of pompano in captivity would require at least $\$ 100,000$ annually for 5 years.

\section{Sablefish or Black Cod}

The most likely species for marine farming in the Pacific Northwest is the sablefish or black cod, Anoplopoma fimbria. Scientists of the Fisheries Research Board of Canada held black cod in tanks of running seawater at Nanaimo, British Columbia, and found that they grew rapidly with good conversion rate when fed chopped marine fish, including the dogfish shark, Squalus sp. Black cod are gregarious and well suited to intensive culture. Limiting factors at this time are the relatively low market value of the product because large quantities are available from the harvest of wild stocks, and the difficulty of obtaining juveniles for aquaculture. Commercial aquaculture would require development of methods for collecting large numbers of wild juveniles or for inducing maturation and spawning in captivity.

\section{Striped Bass}

Several anadromous fish in addition to salmon can be cultured in the marine environment. Striped bass, trout, and char, among others, may have some potential for aquaculture in marine or estuarine waters.

Despite its anadromous nature, the striped bass, Morone saxatilis, has been induced to mature and spawn in seawater; freshwater was needed only for fertilization. Striped bass eggs and larvae require slow acclimation to increased salinity over an 18-day period to survive in seawater. Once this is achieved, metamorphosis is completely successful and growth is rapid if the fish are well fed. This development suggests that a seawater hatchery for this species may be possible where freshwater is at a premium, as in southern California, and that marine farming might be developed.

\section{Tropical Aquarium Fish}

Small colorful marine fish and invertebrates are in great demand for use in aquaria. The value of marine 
and freshwater fish imported annually for the aquarium trade is estimated at $\$ 300$ million. With a questionable supply from wild stocks and the possibility of import restrictions to prevent accidental introductions of undesirable species into U.S. waters, aquaculture of saltwater aquarium fish may develop in the future.

\section{Tropical Food Fish}

There is some research and development in progress in Hawaii and in other Pacific Islands to develop culture methods for selected marine food fishes. In Hawaii, the threadfin "moi", Polydactylus sexfilis, stands out because of its biological characteristics and consumer appeal. Since this fish is widely distributed and highly esteemed as food throughout the Indo-Pacific, techniques developed in Hawaii will benefit aquaculture over a broad geographic area.

Mullet, genus Mugil, is highly prized in the Pacific Islands. Culture methods were investigated in Hawaii under a Sea Grant project and significant progress was made in developing methods for stimulating spawning and rearing the larvae in captivity.

Aquaculture of rabbitfish of the genus Siganus is being developed in Sea Grant-funded projects in the Palau Islands and Guam. Siganids have high aquaculture potential because of the ready availability of fry in shallow water, their rapid growth rate, their subsistence on plant food, and the excellent market. Induced spawning and rearing of larvae have been accomplished on a small scale.

NOAA funding for tropical food fish aquaculture should continue at approximately the 1976 level for about a decade.

\section{Tuna Baitfish}

The pole-and-line fishery for skipjack tuna is primarily dependent upon the baitfish resource. The principal baitfish used by the Hawaiian skipjack fishery is the nehu, Stolephorus purpureus, a small delicate anchovy which possesses most of the qualities of good baitfish but suffers mortality as high as $30 \%$ despite careful handling.

Attempts at aquaculture of introduced baitfish species have been made by NMFS and the Hawaii Department of Land and Natural Resources. The most success was achieved with the tilapia, Tilapia mossambica, but the fishermen were not satisfied with this bait.

Two freshwater species, the threadfin shad, Dorosoma petenense, and the euryhaline topminnow, Poecilia vittata, have some potential for use as baitfish. The threadfin shad established breeding populations in freshwater reservoirs in Hawaii. Topminnows are easy to raise in captivity as indicated by experiments in Hawaii and American Samoa.

A number of native marine species including the cardinalfishes (Apogonidae), the goatfishes (Mullidae), the mullets (Mugilidae), and the milkfish (Chanos chanos) hold potential for aquaculture, but research will be needed to obtain adequate knowledge concerning the biology and culture methods required for successful aquaculture.

The concept of baitfish reared by Pacific islanders for sale to tuna fishermen holds promise for local employment in profitable ventures and increased harvest of underutilized skipjack resources.

\section{SUMMARY}

NOAA programs related to culture of marine fishes have been mainly exploratory attempts to rear a few species which appear to be candidates for aquaculture. Continuation of these efforts, largely through the Sea Grant program, is needed to provide biological and technological information as a basis for decisions regarding the commercial potential for aquaculture.

Funding should increase to about $\$ 1$ million during the next 6 years and continue at that level for as much as a decade to permit development of culture methods with commercial applicability.

\section{TROUT}

Private trout farming based on techniques developed in Government hatchery programs has become well established throughout most of the United States where suitable water supplies are available. All of the rainbow trout that enter commercial channels, about 30 million pounds $(13,600$ metric tons $)$, are produced in private trout farms.

Commercial trout farms are located in 38 States but major production is in Idaho, Colorado, Wisconsin, Michigan, and Pennsylvania. ${ }^{12}$ Over 200 farms produce trout for the fresh and frozen market. Others raise trout for sale to individuals for stocking private waters or to operators of "pay ponds" where the public can catch trout for a fee.

Increased prices of fish food and generally rising production costs have narrowed the profit margin for trout farms. Proposed effluent control regulations also will add to production costs. Major technical problems of trout production have been solved, but improved procedures are needed to lower production costs and thereby increase profitability.

New production techniques, such as the silo system used experimentally in Rhode Island for salmon, might be used for trout culture where availability of land is a constraining factor. However, conventional raceway production facilities are more efficient presently because water, not land, is the limiting constraint.

In the Pacific Northwest, trout have been grown on an experimental basis in saltwater ponds or floating net pens for about a decade. One firm in Oregon has been in commercial production since 1974 .

\footnotetext{
${ }^{12}$ Klontz, George W., and John G. King. 1975. Aquaculture in Idaho and nationwide. Idaho Dept. Water Resources, Boise, 86 p.
} 
With adequate markets, at prices commensurate with production costs, trout production in the United States could double by 1985 . The trout farming industry is a good example of viable aquaculture at the present time, and few additional government efforts are needed. Private trout farmers are likely to apply new techniques developed for use at public trout hatcheries and will benefit from continued government research and development in genetics, nutrition, and disease control for trout and salmon.

NOAA programs related to trout culture have been mainly in the marketing and statistics area plus some State PL 88-309 projects. In addition, some aspects of NOAA research and development related to net pen and ocean ranching of salmon will apply to private aquaculture of the anadromous steelhead trout, Salmo gairdneri irrideus. No expansion of NOAA efforts is anticipated because of extensive programs of other Federal and State agencies related to trout culture.

\section{CRAWFISH}

Crawfish production by aquaculture is estimated at 6 to 10 million pounds (2,700 to 4,500 metric tons). The industry, based largely in Louisiana, began about 1960 and includes many small farmers and a few large processors. The industry is growing and cultured crawfish account for up to $50 \%$ of the total production. Farmers using accepted management techniques have a good chance for success.

One of the major problems of the crawfish industry is the cost of harvesting. Since crawfish require aquatic vegetation for food and cover, they must be harvested by using traps or lift nets and these methods require a great deal of labor.

Another serious problem is the year-to-year fluctuation in the wild crop. This causes severe price fluctuations and in a year of plentiful wild stocks, prices may drop enough to curtail the harvest of the cultured crop.

Although research at Louisiana State University has provided an adequate biological and technological base for aquaculture, additional research is needed in nutrition, disease problems, food formulation, and behavior. In addition, market research is needed to determine the potential for developing additional markets in the United States and Europe. Technological research on product form, quality control, and peeling methods is needed.

Crawfish farming is another example of viable commercial aquaculture that does not need major government efforts. With a successful program to develop markets outside of Louisiana, production could be doubled during the next decade.

NOAA programs related to crawfish include one Sea Grant-supported study in Louisiana and minor NMFS efforts in statistics and marketing. Other Federal and State agencies also fund some crawfish studies.

Funding for NOAA programs should continue near the 1976 level, but if interest develops in farming the northern species of crawfish, some expansion will be needed to develop culture methods.

\section{MUSSELS}

The blue mussel, Mytilus edulis, occurs from the Arctic Ocean to South Carolina on the east coast and from Alaska to California on the west coast. Abundant populations of this small bivalve cover rocks, pilings, and mud flats in many intertidal and shallow areas, firmly attached to almost any solid object by byssal threads. The blue mussel is the most abundant edible mollusk in New England.

In Europe, mussels are a highly prized food and are farmed in Holland, France, and Spain. In the United States only small quantities have been harvested to supply a specialized market in cities with large foreignborn populations.

In 1973, a State agency in Maine began a consumer education program regarding mussels and the resulting market demand exceeded the capacity of the existing fishery. If the market for mussels continues to expand, natural stocks would be insufficient and aquaculture ventures would be needed. The labor-intensive raft culture techniques used in Spain are not directly applicable to northern New England, nor are the techniques of the capital-intensive, on-bottom industry of the Netherlands. However, one new firm began mussel culture in Maine in 1975 on 2 miles of ropes suspended from rafts. This very modest beginning looks promising since rafted mussels reach market size in 18 months.

Looking to the future when increased quantities of seafoods will be required with a coincident need to conserve energy, there may well be a place for mussel culture since this species is known to be one of the most efficient converters of phytoplankton to high-protein food.

Joint efforts of industry, universities, and government will be needed to predict market development, determine quantities available from natural stocks, and develop the technology for an economically competitive aquaculture system.

Sea Grant programs related to mussels include a study of culture techniques at the University of Washington and a joint effort by the University of New Hampshire and the University of Maine to investigate the potential for raft culture in New England. Funding for mussel projects should increase to about $\$ 200,000$.

\section{CRABS}

Several species of crabs are harvested commercially on the U.S. continental shelf and within bays and estuaries. The Alaska king crab, Paralithodes camtschatica, and the snow crab, Chionoecetes bairdi, are found in deeper water, usually well offshore, and it is difficult to visualize commercial aquaculture of these species at this time. Of the remaining species, the Dungeness crab, Cancer magister, of the west coast, the rock crab, Cancer irroratus, of the east coast, and the blue crab, Callinectes 
sapidus, of the Atlantic and Gulf coasts, might be considered for aquaculture. The larvae of all three species have been reared in the laboratory. Juvenile crabs feed readily on low-cost foods such as scrap fish; however, conversion rates are poor and growth is relatively slow.

Natural stocks of crabs vary greatly from year to year with corresponding price changes, although there is a generally upward trend in price and demand for crabs along with other crustaceans. However, the difficulty of rearing carnivorous, cannibalistic crabs for 2 to 3 years for a market with sharp price fluctuations, militates against aquaculture. In the future, as a better technological base is developed, aquaculture of crabs might become an economic possibility if demand increases and natural stocks become fully utilized.

Recent research by NMFS scientists at College Park, Md., provides some basis for optimism regarding culture of the blue crab. Under experimental conditions juveniles grew to marketable size of 5 inches in 15 to 18 months and scientists believe that this growing period can be reduced by development of suitable artificial foods.

Several tropical species such as the stone crab, Menippe sp., the Samoan or mangrove crab, Scylla serrata, and the coconut crab, Birgus latro, hold some potential for aquaculture in the future but adequate biological and technological information concerning these species is not available at this time.

NOAA programs related to the blue crab included a study of nutrition by NMFS in Maryland completed in 1975 and a Sea Grant study of pathology in North Carolina. A small project at the University of Guam investigated mass culture techniques for tropical crabs. NOAA funding related to crab aquaculture should increase to about $\$ 200,000$ for several years to permit evaluation of aquaculture potential of various species.

\section{MARINE BAITWORMS}

The baitworm fishery is the fourth largest fishery in Maine, with an annual landed value of about $\$ 2$ million. The two principal species are the bloodworm, Glycera dibranchiata, and the sandworm or clamworm, Neanthes (Nereis) virens. At retail, marine baitworms are among the most valuable marine products. The principal market for both species, Long Island Sound to Chesapeake Bay, is increasing as recreational fisheries expand.

As the demand for marine baitworms increases, harvests from natural stocks will reach the maximum sustainable yield level. At that time it will be attractive to consider the possibility of supplementing supplies by aquaculture. Researchers at the University of West Florida, funded by Sea Grant, believe there is a commercially profitable way to breed and raise the local lugworm, Arenicola, which also is valuable for bait. Although their findings may not be directly transferrable to the bloodworm and sandworm, their work suggests the desirability of limited research to develop a biological and technological base for aquaculture of marine baitworms in the northern part of our Atlantic and Pacific coasts.

Projected funding trends for low-priority species are shown in appendix figure $\mathrm{C} 1$.

Appendix Figure C1.-Projected NOAA funding trends for lowpriority species.

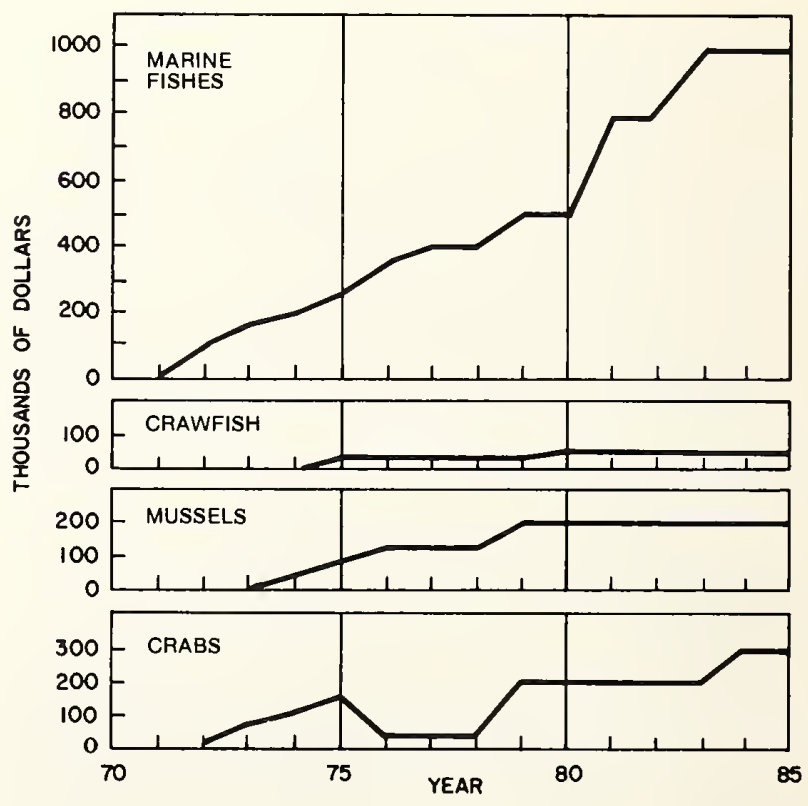

\section{APPENDIX D}

\section{Multispecies Program}

Despite differences among species with variations among regions of the United States are many common elements and problems in the aquaculture of various species. To establish a broad basis for future aquaculture development, several multispecies programs are neєüed.

\section{INTENSIVE CULTURE SYSTEMS}

As shorelines and estuaries become fully utilized it will be increasingly difficult to obtain private control over tidelands and nearshore areas for aquaculture. One 
alternative is to develop intensive culture systems which take less space or which ultimately might be located inland away from the crowded shoreline by using artificial seawater. Even in the freshwater environment, fish culturists face increasing land costs, water shortages, and more stringent waste control requirements. This trend could lead to intensive cultivation in raceways, silos, and similar facilities using recirculated and reconditioned water.

NOAA would be wise to look ahead a decade and begin now to develop the technology for intensive culture systems that will permit continuation and expansion of aquaculture in the United States. Most of the funding needed for development of intensive culture systems is included in the programs proposed for individual species. In addition, about $\$ 200,000$ annually would be needed for a decade beginning in 1979 to develop concepts and designs and to evaluate economics of high-technology culture.

\section{LOW-ENERGY SYSTEMS}

Opposite to the approach suggested in the preceding section is the concept of aquaculture systems that will produce food with the least input of energy. These systems will probably be extensive in area but will utilize wind power, waste nutrients, thermal effluents and geothermal or solar heating, and biological reconditioning of water. Several species will be grown together (polyculture) to utilize all available space and food sources. Species chosen for these systems will largely be fastgrowing herbivores or filter-feeders, low on the food chain, which are the most efficient in converting plants to animal protein.

It also is possible that freshwater aquaculture and agriculture can be brought together to make full use of irrigation systems. Systems could be designed in which the waters, modified by the presence of growing animals, could supply nutrients for agricultural crops, and the residues of agriculture (stalks, plant tops, etc.) could be used for aquaculture feeds and even for production of energy (e.g., through methane digesters) to operate the system. Such systems are operating on a small, experimental scale and much of the technology already exists.

With the growing awareness of energy shortages, NOAA should stimulate research and development to determine the feasibility of low-energy aquaculture systems.

NOAA efforts in culture of low-cost fishes will include some aspects of this problem, but additional efforts are needed to develop concepts and designs of low-energyinput systems and to evaluate their economics. This will require approximately $\$ 400,000$ annually for about a decade beginning in FY 1980.

\section{GENETIC IMPROVEMENTS}

Present aquaculture is based largely on rearing stocks of fish or shellfish that are essentially the same as wild populations. Animals and plants grown in agriculture have been modified genetically by selection or by crossing different strains to achieve desirable characteristics and to resist diseases. The application of scientific genetics research and selective breeding could vastly improve aquatic species to make them more adaptable to aquaculture. Certain species such as trout, salmon, oysters, clams, freshwater prawns, and lobsters can be grown through their entire life cycle in captivity, which means genetic improvement can be achieved. For others such as penaeid shrimp and most oceanic fishes, procedures have not been perfected for achieving maturation in captivity and genetic improvement cannot begin until this has been accomplished.

Some genetic improvements already have been made with trout to increase growth rate and reproductive capacity; salmon to shorten their life cycle from 4 to 3 years; oysters to achieve disease resistance; and with clams to increase growth rate. This is only the beginning. NOAA should develop and maintain continuing geneties programs for major aquacultural species.

Facilities are needed for long-term research on genetic improvement of various species of aquatic animals and plants. Because of the variations in environmental requirements, several stations will be required. Funding needs include new or expanded facilities for genetic improvement of salmonids in $1979(\$ 500,000)$, mollusks in $1979(\$ 500,000)$, freshwater prawns in $1982(\$ 700,000)$, marine shrimp in $1982(\$ 700,000)$, and low-cost fishes in 1984 ( $\$ 1.0$ million). Funding for operations is generally included in programs proposed for individual species.

\section{DISEASE CONTROL}

Most commercial aquaculturists consider disease control to be their most serious problem. Losses are often unpredictable and causes are unknown. Even though disease organisms have been identified, treatments are generally unavailable except for salmonid culture in freshwater. Marine pathology is a new science deserving much more attention if aquaculture is to succeed. The difficulty and long-term nature of this research and its broad application to various species indicates the necessity for Federal funding of university research and major government pathology centers.

It also may be desirable to establish certification and control programs, preferably at the State level, to prevent the spread of certain diseases.

Marine pathology investigations will require several major centers with fully adequate equipment at strategic locations. Funding needs include new or expanded pathology centers for Atlantic $(\$ 500,000$ in 1980$)$, Pacific $\mathbf{( \$ 1 . 5}$ million in 1980 ), Gulf ( $\$ 2.0$ million in 1981 ), and tropical (\$2.0 million in 1983), environments.

\section{NUTRITION AND FEEDS}

Cost-effective food is a primary requirement for most aquaculture since food is often the largest cost item. 
Scientific research to determine the nutritional requirements for each cultured species is needed first. Food rations then can be formulated, often by private industry. Testing of foods at pilot scale also is needed to determine conversion rates, long-term diet deficiencies and effect on disease resistance.

Because of the broad application and long-term nature of nutrition studies, university and Government research is indicated. Funding needs are included in expenditures proposed for individual species.

\section{LEGAL AND INSTITUTIONAL PROBLEMS}

Major deterrents to expansion of aquaculture are the difficulty of obtaining private ownership or control of adequate areas of tidelands or nearshore water areas, and obtaining the numerous permits or clearances required by local, State, and Federal agencies. It is not unusual for a new company to invest $\$ 50,000$ to $\$ 100,000$ just to obtain the required permits to begin an aquaculture venture - and there is always the risk of failing to obtain the final permit.

Government could help this situation by declaring a national policy of encouraging aquaculture and by drafting model legislation to simplify the permit system.

Another problem is the increasing regulation of importation of exotic species which may be useful for aquaculture. Government regulations should provide procedures for testing various species and approving for entry those which are suitable for aquaculture under specified conditions. Funding needed to provide staff attention to legal and institutional problems at national

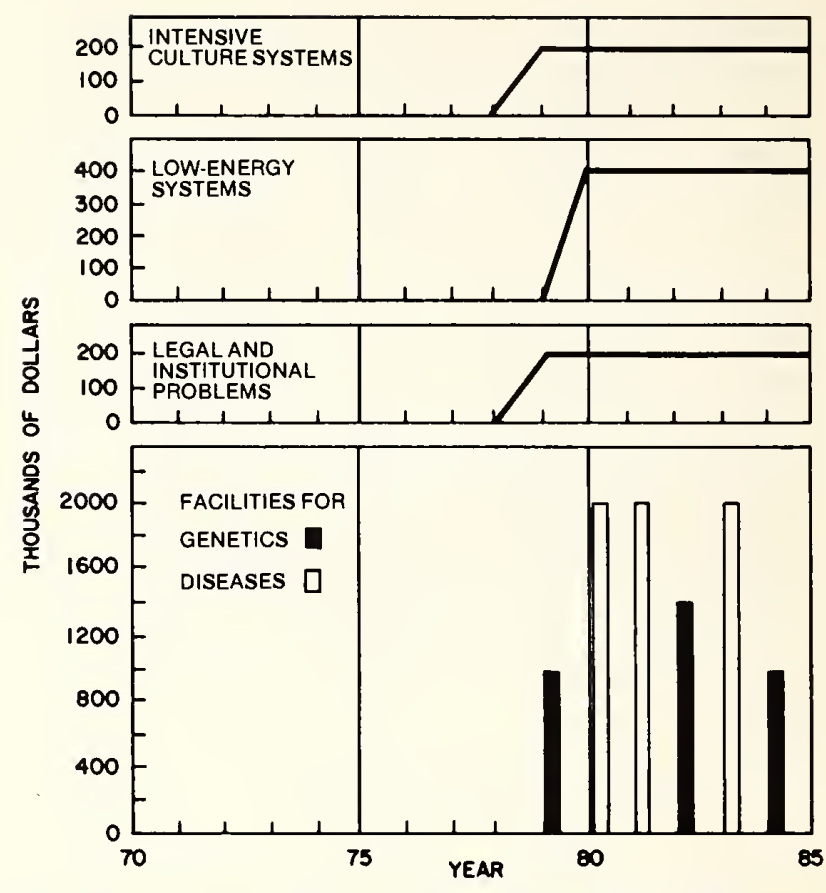

Appendix Figure D1.-Projected NOAA funding trends for multispecies programs.

and regional levels will require $\$ 200,000$ annually beginning in FY 1979.

Projected funding trends for multispecies programs and their facilities are shown in appendix figure D1. Operating funds for these facilities are included in programs proposed for individual species.

\section{APPENDIX E}

\section{Grant and Contract Programs}

Current NOAA activities related to aquaculture include projects at National Marine Fisheries Service laboratories, work conducted by State agencies under contract, or grant programs and Sea Grant projects at universities. About $40 \%$ of the present program is funded by National Marine Fisheries Service, mostly for in-house projects. About $60 \%$ of the program is funded by the Office of Sea Grant for university projects which require non-Federal matching funds as shown in appendix table G2.

Expansion of both National Marine Fisheries Service and Office of Sea Grant programs will be required to accomplish the development of U.S. aquaculture proposed in this report and detailed for certain species in appendices $\mathrm{A}$ to $\mathrm{D}$. This expansion will require an increase in annual expenditures of about $\$ 5$ million as shown in appendix table E1.

In addition to the programs listed above, there is need to make the transition from laboratory research to viable commercial aquaculture. This will require testing of prototype systems to validate laboratory findings, and solving the problems associated with full-scale production of various species. Much of this work can be accomplished best by joint programs with individuals, firms, educational institutions, or State agencies.

A Federal program of grants with suitable matchingfund requirements is needed for joint programs to expedite the commercial application of scientific research. 
It also will be necessary to contract for specific work for which matching funds are not appropriate. This program would require $\$ 5$ to $\$ 7$ million annually as shown in appendix table E1.
Appendix table E1 also lists funds which would be needed to develop the National Aquaculture Plan proposed in this report and to establish and maintain a National Aquaculture Information Center.

Appendix Table E1.-Distribution of additional funds proposed for the NOAA Aquaculture Program.

\begin{tabular}{|c|c|c|c|c|c|c|c|}
\hline Year & $\begin{array}{l}\text { NOAA } \\
\text { base } \\
\text { program } \\
\text { FY } 1976\end{array}$ & $\begin{array}{l}\text { National Aquaculture } \\
\text { Plan development }\end{array}$ & $\begin{array}{c}\text { National } \\
\text { aquaculture } \\
\text { information center }\end{array}$ & $\begin{array}{c}\text { Expansion of } \\
\text { NMFS \& OSG } \\
\text { programs }\end{array}$ & $\begin{array}{l}\text { Research } \\
\text { facilities }\end{array}$ & $\begin{array}{l}\text { Grants } \\
\text { and } \\
\text { contracts }\end{array}$ & Total \\
\hline 1976 & 6.5 & & & & & & 6.5 \\
\hline 1977 & 6.5 & & & & & & 6.5 \\
\hline 1978 & 6.5 & 1.0 & 0.5 & & & & 8.0 \\
\hline 1979 & 6.5 & & 0.5 & 5.0 & 1.0 & 6.0 & 19.0 \\
\hline 1980 & 6.5 & & 0.5 & 5.0 & 2.0 & 5.0 & 19.0 \\
\hline 1981 & 6.5 & & 0.5 & 5.0 & 2.0 & 5.0 & 19.0 \\
\hline 1982 & 6.5 & & 0.5 & 5.0 & 1.4 & 5.6 & 19.0 \\
\hline 1983 & 6.5 & & 0.5 & 5.0 & 2.0 & 5.0 & 19.0 \\
\hline 1984 & 6.5 & & 0.5 & 5.0 & 1.0 & 6.0 & 19.0 \\
\hline 1985 & 6.5 & & 0.5 & 5.0 & & 7.0 & 19.0 \\
\hline
\end{tabular}

\section{APPENDIX F}

\section{NOAA's Authority for Aquaculture Programs}

Following is a partial listing of legislative authorizations which generally or specifically authorize aquaculture activities of the National Marine Fisheries Service and Office of Sea Grant.

(NMFS) Joint Resolution No. 22, 41st CongressOriginal Act of February 9, 1871, Office of Commissioner of Fish and Fisheries Established-Propagation of Food Fishes and Investigations to Ameliorate Predator Damage. 16 USC 744-745.

(NMFS) Public Law 203-Act of April 28, 1922, Propagation of Mussels. 16 USC 750-751.

(NMFS) Public Law 502-Original Act of May 11, 1938, Columbia River Basin Fishery Development Program (Mitchell Act). 16 USC 755-757.
(NMFS) Public Law 1024)-Original Act of August 8, 1956, Fish and Wildlife Act of 1956. 16 USC 742a-742k. (NMFS) Public Law 85-342-Act of March 15, 1958, Fishery Research and Experimentation (Reservoirs and Flooded Rice Lands). 16 USC 778-778c.

(NMFS) Public Law 87-173-Act of August 30, 1961. Construction of a Shellfisheries Research Center at Milford, Connecticut. 16 USC 760h-760i.

(NMFS) Public Law 87-580-Act of August 9, 1962. Propagation of disease resistant oysters. 16 USC 760 j7601 .

(OSG) Public Law 89-688-Act of October 15, 1966, National Sea Grant College and Program Act of 1966 . 33 USC 1121-1124.

\section{APPENDIX G}

\section{NOAA Aquaculture Program, FY 1976}

NOAA has ongoing projects in aquaculture which predate development of the NOAA Aquaculture Plan.
Some of these will require expansion to provide timely solutions to problems; others will be completed or phased 
out when funds are needed for higher priority projects. Appendix table G1 lists the FY 1976 projects of NMFS laboratories, State agencies under the PL 88-309 program, and university and other projects under the Sea
Grant program with Federal and matching funds. Appendix table G2 shows funding by NMFS and OSG for aquaculture programs related to various species or species groups.

Appendix Table G1.-NOAA aquaculture program, FY 1976.

Activities by species, organization, location, funding level, and subject area.

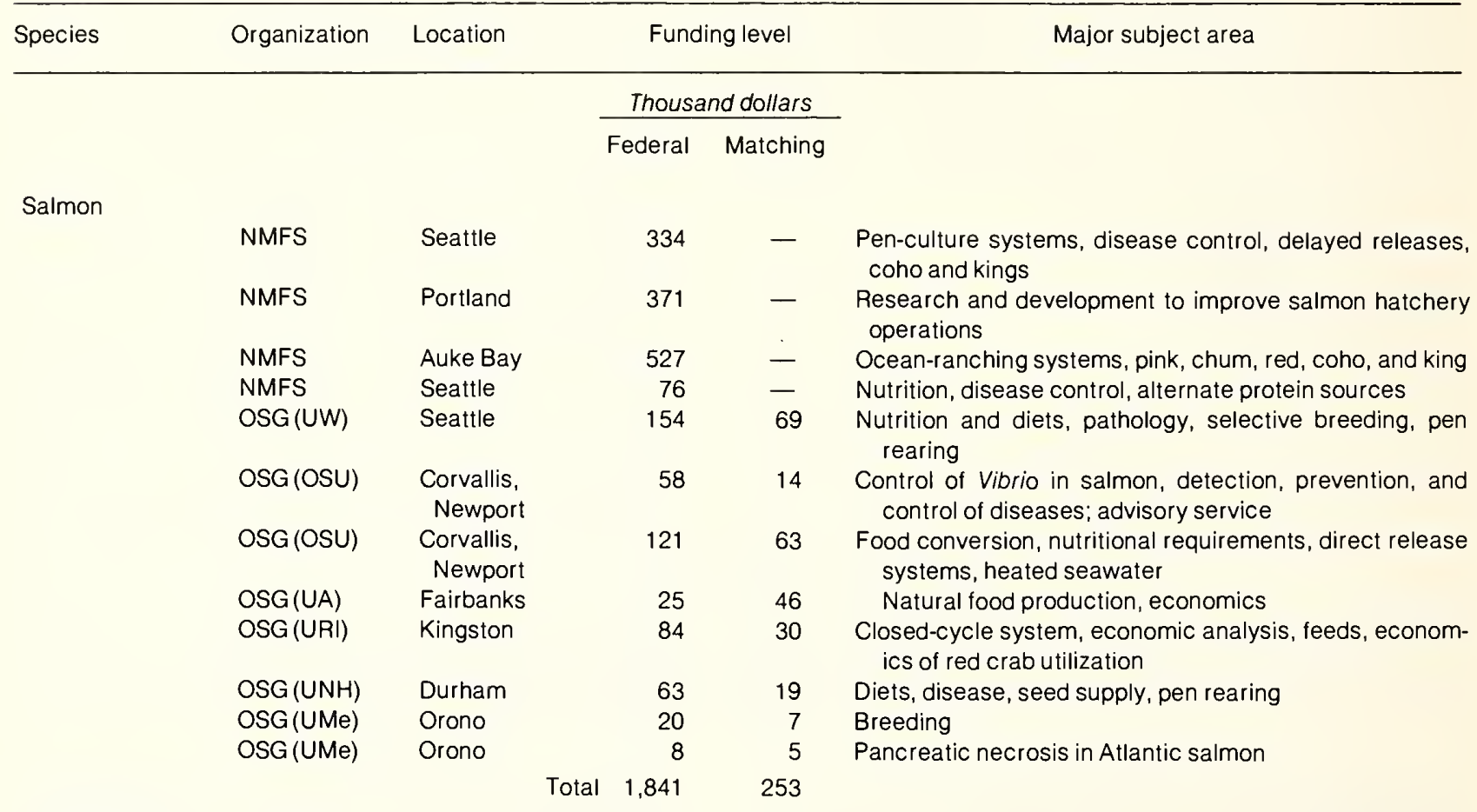

Marine shrimp

\begin{tabular}{|c|c|c|c|}
\hline NMFS & Galveston & 447 & - \\
\hline OSG (TAMU) & $\begin{array}{l}\text { Houston, } \\
\text { College Station }\end{array}$ & 148 & 92 \\
\hline \multirow[t]{2}{*}{ OSG (LSU) } & Baton Rouge & 15 & 4 \\
\hline & Total & 610 & 96 \\
\hline
\end{tabular}

Intensive culture systems, maturation, disease control, nutritional requirements

2 Pond culture systems, disease, feed conversion, economic analysis, maturation

4

Diet formulation

Freshwater

prawn

\begin{tabular}{|c|c|c|c|}
\hline NMFS & College Park & 119 & - \\
\hline NMFS (88-309) & Florida & 30 & 10 \\
\hline NMFS (88-309) & Hawaii & 30 & 30 \\
\hline $\begin{array}{l}\text { OSG } \\
\text { (Hawaii-DLNR) }\end{array}$ & Honolulu & 70 & 35 \\
\hline \multirow[t]{2}{*}{ OSG (MRRI) } & $\begin{array}{l}\text { Charleston, } \\
\text { Clemson }\end{array}$ & 111 & 65 \\
\hline & Total & 360 & 140 \\
\hline OSG (UCD) & $\begin{array}{l}\text { Davis, } \\
\text { Bodega Bay }\end{array}$ & 134 & 192 \\
\hline OSG (SDSU) & San Diego & 108 & 100 \\
\hline OSG (URI) & Kingston & 68 & \\
\hline \multirow[t]{2}{*}{ OSG (UMe) } & Orono & 8 & 5 \\
\hline & Total & 318 & 30 \\
\hline
\end{tabular}

Basic nutritional requirements

Mass culture, nutritional needs

Culture technology, some work on catfish

Nutrition feeds, selective breeding, disease, pond systems, pilot-scale plant

Larval feeds, nutrition, breeding, pilot-scale hatchery, engineering, water quality

American

lobster

Artificial and natural feeds, diseases, genetics and selective breeding, system development, growth and survival, system engineering, cost analysis

Heated effluents-feeding requirements, growth and survival, raceway systems, disease

Culture systems

Nutrition 


\begin{tabular}{llll}
\hline Species & Organization Location & Funding level & Major subject area
\end{tabular}

\section{Thousand dollars \\ Federal Matching}

Oysters and clams

Mussels

\section{Crabs and}

crawfish

OSG (LSU)
OSG (ECU)
OSG(UGuam)

NMFS (88-309) Puerto Rico

NMFS Milford

24

250

NMFS (88-309) Oregon

OSG(VIMS) Gloucester Point

20

69

OSG (OSU)

Newport

78

OSG (UDel)

Lewes

241

OSG (UW)

Seattle

OSG (UMe)

Charleston

Orono, Walpole

\section{1}

23

124

$\begin{array}{ll}\text { OSG (UMe) } & \text { Orono } \\ \text { OSG } & \text { Ithaca } \\ \text { (SUNY/Corneli) } \\ \text { OSG(UGa) } & \text { Athens } \\ \text { OSG(UMass) } & \text { Amherst }\end{array}$

\section{8}

Total 1,040

OSG(UW)
OSG (UMe)
OSG (UNH)
OSG(AF)

\section{Seattie}

Orono

Durham

14

47

30

Damariscotta

Baton Rouge

Greenville

Agana

Total

Marine plants

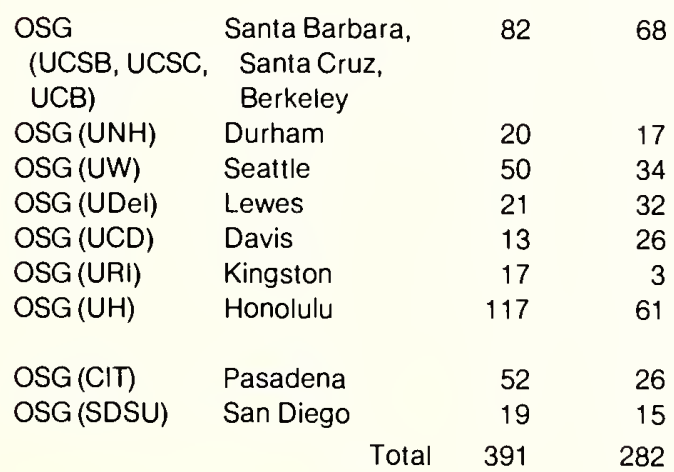

Finfish

20

479

\section{4}

13

6

28

282
OSG (MRRI)

Total 114

8 Culture of mangrove oysters

Genetic improvement, nutrition, hatchery diseases control, rearing and spawning

7 Spawning and rearing of clams

99 Nutrition, feeds, disease monitoring, selective breeding, open systems production of spat, pilot testing

50 Larval feeds, diseases, selective breeding, hatchery improvement, heated effluents

128 Natural foods, pathology, closed-cycle systems, water quality, engineering, pilot testing

Oyster diseases and genetics, clam culture

Culture in impoundments

52 Pathology, genetics, selected breeding, cultchless rearing, evaluation of environment, thermal discharge rearing, radio isotope uptake

5 In vitro cell culture

59 Bacterial and viral diseases of shellfish

\section{Genetics}

Heated effluents, aquaculture engineering

Raft culture, Puget Sound

Raft culture, power plant effluents

Cooperative project with UMe

Raft culture

Crawfish culture and economics

Fungal diseases in crustaceans

Culture of mangrove and coconut crabs

Nutrition and genetics (Iridaea)

\section{Ecology of red algae}

Marine algae culture

Saline plants

Salt-tolerant plants

Culture of algae in silos

Selective breeding (Euchema), seaweed farms, economic analysis of farms, seed supply, pilot testing

Kelp bed establishment, seed supply

Bioproducts from algae for disease control

\begin{tabular}{|c|c|c|c|}
\hline NMFS & St. Petersburg & 154 & - \\
\hline NMFS (88-309) & Puerto Rico & 25 & 8 \\
\hline NMFS (88-309) & New Mexico & 15 & 5 \\
\hline OSG (UWisc) & Madison & 57 & 25 \\
\hline OSG (UGuam) & Agana & 10 & 7 \\
\hline \multirow[t]{2}{*}{ OSG (NCSU) } & Raleigh & 24 & 14 \\
\hline & Total & 285 & 59 \\
\hline
\end{tabular}

Catfish contract with FWS, biological, nutrition, gear

Polyculture of channel catfish with tilapia

Vertical raceway production of trout

Culture of perch and walleye, thermal effluents, waste treatment

Rabbitfish culture

Eel culture 


\begin{tabular}{llll}
\hline Species & Organization Location & Major subject area \\
\hline & $\frac{\text { Thousand dollars }}{\text { Federal Matching }}$
\end{tabular}

Mixed species

\begin{tabular}{|c|c|c|c|c|}
\hline NMFS (88-309) & Guam & 28 & 25 & $\begin{array}{l}\text { Polyculture of freshwater prawns, eels, catfish, carp, and } \\
\text { milkfish }\end{array}$ \\
\hline NMFS (88-309) & California & 62 & 21 & Mass culture of abalone, crab, shrimp, etc. \\
\hline NMFS (88-309) & Alabama & 32 & 11 & Culture of freshwater prawns and pompano \\
\hline OSG (WHOI) & Woods Hole & 110 & 50 & Polyculture using sewage wastes \\
\hline OSG (TTPI) & Palau & 55 & 68 & $\begin{array}{l}\text { Cooperative aquaculture of rabbitfish, prawns, shrimp, } \\
\text { milkfish }\end{array}$ \\
\hline OSG(UA) & Fairbanks & 24 & 12 & Development of aquaculture \\
\hline OSG (UCD) & Davis & 11 & 9 & Economics of aquaculture \\
\hline OSG (UCSC) & Santa Cruz & 8 & 12 & Aquaculture regulations \\
\hline OSG (UMe) & Walpole & 1 & 2 & Aquaculture course \\
\hline OSG (OI) & Waimanalo & 60 & 39 & Open sea mariculture engineering \\
\hline OSG (VIMS) & Gloucester Point & 34 & 6 & Information systems \\
\hline OSG (UW) & Seattle & 23 & - & Aquaculture feasibility \\
\hline OSG (UH) & Honolulu & 267 & 138 & $\begin{array}{l}\text { Tropical animal aquaculture and cooperative studies in } \\
\text { Micronesia }\end{array}$ \\
\hline OSG (Col) & St. Croix & 330 & 192 & $\begin{array}{l}\text { Artificial upwelling; culture of clams, oysters, marine } \\
\text { plants, etc. }\end{array}$ \\
\hline OSG (LSU) & Baton Rouge & 16 & 12 & Salmonella in turtles \\
\hline OSG (TAMU) & College Station & 55 & 28 & Diseases of fish and shrimp \\
\hline OSG (URI) & Kingston & 37 & 6 & Marine pathology \\
\hline OSG (GCRL) & Gulf Springs & 27 & 34 & Parasites in marine animals \\
\hline & Total & 1,180 & 665 & \\
\hline
\end{tabular}

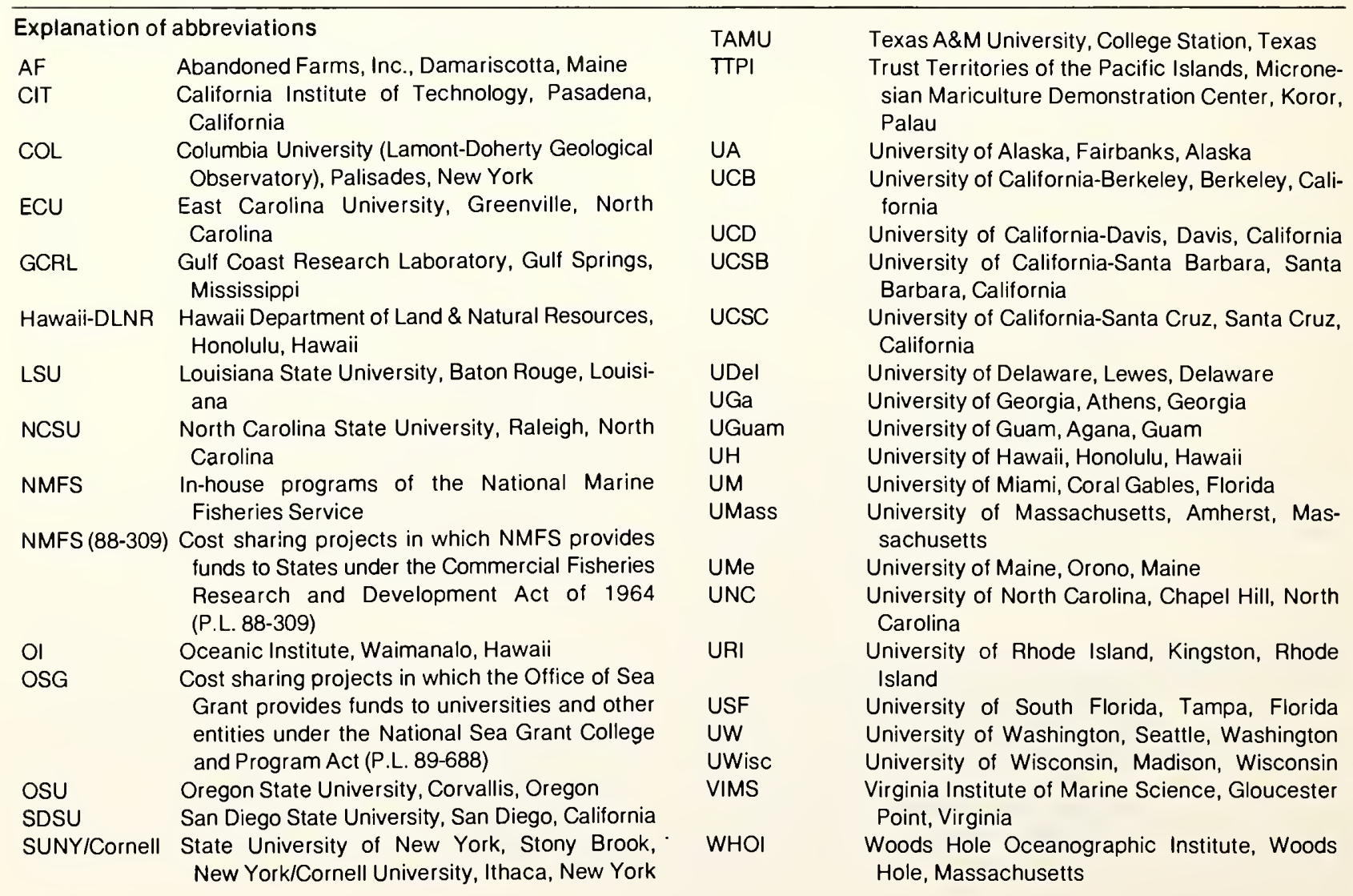


Appendix Table G2.-Funding by NMFS and OSG for aquaculture programs, FY $1976^{1}$.

\begin{tabular}{|c|c|c|c|c|c|c|c|c|}
\hline \multirow[b]{3}{*}{ Species } & \multicolumn{2}{|c|}{ Total 1976} & & & & & & \\
\hline & \multirow[b]{2}{*}{ Federal } & \multirow{2}{*}{$\begin{array}{c}\text { Federal } \\
\text { and } \\
\text { matching }\end{array}$} & \multicolumn{4}{|c|}{ Funding by } & \multicolumn{2}{|c|}{ Percentage } \\
\hline & & & NMFS & Matching & $\overline{O S G}$ & Matching & NMFS & $\overline{O S G}$ \\
\hline & \multicolumn{6}{|c|}{ Thousand dollars } & & \\
\hline Salmon & 1,841 & 2,094 & 1,308 & 0 & 533 & 253 & 71.0 & 29.0 \\
\hline Marine shrimp & 610 & 706 & 447 & 0 & 163 & 96 & 73.3 & 26.7 \\
\hline Freshwater prawn & 360 & 500 & 119 & 0 & 241 & 140 & 33.1 & 66.9 \\
\hline Oysters and clams & 1,040 & 1,519 & 294 & 15 & 746 & 464 & 28.3 & 71.7 \\
\hline Lobsters & 318 & 624 & 0 & 0 & 318 & 306 & 0 & 100 \\
\hline Mussels & 114 & 188 & 0 & 0 & 114 & 74 & 0 & 100 \\
\hline Crabs and crawfish & 70 & 98 & 0 & 0 & 70 & 28 & 0 & 100 \\
\hline Marine plants & 391 & 673 & 0 & 0 & 391 & 282 & 0 & 100 \\
\hline Finfish & 285 & 344 & 194 & 13 & 91 & 46 & 68.1 & 31.9 \\
\hline Mixed species & 1,180 & 1,845 & 122 & 57 & 1,058 & 608 & 10.3 & 89.7 \\
\hline Total & 6,209 & 8,591 & 2,484 & 85 & 3,725 & 2,297 & 40.0 & 60.0 \\
\hline
\end{tabular}

${ }^{7}$ Excludes operation of Columbia River salmon hatcheries under the Mitchell Act. 
The National Marine Fisheries Service (NMFS) does not approve, recommend or endorse any proprietary product or proprietary material mentioned in this publication. No reference shall be made to NMFS, or to this publication furnished by NMFS, in any advertising or sales promotion which would indicate or imply that NMFS approves, recommends or endorses any proprietary product or proprietary material mentioned herein, or which has as its purpose an intent to cause directly or indirectly the advertised product to be used or purchased because of this NMFS publication. 
UNITED STATES

DEPARTMENT OF COMMERCE

NATIONAL OCEANIC AND ATMOSPHERIC AOMINISTRATION

NAIIONAL MARINE FISHERIES SERVICE

SCIENTIFIC PUBLICATIONS STAFF

$$
\text { ROOM } 450
$$

SEATTL WA $8 B 105$

SEATTLE, WA 98105

OFFICIAL BUSINESS
PENN STATE UNIVERSITY LIBRARIES

(III) (1)

A000072019573 